\title{
Comparative Analysis of Energy Data Bases for the Industrial and Commercial Sectors
}
J. M. Roop
D. B. Belzer
A. A. Bohn

December 1986

Prepared for the U.S. Department of Energy under Contract DE-AC06-76RLO 1830

Pacific Northwest Laboratory Operated for the U.S. Department of Energy by Battelle Memorial Institute 


\title{
DISCLAIMER
}

This report was prepared as an account of work sponsored by an agency of the United States Government. Neither the United States Government nor any agency thereof, nor Battelle Memorial Institute, nor any of their employees, makes any warranty, expressed or implied, or assumes any legal liability or responsibility for the accuracy, completeness, or usefulness of any information, apparatus, product, or process disclosed, or represents that its use would not infringe privately owned rights. Reference herein to any specific commercial product, process, or service by trade name, trademark, manufacturer, or otherwise, does not necessarily constitute or imply its endorsement, recommendation, or favoring by the United States Government of any agency thereof, or Battelle Memorial Institute. The views and opinions of authors expressed herein do not necessarly state or reflect those of the United States Government or any agency thereof, or Battelle Memorial Institute.

\author{
PACIFIC NORTHWEST LABORATORY \\ operated by \\ BATTELLE \\ for the \\ UNITED STATES DEPARTMENT OF ENERGY \\ under Contract DE-ACO6-76RLO 1830
}

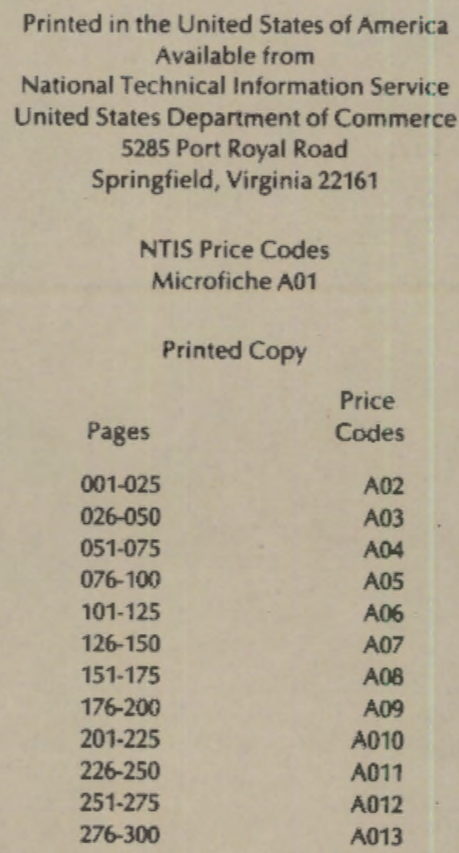




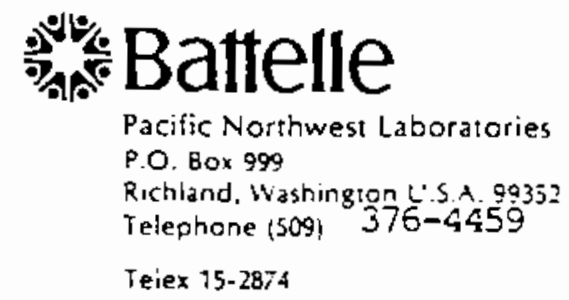

March 6, 1987

Recipients of PNL-5ó21

Dear Recipients:

RE: Comoarative Anaiysis of eneroy Data Bases for the Industrial and Commercial Sectors, Pacific Nortnwest Ladoratory, Richland, Wh Decemper 1980

Please add the following clarification:

The description of the Drexel derivative data base attributed to wilfert, et a). (1984) is not characteristic of the subsequent PNL modifications to Drexel known as INDUST. The references to INDUST in Section 2.0 should, rather, be understood as the Drexel data base as modified by wilfert, et al.

Thank you.

sincerely,

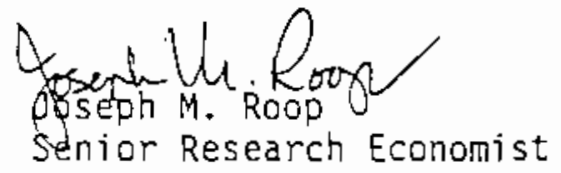

JMR: Tiw 
PNL -5621

UC -98

COMPARATIVE ANALYSIS OF ENERGY

DATA BASES FOR THE INDUSTRIAL

AND COMMERCIAL SECTORS

J. M. Roop

D. B. Belzer

A. A. Bohn

December 1986

Prepared for

the U.S. Department of Energy

under Contract DE-AC06-76RLO 1830

Pacific Northwest Laboratory

Richland, Washington 99352 

SUMMARY

Energy data bases for the industrial and commercial sectors were analyzed to determine how valuable this data might be for policy analysis. The approach is the same for both end-use sectors: first a description or overview of relevant data bases identifies the available data; the coverage and methods used to generate the data are then explained; the data are then characterized and examples are provided for the major data sets under consideration. A final step assesses the data bases under consideration and draws conclusions.

There are a variety of data bases considered for each of the end-use sectors included in this report. Data bases for the industrial sector include the National Energy Accounts, process-derived data bases such as the Drexel data base and data obtained from industry trade associations. For the commercial sector, three types of data bases are analyzed: the Nonresidential Building Energy Consumption Surveys, Dodge Construction Data and the Building Owners and Manager's Association Experience Exchange Report.

To distill the major findings of this study into a few words, there are major shortcomings in the available data bases for both the industrial and commercial end-use consumption of energy. Indeed, there is no single source of data on consumption of energy that would satisfy even modest policy requirements for either of these sectors. On the supply side--i.e., data that relies on reports filed by the suppliers of energy to each sector--however, the data are adequate for many policy questions.

This document is a companion study to an assessment of residential and personal transportation data bases, conducted by Argonne National Laboratory. The title of that report is: Comparative Analysis of Energy Data Bases, December, 1985. The authors are Y. Klein, S. LaBelle and D. Wernette. 



\section{ACKNOWLEDGEMENTS}

The authors wish to acknowiedge the assistance received from a number of individuals at Pacific Northwest Laboratory (PNL) and at Argonne National Laboratory. We have benefitted from the helpful comments of R. Moe and R. Scheer of PNL. We also acknowledge the help of J. Krudner on the commercial data base assessment. The project leader at Argonne, J. Throgmorton, has also contributed by sharing his ideas about the structure of the report and assisting in coordination of this project. 



\section{CONTENTS}

SUMMARY

ACKNOWLEDGEMENTS

1.0 INTRODUCTION

1.1 PURPOSE OF ASSESSMENT

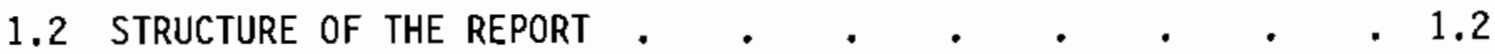

2.0 AN ASSESSMENT OF INDUSTRIAL ENERGY DATA BASES $\quad$ • $\quad$ • $\quad . \quad 2.1$

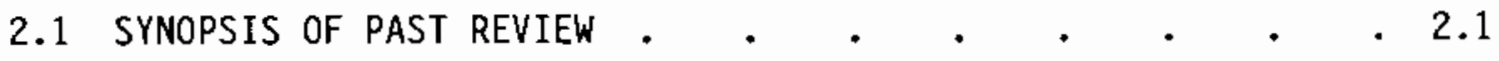

2.2 DESCRIPTION OF RECENT DATA BASES $\quad . \quad \cdot \quad \cdot \quad \cdot \quad \cdot 3$

2.2.1 National Energy Accounts . . . . . . . 2.4

2.2.2 Drexel Derivative Data Bases . . . . . . 2.4

2.2.3 Supplemental Data Bases . . . . . . . 2.5

2.3 SCOPE AND METHODS • . . . . . . . . . . . 2.6

2.3.1 National Energy Accounts . . . . . . 2.6

2.3.2 Drexel Derivative Data Bases . . . . . . 2.7

2.3.3 Supplemental Data Bases . . . . . . . 2.11

2.4 CHARACTERIZATION DF DATA BASES $\quad$ • . . . . . . 2.15

2.4.1 National Energy Accounts . . . . . . 2.15

2.4.2 Drexel Derivative Data Bases . . . . . . 2.17

2.4.3 Supplemental Data Bases . . . . . . . . 2.19

2.5 OATA BASE EXAMPLES $. \quad . \quad . \quad . \quad . \quad . \quad .20$

2.5.1 Paper and Alijed Products . . . . . . . 2.21

2.5.2 Food and Kindred Products . . . . . . . . 2.25

2.5.3 Refined Petroleum and Coal Products . . . . . 2.26

2.5.4 Primary Ferrous Metals . . . . . . . . 2.32 
2.5.5 Stone, Clay and Giass Products . . . . . 2.35

2.5.6 Transportation Equipment . . . . . . . 2.38

2.6 ASSESSMENT AND CONCLUSIONS . . . . . . . . 2.42

2.6 .1 Assessment $. \quad . \quad . \quad . \quad . \quad . \quad . \quad . \quad 2.43$

2.6 .2 Conclusions . . . . . . . . . . . 2.45

3.0 AN ASSESSMENT OF COMMERCIAL SECTOR DATA BASES $\quad$ • $\quad$ • $\quad$ • 3.1

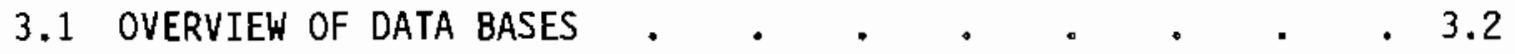

3.1 .1 Nonresidential Building Energy Consumption
Surveys. . . . . . . . . . 3.2

3.1 .2 Dodge Construction Data $\quad$ • $\quad$. $\quad$. 3.3

3.1.3 Building Owners and Manager's Association
Experience Exchange Report . . . . . 3.4

3.2 SCOPE AND METHOD . . . . . . . . . . . . . 3.4

3.2 .1 NBECS $. \quad . \quad . \quad . \quad . \quad . \quad . \quad .5 .5$

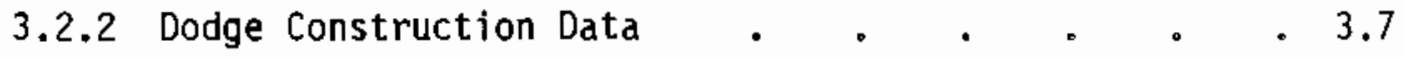

3.2.3 BOMA Experience Exchange Report . . . . . 3.7

3.3 ChARACTERIZING THE DATA BASE.$\quad \cdot \quad \cdot \quad \cdot \quad \cdot \quad \cdot \quad \cdot 3.9$

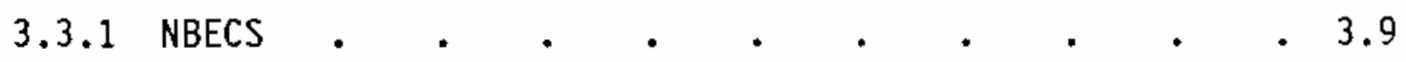

3.3.2 Dodge Construction Data . . . . . . 3.12

3.3.3 BOMA Experience Exchange Report . . . . . 3.13

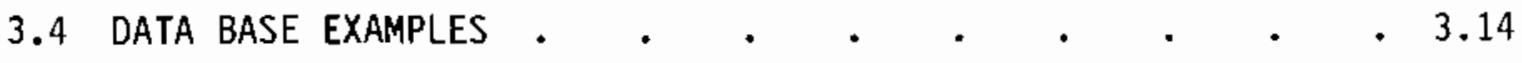

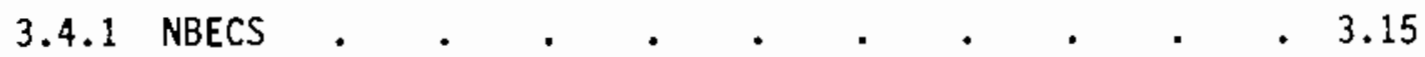

3.4.2 Dodge Construction Data $\quad . \quad$. $\quad . \quad$. 3.15

3.4.3 BOMA Experience Exchange Report . . . . . 3.20

3.4.4 Comparison of Dodge and NBECS Information . • . 3.20

3.4.5 Comparison of NBECS and SEDS . . . . . . 3.29 


\begin{tabular}{|c|c|c|c|c|c|c|c|c|c|c|c|c|c|c|}
\hline & 3.5 & ASSESS & MENT & AND CONC & US & & • & ${ }^{\circ}$ & - & ${ }^{\bullet}$ & . & • & - & 3.31 \\
\hline & & 3.5 .1 & Asse & ssment & . & . & . & • & . & - & - & - & - & 3.31 \\
\hline & & 3.5 .2 & Conc & Jusions & . & - & . & • & . & • & - & • & & 3.34 \\
\hline 4.0 & CONCL & UUSIONS & AND & RECOMMEN & AT & & 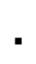 & • & " & - & $\bullet$ & $\bullet$ & . & +.1 \\
\hline & 4.1 & CONCLUS & SIONS & • & - & $\bullet$ & • & • & ${ }^{*}$ & $\bullet$ & " & $\bullet$ & • & .1 \\
\hline & 4.2 & RECOMME & ENDAT & IONS & - & - & $\bullet$ & " & $\bullet$ & " & " & " & 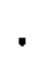 & 4.3 \\
\hline REFE & ENCES & • & & . & - & • & 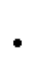 & • & - & $\cdot$ & • & • & & 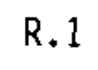 \\
\hline
\end{tabular}




\section{FIGURES}

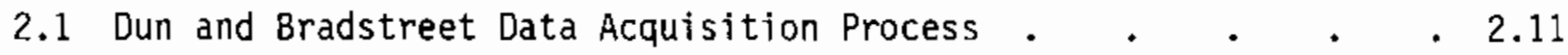

2.2 Total Energy Use in Paper and Allied Products $\quad . \quad$. $\quad$ • 2.21

2.3 Coal Use in Paper and Allied Products . . . . . . . . 2.22

2.4 Natural Gas Use in Paper and Allied Products . . . . . 2.23

2.5 Fuel $0 i 1$ Use in Paper and Allied Products . . . . . . 2.24

2.6 Electricity Use in Paper and Allied Products . . . . . . 2.24

2.7 Total Energy Use in Food and Kindred Products . . . . . 2.25

2.8 Coal Use in Food and Kindred Products . . . . . . . . 2.26

2.9 Natural Gas Use in Food and Kindred Products . . . . . . 2.27

2.10 Fuei $0 i 1$ Use in Food and Kindred Products . . . . . . . 2.27

2.11 Electricity Use in Food and Kindred Products . . . . . . 2.28

2.12 Total Energy Use in Petroleum Refining and Coal Products • . 2.28

2.13 Coal Use in Petroleum Refining and Coal Products . . . . 2.29

2.14 Natural Gas Use in Petroleum Refining and Coal Products . . 2.30

2.15 Fuel oil Use in Petroleum Refining and Coal Products . . . 2.31

2.16 Electricity Use in Petroleum Refining and Coal Products . . 2.31

2.17 Other Fuel Use in Petroleum Refining and Coa1 Products. • • 2.32

2.18 Total Energy Use in Primary Ferrous Metals . . . . . . 2.33

2.19 Coal Use in Primary Ferrous Metals . . . . . . . . . 2.34

2.20 Natural Gas Use in Primary Ferrous Metals . $\quad . \quad$ • . . . . 2.34

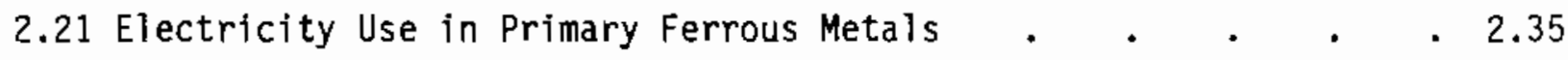

2.22 Fuel $0 j 1$ Use in Primary Ferrous Metals . . . . . . . 2.36

2.23 Total Energy Use in Stone, Clay and Glass Products. • • . 2.36

2.24 Coal Use in Stone, Clay and Glass Products . . . . . . 2.37 
2.25 Natural Gas Use in Stone, Clay and Glass Products • • • . 2.38

2.26 Fuel 011 Use in Stone, Clay and Glass Products . . . . . 2.39

2.27 Electricity Use in Stone, Clay and Glass Products . . . . . 2.39

2.28 Total Energy Use in Transportation Equipment . • • • • • 2.40

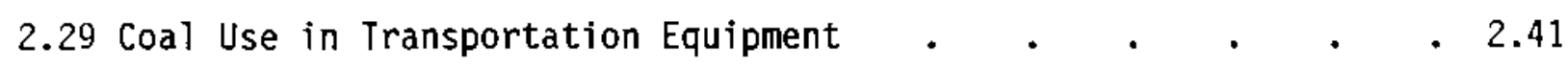

2.30 Natural Gas Use in Transportation Equipment . $\quad . \quad$. 2.41

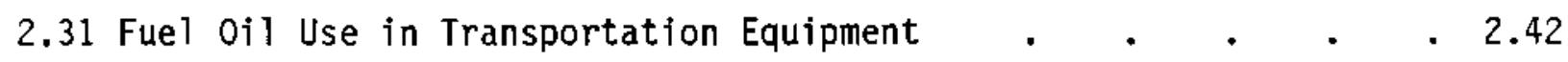

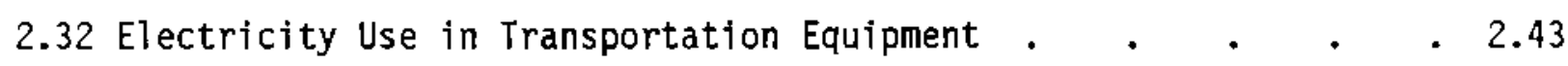

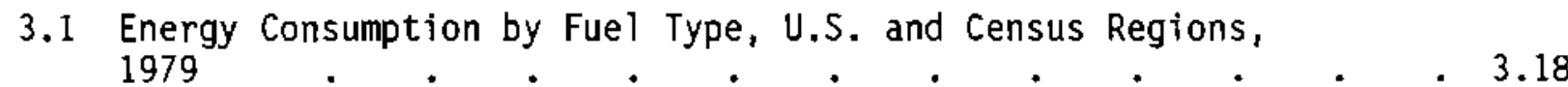

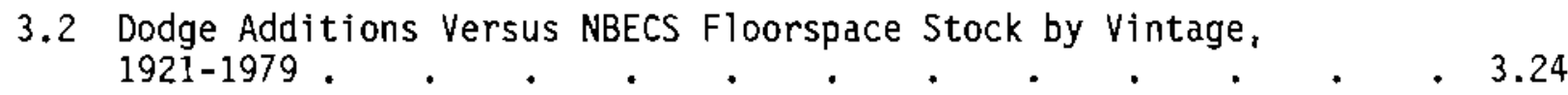

3.3 Dodge Versus NBECS Floorspace Stock by Building Type, 1974-1979 . 3.28 


\section{$\underline{\text { TABLES }}$}

2.1 Energy Products and Functional Uses In National Energy

Accounts . . . . . . . . . . . . . 2.8

3.1 Square Footage by Type of Commercial Building, U.S. Total, 1979 .

3.2 Square Footage by End Use Fuel Type, U.S. Total, 1979 . . . 3.17

3.3 Characteristics of New Office Construction by Size

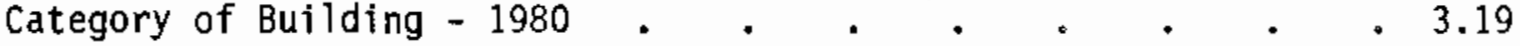

3.4 U.S. Private Sector All Electric Buildings . . . . . 3.21

3.5 Percent Change in Utility BiTls, 1973-1981 U.S. Private
Sector Office Buildings. . . . . . 3.22

3.6 Number of Buildings Listed by Dodge During 1974-1979, and NBECS Estimates of Number of Buildings Constructed from 1974 to the Time of the Survey, by Square Footage Class and Building Type . . . . . . . : . . . 3.23

3.7 Number of Buildings by Size Class Listed by Dodge During 1974-1979 and by NBECS for 1974-1979, Normalized to Tota 1980-1983 NBECS 1980-1983 New Building Count . . . . 3.26

3.8 Regional Energy Consumption and Expenditure in the Commercial Sector for Calendar Year, by Fuel Type . . . . . . 3.30 


\subsection{INTRODUCTION}

This document is a comparative analysis of energy data bases in two of the four major end-use sectors defined by the Department of Energy--the industrial and commercial sectors. This report is the product of a joint effort conducted by Argonne National Laboratory and Pacific Northwest Laboratory (PNL) for the Office of Minority Impacts and the Office of Policy Integration of the U.S. Department of Energy. The comparative analyses of the residential and (personal) transportation data bases were conducted at Argonne, the commercial and industrial sector assessments at PNL. A copy of the Argonne report is available from the Energy and Environmental Systems Division of Argonne National Laboratory, 9700 S. Cass Avenue, Argonne, IL 60439.

The analysis is undertaken from the perspective of the policy analyst. Accordingly, the sources, time periods, unit of analysis, method of collection, extensiveness, and reliability are examined for each major data source. This information forms the basis for assessing the strengths and weaknesses of the data, how to use the data, and how to improve the data sources. For the industrial and commercial sectors examined, this information is summarized in a separate subsection in the chapter that addresses that sector, and a final chapter summarizing the major finding for both sectors. Since the focus is on assessment, only a limited amount of description and documentation of the data bases is provided, but sources are referenced. Both the perspective of the policy analyst and the meaning of the word assessment require some explanation, which is provided next.

\subsection{PURPOSE OF ASSESSMENT}

The objective of this comparative analysis is to assess, i.e., determine the value of, data bases in two different end-use sectors. The role of the assessor typically is to determine value for a particular purpose, e.g., to fix a tax. The purpose of this assessment is less onerous: it is to determine the value of these data bases for policy analysis purposes.

A policy question, as viewed here, would fall into one of three generic forms: 1) How would the imposition of a particular policy (P) influence one or more key variables (V)? 2) How would the relationship between $P$ and $V$ vary spatially, temporally, or demographically? and 3) what do we know, 
historically, about $P$ and $V$ ? The last of these questions, intelligencegathering of a sort, can provide some insight into the second question, which in turn can lead to hypotheses about the first question. Clearly all of these questions are somewhat related.

For any specific policy question the relevant data may vary. Indeed, policy questions may cover a wide range of issues that require an equally wide range of data. In the industrial sector, for example, a policy question that is directed at the energy-use consequences of a change in corporate tax policy will require a substantially different set of data from a policy question that asks about the economic consequences of an oil embargo. The first of these, at minimum, requires that the analyst determine the chain of influence from tax policy to investment in, and replacement of, equipment and the energyuse consequences of that investment. The second question would require information about the substitution of fuels in each end-use sector, assuming that the embargo would operate primarily through market price changes. For other sets of policy questions, the data may overlap to a large extent. Before the policy issue is specified, it is extremely difficult to anticipate the data requirements that will suffice to answer questions about that issue.

But recognizing the need for a broad range of information does provide some guidelines in the choice of the criteria used to assess the data bases. Generally, the data bases are more appropriate for policy analysis if they can be used for an entire sector, contain some historical perspective, and contain a broad enough range of information to be used for a variety of different questions. Accordingly, this assessment will be concerned with those criteria that are relevant for policy analysis: timeliness, reliability, etc. This report will cover only those data bases that might be readily available to the policy analyst and that are broad-based enough to be useful for a wide variety of policy questions.

\subsection{STRUCTURE OF THE REPORT}

This report is organized into five sections, the first of which is this introduction. The next two sections contain an assessment of the industriai sector and the commercial sector, respectively. The fourth section provides 
the major recommendations and assessments for each of the end-use sectors and presents them separately. The final section cites the references used as sources. 


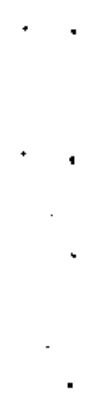




\subsection{AN ASSESSMENT OF INDUSTRIAL ENERGY DATA BASES}

In recent years a number of industrial sector data bases have been reviewed. The most recent review was completed by Synergic Resources Corporation (SRC) for the Electric Power Research Institute in late 1982 (Isser and Limaye, hereafter, $I L)$. The emphasis in this section will be on data bases not included in the IL review. However, a catalog of the data bases reviewed by IL will be included, along with a brief synopsis of the findings.

Following that synopsis, several major data bases not covered by IL will be assessed. This assessment will consist of a brief description of the data set; information about data acquisition; a characterization of data, with examples; and finally a summary of the strengths and weaknesses of the data bases examined.

\subsection{SYNOPSIS OF PAST REVIEW}

The IL review was undertaken to determine the applicability of available data bases for electric utility information needs. They concluded that none of the data bases examined would satisfy all the requirements for electric utjlities. Eleven major data bases were covered (see IL for references):

- Gordian Associates: Prepared for the Federal Energy Administration in June, 1974 this data base examines nine industries: pulp and paper, plastics, synthetic rubber, petroleum refining, glass containers, cement, steel, copper and aluminum. Most of the data is pre-1970.

- Battelle Columbus: This study examines the potential for conservation in seven basic industries. It was prepared for the FEA in July, 1975, and includes some data for paper, selected plastics, synthetic rubber, glass, steel, copper and aluminum. The focus of this study is a thermodynamic analysis of the minimum energy needed for particular processes, but includes major process flows for each industry.

- Dow Chemical Study: Three reports were prepared for the Environmental Protection Agency (EPA) in 1974 and 1975. One report is devoted to the chemical industry, another to the primary metals and petroleum industries, and a third to paper, stone, clay, glass, concrete, and food industries. The study is based primarily on studies of process flow energy requirements for various industries done by the American Gas Association and Stanford Research Institute, and contains very little explanatory text. 
- A. D. Little: In a 15-volume report prepared for the EPA in late 1976, ADL describes about 80 process options in use or being adopted by industry, but the reports contain little in the way of energy consumption data. The focus of the study is environmental effects in energy conservation.

- Battelle Solar Study: Prepared for the Energy Research and Development Administration (ERDA) in 1977, this study attempts to determine what process heat requirements could be satisfied by solar energy. The bulk of the research is based on the Gordian report and other prior Battelle Columbus studies. The report first identified the major process steps in 33 4-digit industries in manufacturing and mining and in one 2-digit industry (textiles). The major weakness of this report is that the processes chosen for analysis by industry are frequently not representative of that industry.

- ITC Solar Study: Prepared for ERDA in 1977 by InterTechnology Corporation, this study is similar to the Battelle Solar Study but covers more industries in somewhat less detail. Major data sources are familiar--Gordian report and other Battelle studies.

- Energy Consumption Data Base (ECDB): Prepared for the FEA by Energy and Environmental Analysis (EEA), the ECDB is organized by industry and includes energy consumption by major end-uses: direct heat, process steam, etc. Information is available only for 1974. The data are reported by 2-digit industry with the exceptions of aluminum, steel and paper. For a more recent version of this, see EIA, 1979.

- Drexel Data Base: Prepared for the Department of Energy in mid-1979, the Drexel data provide detailed process flow information for 108 industrial processes that are presumed to account for about 70 percent of all energy use in manufacturing industries. These data are based on the Battelle, Gordian and ADL studies, supplemented by data from engineering texts.

- UTC Process Characteristics: Prepared for DOE and NASA by United Technologies Corporation in early 1980, the focus of this data base is cogeneration technology. This is an update of the Gordian data, using a number of energy studies that had been performed in subsequent years.

- Oak Ridge Data Book: Prepared for DOE by Oak Ridge Associated Universities in 1980, this publication is a valuable reference. Among other topics, it inciudes both a general discussion of industrial energy-use data and a discussion of energy use in 12 selected industries. Several appendices provide conversion factors, regional definitions, and a listing of data by industry. An annotated bibliography is also included. This publication is a valuable reference.

- Industrial Plant Profiles: General Energy Associates developed this proprietary data base from the Drexel data base. In this data base, information from the Drexel process flows is integrated with detailed plant 
information derived from the Dun and Bradstreet plant files. This data base was the forerunner of the Dun and Bradstreet data base described in more detail below.

From the perspective of this assessment, none of these data bases are satisfactory for policy analysis because they lack generality and historical perspective. Any data base derived from a simplified characterization of industrial process flows--and most of the IL data bases are of just that type--will provide only a snapshot of the industry. They lack historical perspective because industries change over time; if dramatic structural changes occur, these data bases will be outdated even sooner. The historical perspective is particularly important because in the last 15 years dramatic shifts in relative energy prices have caused major changes in energy use in all sectors, but most particularly in the industrial sector.

But process flow models, such as the Drexel data base, can provide useful insight in conjunction with more general energy use data bases because these process flow models include both energy and material balances. With the additional information about the set of processes that typify the industry and given the level of output for the industry, it is possible to construct crude estimates of the process equipment requirements and energy use. There may be policy questions that would require this level of detail that would not be overly sensitive to the major drawback to this approach: even over short periods of time, a single process may change or the set of processes that are typical of an industry may change.

With respect to policy analysis, then, the conclusions that IL drew from their review of data bases as they apply to electric utilities still stand. Al though valuable as references and of some $11 \mathrm{mited}$ use, the 11 data bases surveyed cannot be the foundation for answering broad policy questions.

\subsection{DESCRIPTION OF RECENT DATA BASES}

Since the IL review in 1982, there have been several major efforts to organize data bases for the industrial sector. These efforts fall into two camps--one that combines the Bureau of Census of the U.S. Department of Commerce (USDOC) and Department of Energy data that we refer to as the National Energy Accounts (NEA), and a second set of data bases that are derivatives of 
the Drexel data base. A third set of data that include only limited coverage of the industrial sector is also available from several sources. A brief description of each of these data bases follows.

\subsubsection{National Energy Accounts}

These accounts trace the flow of energy products throughout the economy from primary energy sources through energy conversion processes to final users. They provide a time-series of energy use by industry from 1958 to 1981 for eight primary energy sources and 27 conversion products. For each year and each fuel type both value and quantity of energy use is provided by industry, where the industry classification is at roughly the 3-digit SIC level. The most recent set of National Energy Accounts was completed in late 1984 by Jack Faucett Associates under the joint sponsorship of contract to the office of Business Analysis (DOC) and Office of Industrial Programs (DOE). The data base consists of over 65 thousand records in the energy use file alone, with other files for inventory and supply of energy products. There are 131 industry categories including 4 for agriculture, 10 for mining, 3 for construction, and 62 for manufacturing. The data base is available from the Department of Commerce or Jack Faucett Associates at a cost of about $\$ 600$. The basic documentation for the NEA is contained in Faucett (1984).

\subsubsection{Drexel Derivative Data Bases}

The original Drexel data base of 108 industrial processes has evolved along two paths. The first of these began with the construction of the General Energy Associates proprietary data base, then merged with Dun and Bradstreet (D\&B) to become D\&8's Technical Economic Services Data base. The second evolution of the Drexel data base occurred when DOE turned over responsibility for the data base to Pacific Northwest Laboratory (PNL). At PNL, the process information has been updated, reorganized, and used for a number of studies, most notably an assessment of waste heat recovery potential for major energyconsuming industries.

\section{Dun and Bradstreet Data Base}

At the core of the D\&B data base is a set of individual plant data called the Major Industrial Plant Data base (MIPD), consisting of information on more than 20,000 of the largest manufacturing plants. According to D\&B, these 
plants account for most of the employment, production and energy consumption in the manufacturing sector. Once the output of the plant has been determined, a set of industrial processes is used to characterize the plant as belonging to one of 3500 specific plant types. The plant-specific information is used to assist in collecting of data annually. This proprietary data base is available from D\&B for a negotiable fee (depending on the scope of the data required), and includes data for 1983 and 1984. A description of the Dun and Bradstreet Technical Economic Services data base can be found in Kresge (1984.)

\section{PNL INDUST Data Base}

Under contract to the Office of Industrial Programs, DOE, PNL has updated and extended the Drexel data base. The data base comprises industrial data files that consist of three types of records: general industry information records, unit operation records and flow stream records. The PNL update inciuded revising the unit operation records and the flow stream records for each of the 108 product code industrial processes. In addition, significant changes made to 14 major process descriptions in textiles, lumber, chemicals, petroleum and primary metals required changing much of the process flow data. The entire data base was also converted to a "per unit output" basis, so that known industry output levels could be converted to energy use. The basic documentation for these changes is contained in wilfert, et al. (1984).

\subsubsection{Supplemental Oata Bases}

There are limited alternatives to the comprehensive industrial sector data bases mentioned above. One involves the collection of data from trade associations such as the American Paper Institute, the American Gas Association or the American Iron and Steel Institute. The other alternative is the Industrial Energy Efficiency Improvement Program conducted by DOE's Office of Conservation and Renewable Energy (CE). Results of this program are reported to Congress each year as required by Public Law 94-163. A sample of this report is provided in DOE (1980). 


\subsection{SCOPE AND METHOD}

This section will provide a variety of technical data on each of the data bases mentioned above. Such information as coverage--sectoral, demographic, geographic, etc.--data sources, survey methods and sampling techniques, time period and unit of analysis are provided. This technical information provides a basis for the assessment that follows.

\subsubsection{National Energy Accounts}

This data base is available to the general public from either the Department of Commerce or Jack Faucett Associates. It is available on the Energy Information Agency computer through the Office of Industrial Programs as a result of 0IP's financial support of the data base development.

\section{Coverage}

The NEA is an aggregate U.S. data base with no regional or state coverage. It identifies 41 separate primary and end-product fuels for 130 industries annualiy from 1958 through 1981. Three separate files identify primary energy sources, inventories and consumption.

\section{Data Sources}

For primary energy, the NEA relies primarily on source data collected by the Department of Energy and predecessor agencies and the Department of Interior's Bureau of Mines. The flow of these primary energy sources through a variety of conversion processes to the final consumer is tracked, benchmarking consumption to a variety of sources, including the various quinquennial censuses (Manufacturing, Mining, etc.), and then balancing these uses and inventory changes to primary source data. In years when the census is not collected, the data are interpolated; except for manufacturing for which data were collected on purchased heat and power in off-census years unti] 1981. Information from the 1972 and earlier censuses was used to trace the flow of energy products through the economy from the sources to final use.

\section{Collection of Data}

The NEA is based on census data that are an enumeration of over 225,000 businesses throughout the United States. The major sources of the primary energy data are merchandise trade data collected by the Department of Commerce 
and mandatory reporting of energy source transactions from major producers within the U.S. to the Department of Energy. The Annual Survey of Manufacturers that provides information on purchased heat and power by industry during the off-census years is based on a survey with two components. The mail portion of the survey is a probability sample of about 55,000 firms selected from all prior census establishments. The mail survey is supplemented with a list provided by the Social Security Administration of new establishments that have opened since the prior census (USDOC, 1981).

\section{$\underline{\text { Time Period }}$}

The data in the NEA are annual from 1958 to 1981. This data base is not likely to be extended until further industry data are collected. The Bureau of Census no longer collects annual information on purchased heat and power. The Energy Information Agency has proposed and formulated an energy consumption survey for the manufacturing sector that could be the basis for an update to the NEA, but results from this survey are not expected until late 1987 . The Census Bureau will likely collect information on heat and purchased power again in the 1987 census.

\section{Unit of Analysis}

Data are reported in the NEA by physical quantity (e.g., barrels of oil), by energy content (Btu), by producer value in current dollars, by producer value in constant (1972) dollars, by purchaser value in current dollars and by purchaser value in constant dollars. The data are further segmented by use (e.g., transportation, heat and power, feed stocks, etc.). Table 2.1 provides a taxonomy of fuel products and uses that are identified in the NEA. A list of industries is given in Faucett (1984).

\subsubsection{Drexel Derivative Data Bases}

of the two major derivatives of the Drexel data base, only one is in the public domain. The D\&B Technical Economic Services data base is a proprietary version that is generally not available to the public. Because it is a proprietary data base, technical information about the data set can only be inferred from the promotional literature and published explanations such as Kresge (1984). Accordingly, the major focus of this section will be on the PNL version of the Drexel data base. 
TABLE 2.1. Energy Products and Functional Uses in National Energy Accounts

NEA

Code

110

120

130

140

150

160

180

221

211

212

221

222

223

231

232

233

234

235

236

237

238

241

242

243

250

270

271
Energy Product

Primary Energy Products

Crude oil (including lease condensate)

Natural gas--wet

Coal

Nuclear power

Water power

Geothermal power

Wood for fue 1

Natural gas (dry, from gas wells)

Converted Hydrocarbons

Light Hydrocarbon Gases

Ethane and ethylene

Liquid petroleum and refinery gases (propane, butane, isobutane and propane-butane mixtures)

Natural Gas and Similar Products

Natural gas (dry, from gas plants) and other utility gases

Still gas

Coke oven gas

Gasoline and Naphthas

Motor gasoline

Aviation gasoline

Special naphthas

Naphtha 400 and other petrochemical feedstocks

Naphtha type jet fuels

Natural gasoline and isopentane

Plant condensate

other natural gas liquids

Distillate Fuel 0ils

Xerosine jet fue]

Kerosine, except kerosine jet fuel

Distillate, except kerosine

Residual Fuel $011 \mathrm{~s}$

Unsaturated light hydrocarbons

Crude light oil (from coal)

Other Petroleum Products

Lubricating oils and greases

Asphalt, road tar, road oil

Miscellaneous petroleum products

Unfinished oils 
TABLE 2.1. (contd)

NEA

Code

Energy Product

Coal Derivatives and Petroleum Coke

291 Coke and Breeze

292 Other coal derivatives

293 Crude coal tar

Electricity

$410 \quad$ Electricity

999 Conversion Losses

NEA

Code Functional Use

10 Heat and power

Transportation

31 Passenger highway vehicles, excluding buses

32 Buses

33 Trucks

34 Aircraft

35 Rall road vehicles

36 Pipeline equipment (stationary)

37 Waterborne vehicles

38 Transportation fuel--off the road

39 Communications transmission

40 Energy materials--inputs to energy conversion process

50 Energy materials--inputs to nonenergy activities

60 Energy losses

80 Export

$90 \quad$ Produced and consumed

99 Unallocated, use unknown

Source: Faucett 1984, pp. 187, 188. 


\section{Coverage}

The PNL INDUST data base includes the same 108 industrial processes included in the original Drexel data base, with substantial modifications and updating to 1980 as explained in Wilfert et al. (1984). These modifications include keying process flows to Census of Manufacturers data on output so that output levels can be used as a measure of the various input requirements and waste stream outputs. Basically, the data are at the process level rather than at the industry lever.

\section{Data Source}

The basic data source for both the PNL INDUST data base and the D\&B data base is the Drexel data base. Updates to the PNL INDUST data base relied on published studies of industries and equipment, for example, the study by General Electric Company for the Department of Energy that examined industrial process heat pump services (GE 1981). The D\&B data base augments the Drexel data with site-specific information derived from D\&B's plant file and telephone interviews with plant managers.

\section{Collection of Data}

The major independent source of data for the PNL data base is the Census of Manufacturers and the Annual Survey of Manufacturers, the collection techniques for which have already been discussed. Kresge (1984) explains how D\&B collect data. In short, they survey by telephone more than 20 thousand plants that consume as much as 95 percent of the energy used in manufacturing. They validate the information received from these interviews by organizing a plant energy profile constructed by piecing together the appropriate set of processes that describe the plant operation, then comparing the survey data with the implicit energy use derived from the plant profile. When these two sources do not agree, they resurvey the plant to try to determine the source of the discrepancy. The process D\&B uses to acquire data is shown schematicaliy in Figure 2.1.

\section{Time Period}

The PNL data base is calibrated to 1980; the D\&B data are available for 1983 and 1984, with annual updates thereafter. 


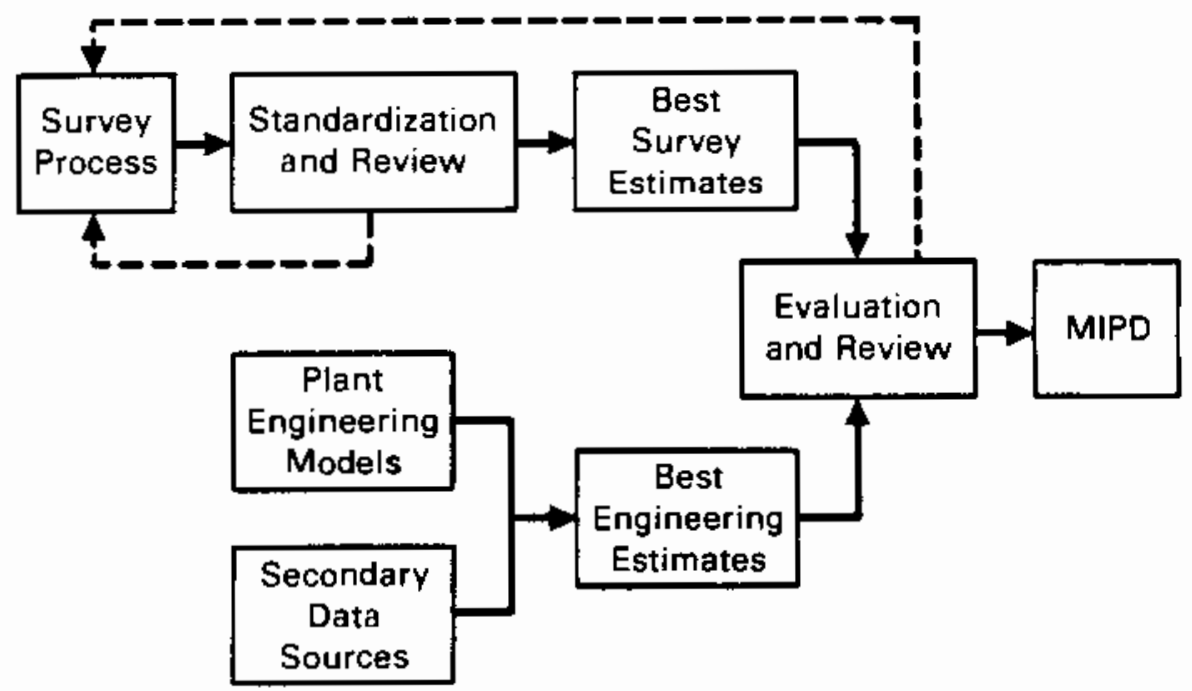

FIGURE 2.1. Dun and Bradstreet Data Acquisition Process (Kresge 1984)

\section{Unit of Analysis}

Both of the Drexel derivative data bases use a plant as the basic unit of observation. A plant is composed of a set of unit operations and will usually fall into a 4-digit standard industrial classification (SIC). PNL's data base covers 60 4-digit SICs that account for about 75 percent of total energy use in manufacturing. There are about 450 SIC categories in manufacturing. In PNL's INDUST data base, the SICs that are not covered are reported at the 2-digit SIC Tevel after taking into account the energy use at the 4-digit level. The D\&B data are organized into over 3,600 generic plant types for which engineering models are available. These plants are then organized into three major groups--basic materials production, large finishing/assembly plants, and other energy intensive plants. The survey covers 7,000, 3,000, and 10,000 plants in each of the respective groups.

\subsubsection{Supplemental Data Bases}

The supplemental data bases considered in this section come from two sources: 1) the Industrial Energy Efficiency Improvement Program monitored by the DOE's Office of Conservation and Renewable Energy (CE) and 2) trade associations. These sources are first explained and then examined in this section. 


\section{CE's Energy Efficiency Improvement Program}

Since the Energy Policy and Conservation Act (1975) was signed into law, the CE has been mandated to collect information on energy consumption from large energy consumers. At that time, data from the 10 industries that consumed the most energy were sought. In 1978, the National Energy Conservation Policy Act was enacted which empowered the Department of Energy to expand the collection of data from companies with operations in all manufacturing sector industries SICs 20 through 39. The data collected are from companies that use over one trillion Btu (TBtu) annually. This program is called the Industrial Energy-Efficiency Improvement Program; an annual progress report is sent to Congress.

The data collected may either be submitted to CE directly or submitted to a trade association which, in turn, sends the aggregated data to CE. In addition to the mandatory data collected, trade association, and private corporations in some instances, provide CE with data from companies consuming less than one TBtu. This information is incorporated into CE's aggregated data.

Coverage of CE Data. Data collection is mandatory from companies that consume at least one TBtu, regardless of the location of the company. Both mandatory and supplemental information from trade associations and private corporations appear to lack any geographical bias. The CE data base is not representative because large companies are required to submit data while data from small companies is collected only on a voluntary basis. For this reason, large companies are better represented in the CE sample than are small companies.

Data Sources. As required by law, the source of the data provided to CE is companies consuming over one TBtu. Trade associations can act as intermediaries in the data collection process. In addition to the data from the large energy-consuming companies, the trade associations submit data on energy consumption collected from smaller companies received on a voluntary basis.

Sample Size/Techniques. The CE sample size changes annually since the number of trade associations providing data changes each year. CE estimated that in 1979, 53 percent of the total energy use in the industrial sector was 
monitored in the program. In 1981, 47 trade associations and 260 corporations supplied data to CE. In 1982, 45 trade associations and 237 corporations supplied data to $C E$. CE does not adjust the data to take into account the change in the sample size from year to year. Furthermore, CE does not prorate the information received to represent the entire industry.

Survey Methods. The CE survey form sent to trade associations and large energy-consuming companies requests data on actual fuel consumption for the current year. Companies are also asked to estimate thefr fuel consumption using the 1972 or 1978 intensity level calculated by the company. This information is disaggregated by two-digit SIC code and by fuel type. The trade associations and/or companies are also queried as to the possible reasons for changes in energy intensities. The list of possible changes includes weather, capacity utilization, and fuel switching.

Time Period. CE has information on annual energy consumption by SIC from 1975 onward. Before 1978, the data were obtained for ten SIC industries; after 1978, the data obtained were for all 20 2-digit SIC industries.

Unit of Analysis. Actual consumption and estimated consumption of energy, by fuel type, based on previous energy intensity levels are the two variables analyzed in the CE reports. When the data are aggregated to avoid disclosure problems, the industry SIC, at the 2-digit level, is the unit of observation. Note that the company, not the establishment, is the organization to which the reporting requirement applies. Aggregating over companies to the 2-digit SIC level will occasionally result in different totals than would occur if establishments had been used as the unit of observation.

\section{Trade Associations}

One of the functions of a trade association is to collect and analyze information on the operations of the member companies; the analysis is usually published and provided to the member companies. An extensive number of trade associations were contacted in an attempt to obtain any data they might have collected on energy consumption. In total, about 75 associations were contacted including major energy trade associations such as the Edison Electric Institute, the American Petroleum Institute and the American Gas Association. 
Most trade associations contacted collect energy consumption information in order to provide data to CE. Some of the associations even provided a copy of the survey form submitted to CE. Other trade associations had been monitoring energy use long before the data were required at CE. The historical data have been referenced in the following report.

Coverage. Only national trade associations were surveyed during the data collection stage of this study. As national associations, these groups collect information from companies across the United States. Trade associations collect data on a voluntary basis from member companies. These data generally comes from larger companies which have the resources to comply with the request for data. For this reason, trade association data bases have a high representation of large companies than small companies. Since they receive a copy of the analytical results, there is some incentive for smaller companies and nonmember companies to comply with trade association requests for data.

Data Sources. Statistics on energy consumption were obtained from four trade associations: the Chemical Manufacturers Association, the American Paper Institute, the American Iron \& Steel Institute and the American Gas Association. The Chemical Manufacturers Association provided data for 1982 and 1983 only, and therefore could not be compared to the NEA data series which terminated in 1981 .

The American Paper Institute (API) had collected data for most of the years between 1972 and 1983. The API data were assumed to correspond to the SIC 26 definition for paper and allied products.

The American Iron and Steel Institute (AI\&SI) data were for 1979 through 1983. Unfortunately, AI\&SI data did not contain statistics on energy consumption in the production of nonferrous metals which would have allowed a direct comparison to SIC 33 data for the primary metals sector.

The American Gas Association (AGA) data were for many of the intervening years between 1955 and 1983. AGA surveys natural gas companies on the amount of natural gas sales by two-digit SIC code. Even though the data are limited to natural gas, the information was useful in a fuel-by-fuel comparison of data within the industrial sector. 
Sample Size/Techniques. None of the trade associations reviewed modified their data to represent companies not responding to the survey. Accordingly, the sample size changes from year to year. API estimated that between 85 and 92 percent of the industry production was covered in the energy consumption survey in the years 1972 to 1983. AI\&SI estimated that their response rate was over 90 percent in the years after 1979. AGA calculated their response rate in terms of total sales reported by SIC as a percent of total gas utility industry sales. On this basis, the AGA response rate ranged between 60 and 90 percent in the 1955 to 1983 interim; the more recent years had a lower response rate.

Survey Methods. API, AI\&SI, and AGA surveyed alT member companies about energy consumption. API and AI\&SI requested data on energy consumption by fuel type while AGA requested data from gas utility sales by SIC. Reliable statistical sampling methods were not employed by these associations.

Time Periods. The API data received covered the period 1972 through 1983. AI\&SI data received covered the period 1979 to 1983, while the AGA time series started in 1955 and ended in 1983.

Unit of Analysis. The information published by the three associations reviewed was for actual energy consumption on a Btu basis. The energy data are reported by industry and by fuel types.

\subsection{CHARACTERIZATION OF DATA BASES}

In this section, the technical information related to scope and method is used to characterize each of the industrial sector data bases. This characterization will be in terms of timeliness, reliability, and applicability to policy analysis. Again, this characterization proceeds by looking at each of the separate data bases.

\subsubsection{National Energy Accounts}

Over the period 1958 to 1981, the NEA is probably the single best source for industrial sector energy use. The major drawback is that additional industrial sector data on energy use by industry have not been collected since the 1981 Annual Survey of Manufactures. 


\section{Timeliness}

The Department of Energy information that is the basis for the supply side of the NEA is collected throughout the year, reported periodically in the Monthly Energy Review and various other publications of the Energy Information Agency, and summarized annually in the Annual Energy Review. Unfortunately, this is only half the story. From the early 1970s to 1981, the Census Bureau collected annual consumption information for manufacturing, which accounts for the bulk of industrial sector energy use. With this information, the industry-by-industry consumption of energy in the manufacturing sector could be constructed with reasonable accuracy. Without it, there is only sporadic coverage of manufacturing and only census benchmarks to calibrate the data.

\section{Reliability}

The construction of the NEA, predicated as it is on balancing the supply of energy to consumption of energy and inventory changes, has inherently more reliability than many other data sources. As a general characterization of industrial energy use, the NEA is the most reliable of the data sets examined here.

\section{Application to Policy Analysis}

Although it is limited because it terminates in 1981, the reliability of the NEA makes it a useful tool for policy analysis. For some policy analysis, the NEA can be used directly (questions categorized as types 2 and 3 in Section 1.1), e.g., to analyze the relationship of policy to key variables or to establish the historical perspective. For the other type of policy question--what would be the effect of a policy on key variables--the NEA would need to be updated. To the extent that the NEA can be extrapolated or basic trends are revealed by it, it could be of use in answering this latter policy question. For many policy questions, such as how the industrial sector responded to dramatic changes in prices of specific fuels, the length of the NEA and the coverage allow the sort of historical analysis from which prescriptive policy can be obtained. In combination with other data bases, there are other broad policy questions for which the NEA would be useful. 


\subsubsection{Drexel Derivative Data Bases}

The PNL INDUST data base and the D\&B data base are composed of process information at their core. As such, there is no readily available source of data against which to check the characterization of a particular industry. But the development of these two data bases is sufficiently different that they need to be characterized separately.

\section{PNL INDUST Data Base}

The PNL version of the Drexel data base is currently being modified and improved. These current efforts may alter the characterization of the data base that is based on the version used for the waste heat study (wilfert, et al., 1984).

Timeliness. The PNL data base was updated and calibrated to 1980 industry energy use. The changes to the process flows that were accomplished by this update appear to have been reasonable; the estimates of energy use calculated from the coefficients of the process flows were not grossly out of line with the published energy use numbers. But five years have passed since the process flows were calibrated. Insofar as processes change only slowly, this information should be useful for some time to come. But to the extent that the 60 4-digit industries represented by this data base have grown or declined (e.g., beet sugar processing has been almost entirely replaced by high fructose corn sweeteners), it may be difficult to build up a manufacturing or industrial sector profile of energy use. Improvements currently under way will improve the characterization of particular processes contained in the INDUST data base.

Reliability. For the most energy-intensive industries, the PNL data base represents a generic industry process. In this sense, the data are reliable. But since a process is representative of an industry, it wili not accurately represent any particular plant. No study has been undertaken to determine if this data base can replicate energy use by industry over time, based on known information about output. Over reasonably short periods of time, the industry characterization should track energy use quite well near the calibration year, 1980. 
Application to Policy Analysis. For specific policy questions that apply at the industry level, the PNL data base should be useful. It is not known if the data base can indicate levels of energy use for broad aggregates of industries such as the industrial sector or total manufacturing.

\section{D\&B Data Base}

Access to the D\&B data is contingent on subscription, as with any other proprietary data base. Thus this characterization is not based on firsthand experience with the data, but rather on the published descriptions and the promotional 1iterature available from Dun and Bradstreet.

Timeliness. The data are reported to be updated annually by telephone surveys of over 20,000 plants throughout the United States. The survey results are compared with plant descriptions built up from process information. When the information reported is not consistent with the plant description, a follow-up survey is conducted to determine the source of the discrepancy. There is reported to be a six-month lag after the end of the year before results of the survey are available.

Reliability. The D\&B data was initiated in 1983 and has been updated annually. Since the Bureau of Census ceased collection of purchased fuel and power data after 1981, there is no overlap of the D\&B data with published industry data for all manufacturing industries. The reasonableness of the data could be assessed by comparing industry aggregates from D\&B with historical evidence from the same industries to determine if the data were within an acceptable range. To the best of our knowledge, this has not been done. The comparison that IL made between the General Energy Associates data and the Census data suggests that there might be major discrepancies between the two.

Application to Policy. The major drawback in using the D\&B data base for policy analysis is its proprietary status. If it were publiciy available, it would be applicable in the same way that the PNL INDUST data base is: for industry-specific studies, the engineering detail could be valuable, but because they are not based on a statistical sample of establishments, neither the D\&B data nor the PNL INDUST data will provide a statistically reliable pattern of energy use for broad industry aggregates. 
For other applications of the D\&B data, see Kresge (1984) and Horvath (1984).

\subsubsection{Supplemental Data Bases}

Again, the two supplemental data bases we characterize are the DOE CE Energy Efficjency Improvement Program data base and trade association data sources.

\section{CE's Energy Efficiency Improvement Program}

With the termination of the purchased fuel and power survey in the Annual Survey of Manufactures, it would be useful if the routinely collected data from the CE program matched the published data for years when both sets were collected. Other characteristics of the CE data set are as follows.

Iimeliness of the Data Base. The trade associations compile information from member companies and supply the information to CE in less than a year after the survey year. Within six months $C E$, coordinates the information supplied by the trade associations and industrial companies and then publishes a report to Congress on energy use in the industrial sector. In total, the Report to Congress is generally provided a year and a half after the study year.

Reliability. The data, though not expanded to represent unreported companies, are reliable in the sense that data are provided for each year since 1975. The series of annual statistics is expected to continue since an act of Congress would be required to change the mandatory status of the report.

Application to Policy Analysis. The purpose of the CE report is to analyze energy consumption and to gauge the effects of energy conservation on an industry-by-industry basis for the industrial sector. The report appears to accomplish this goal. In addition to these analyses, trends in energy consumption in each of the industrial sectors can be evaluated to the extent the sample does experience change from year to year. It should be noted, however, that this data set is conceptually different from other data bases since it relies on company rather than establishment reporting.

Trade Association Data

Although trade association data do not cover the entire industrial sector, the industry data can be a valuable supplement to data from other sources and 
possibly may be used to extend the data past 1981. Insofar as the data can be useful for characterizing the sector, consider each of the data sets mentioned. API data are useful in characterizing the paper industry sector. The association's response rate is over 90 percent and the data collected corresponds well to SIC 26, the paper and allied products sector. AI\&SI data provide a good characterization of energy consumption in the production of iron and steel products; however, these data are only a subset of SIC 33, which is defined as the primary metals industry. Energy consumption data for SIC 33 contains consumption of energy in the production of nonferrous as weli as ferrous metals. The AGA data characterize only natural gas sales to each sector. These estimates are performed at the gas utility level, where characterization of the energy consumption is more difficult. Gas utilities may incorrectly identify the appropriate SIC code.

Timeliness. Based on the publication dates of the material received from the trade associations, the data on energy consumption are pubiished in a timely manner. The data are compiled by the associations and reported in the year following the study year.

Reliability. Since the sample size changes from year to year, the reliability of trade association data is uncertain. An increase or decrease in energy consumption can be attributed to either a change in the energy intensity of the industry, a change in the level of output of the industry, or a change in the sample size.

Application to Policy Analysis. API collects detailed energy consumption data in order to monitor the shift in the consumption away from fossil fuels and electricity to paper and wood waste products (i.e., biomass) as the paper companies seek to minimize energy costs. AGA collects data by SIC in order to determine the existence of fuel switching in specific industrial sectors.

\subsection{DATA BASE EXAMPLES}

In this section examples of the data available from the National Energy Accounts will be compared to data by industry available from the CE Energy Efficiency Improvement Program and data available from several trade associations. The data will be presented in graphs that show the use of various fuel types by industry over time. Five of the six most energy-intensive 
industries will be used with one additional industry, transportation equipment, to show typical fuel use in one of the less energy-intensive industries. For the data sets that cover all industries, the NEA data are reported annually for 1958-1981, the CE data are for 1978-1981, and the AGA data are for 1960, 1965,1970 , and 1972-1981.

\subsubsection{Pulp and Allied Products}

In the paper and allied products industry, data from CE and the API are compared to NEA data. The API data are for 1972 and 1975-1981. The historical estimates for total energy consumption in this sector range from about 0.7 quadrillion Btu (quads) according to NEA to about 2.2 quads (API). CE placed consumption at about one quad (Figure 2.2). The CE and NEA numbers are much smaller because they do not include biomass sources. When biomass and other nonfossil fuels are included in this industry, the discrepancy between the NEA data and the API data is minor: for the years 1977 to 1981, the difference ranges from 7 percent to less than 5 percent (Roop and Clement, 1984).

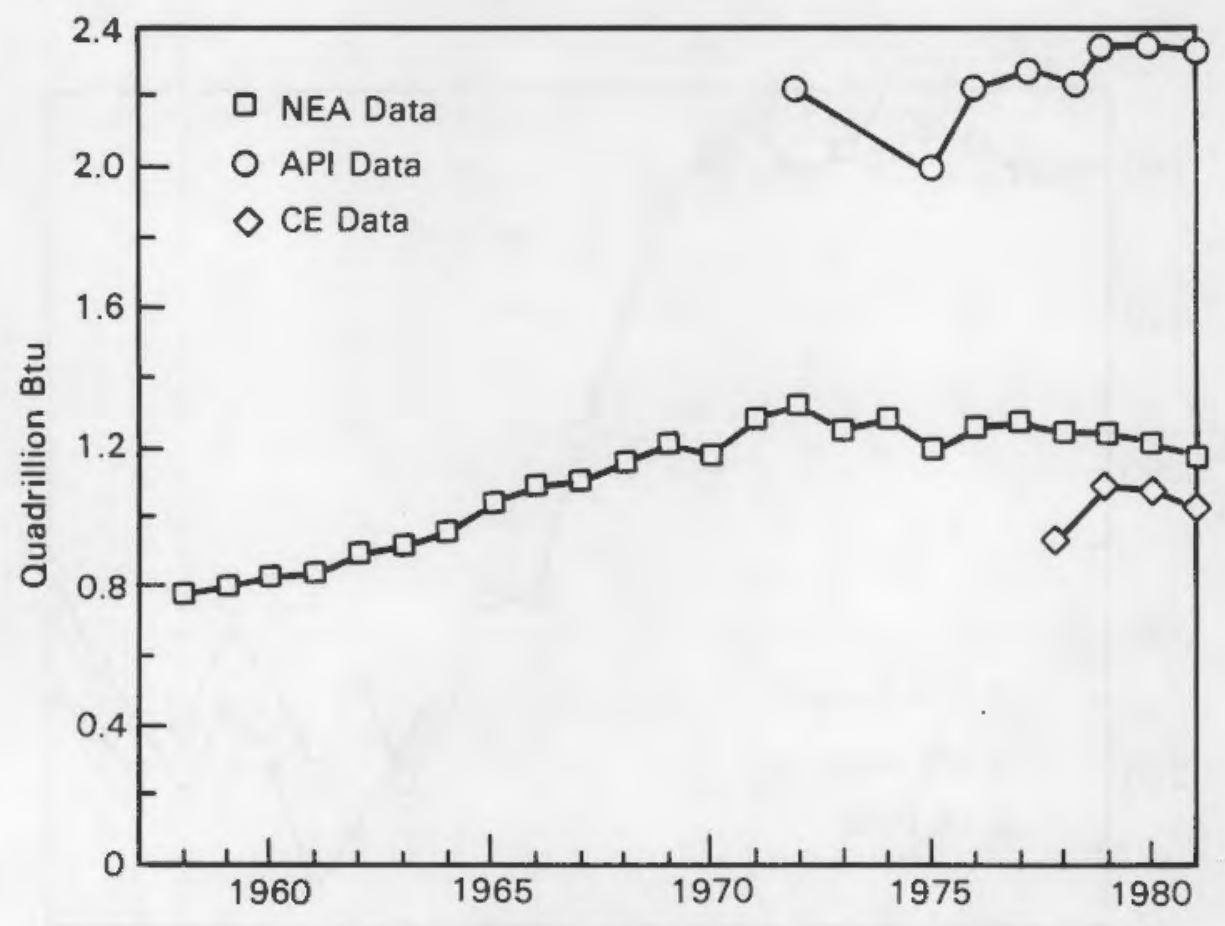

FIGURE 2.2. Total Energy Use in Paper and Allied Products 
Logically, the API data and CE data should have been less than NEA's information since API and CE did not expand their survey information to represent the entire industry. For the years mentioned above, the NEA fuel use totals are slightly larger than API's data in all cases. API's figures showed that in the paper industry a significant amount of biomass energy consumption is in the form of waste paper and wood products.

\section{Coal}

The API, CE and NEA data all indicated that coal consumption increased after 1979 (Figure 2.3). Except for 1972, API and CE show somewhat less coal use in the paper and allied products industry than does the NEA data. After 1978, the API and NEA data track very closely.

\section{Natural Gas}

Except for the American Gas Association (AGA) data after 1977, NEA data showed the lowest consumption of natural gas. Each of the data series, NEA, $A G A, A P I$, and CE, exhibited the same increasing trend between 1958 and

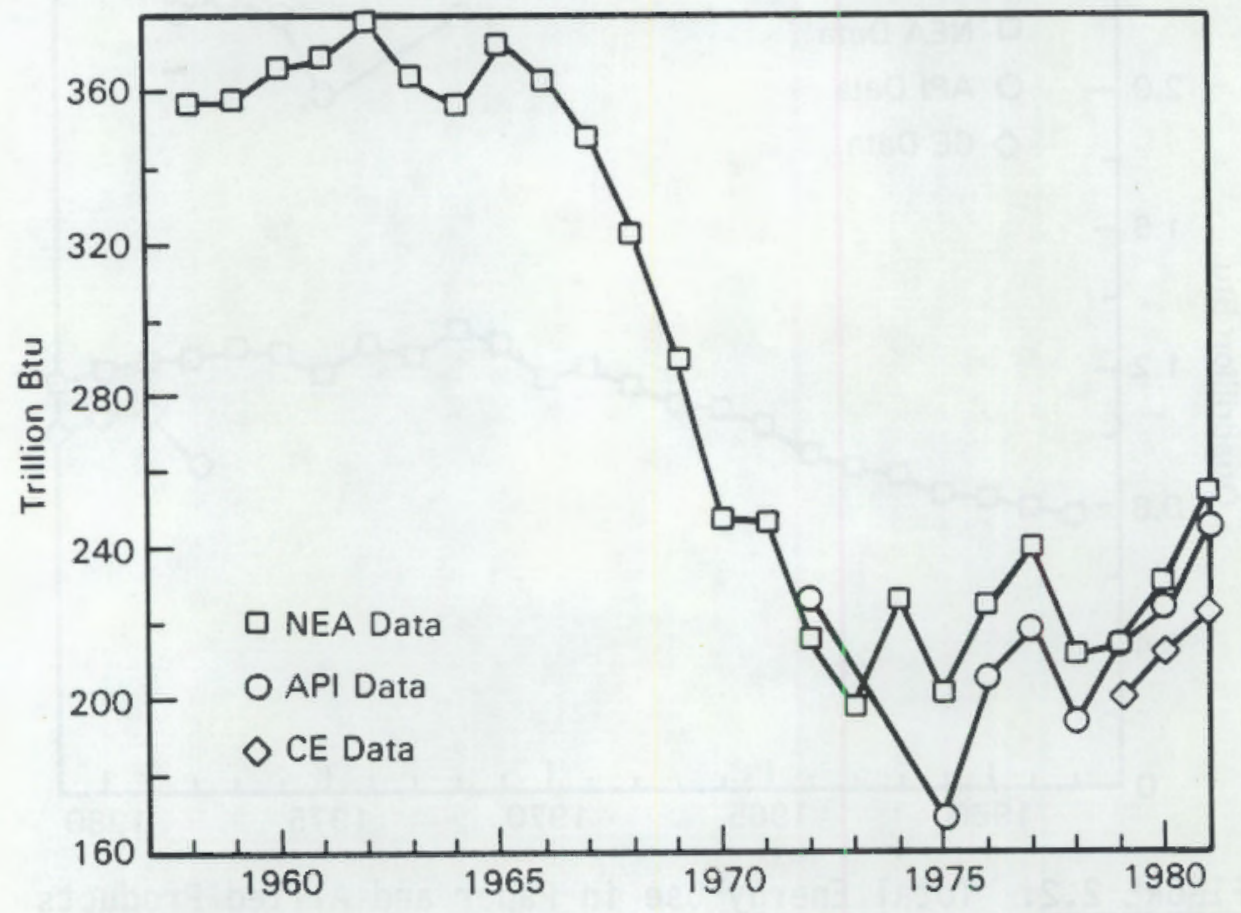

FIGURE 2.3. Coal Use in Paper and Allied Products 
1970 and the subsequent increasing and decreasing trends (see Figure 2.4). Although the levels are somewhat different, the movements follow much the same pattern.

\section{Fuel 0 il}

The trends in fuel oil consumption in each of the data series examined were similar, especially after 1978 when fuel oil in paper and allied products decreased rapidly. API calculations of fuel oil consumed in this industry were twice those of the NEA. CE also showed a higher level of oil consumption, though not nearly as high as API's estimates (see Figure 2.5).

\section{Electricity}

After 1973, API data indicate a faster increase in electricity use than do the NEA data. Both API and CE estimates for electricity consumption were about 40 trillion Btu (TBtu) higher than NEA's data (see Figure 2.6).

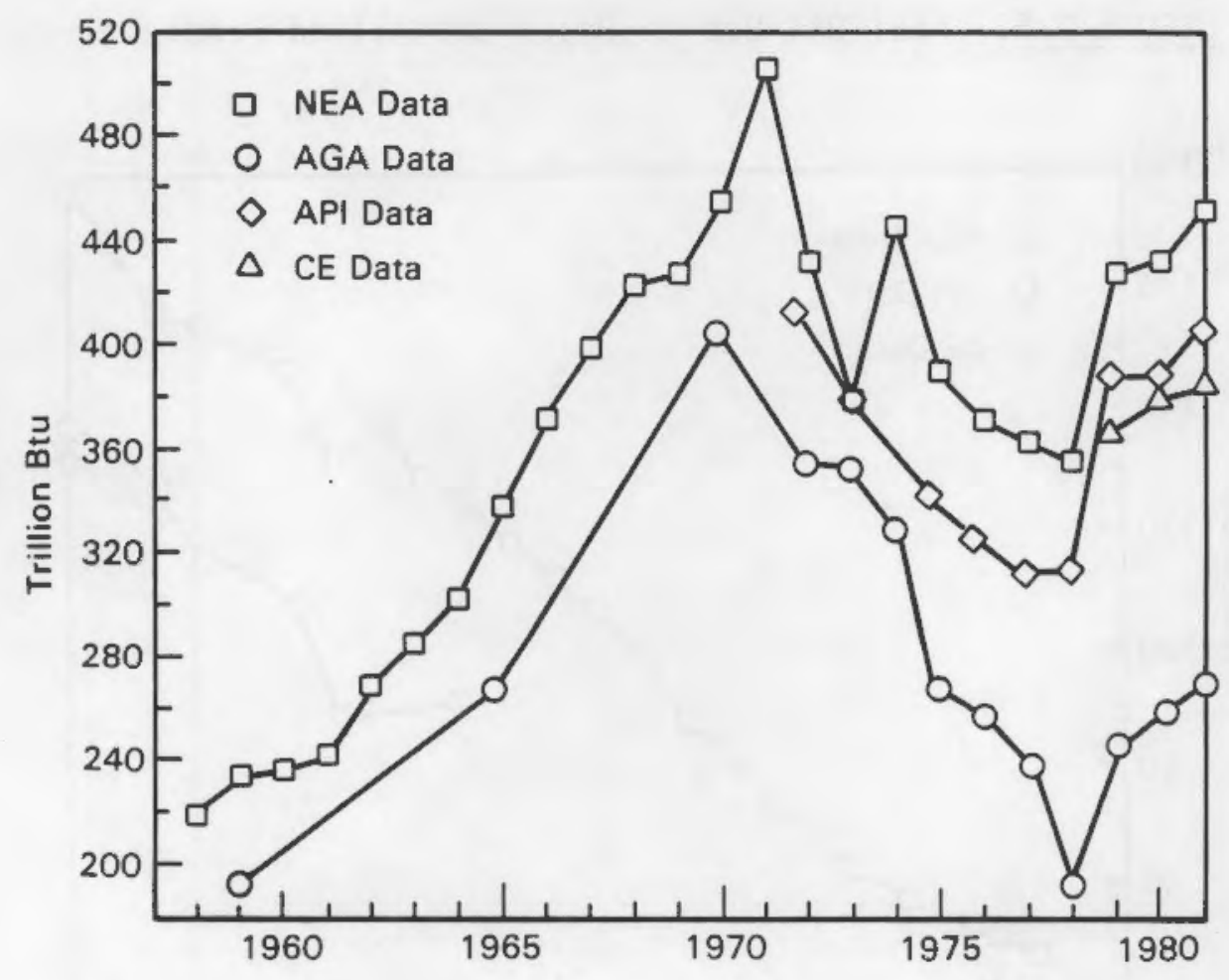

FIGURE 2.4. Natural Gas Use in Paper and Allied Products 


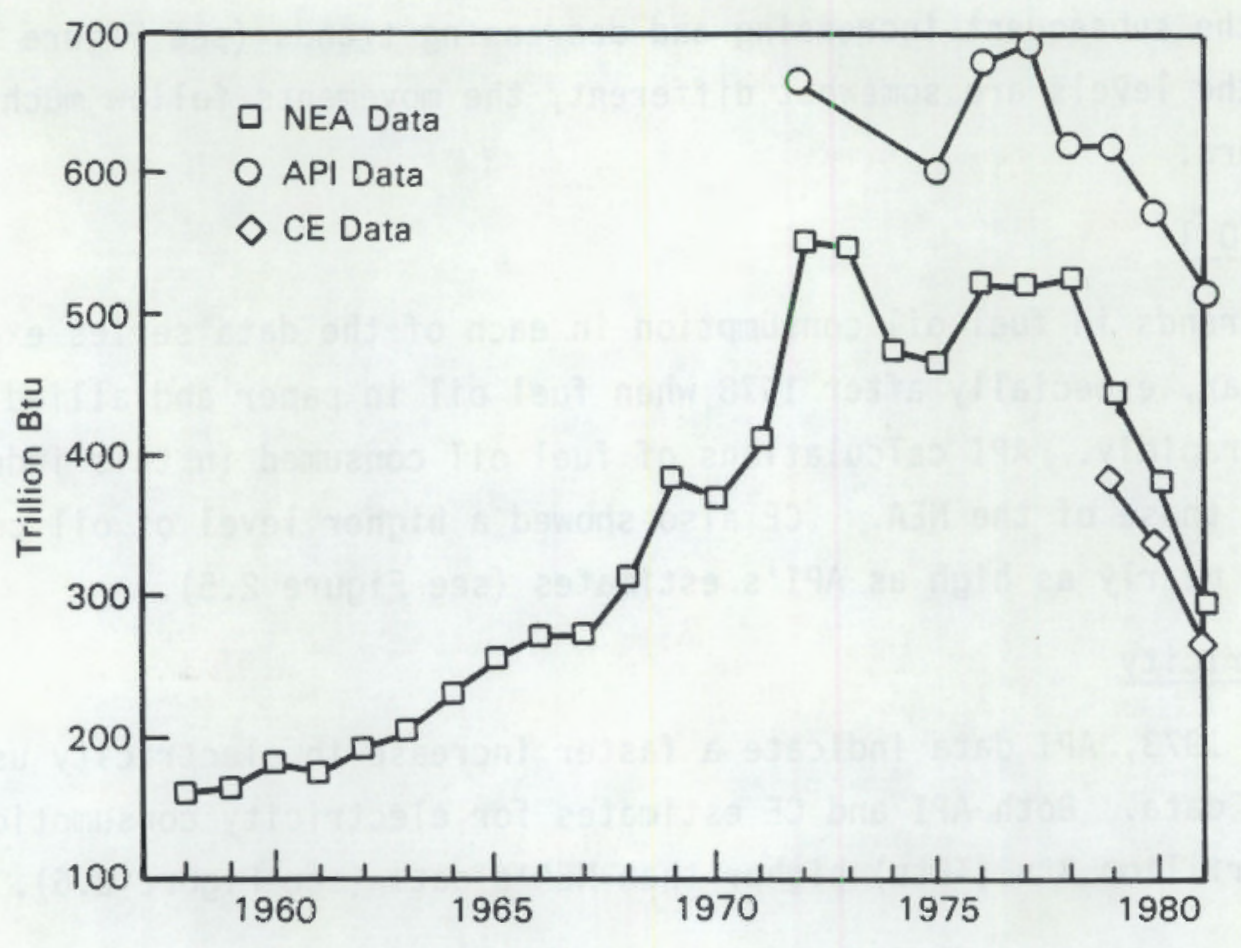

FIGURE 2.5. Fuel $0 i 1$ Use in Paper and Allied Products

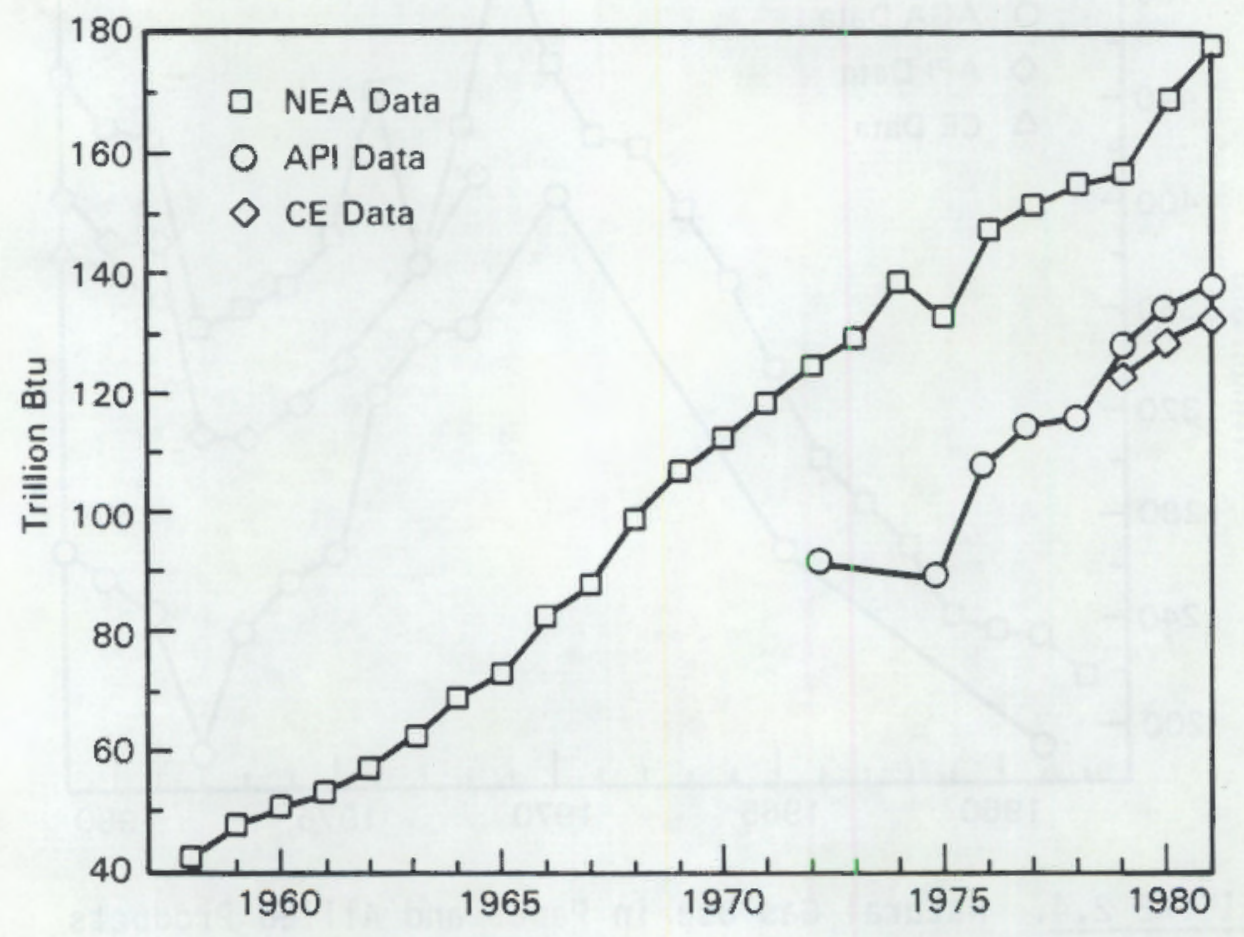

FIGURE 2.6. Electricity Use in Paper and Allied Products 


\subsubsection{Food and Kindred Products}

In NEA data, total energy consumption in the food and kindred products was higher than the amount measured by CE by at least 0.3 quads (see Figure 2.7), probably because the CE survey data do not represent the entire industry. The CE data for each of the fuel types were also less than the NEA information. The overall trends in the total energy consumption data for the food and kindred products sector were dissimilar.

Coal

The CE data were again less than NEA estimates. NEA indicated that coal consumption increased steadily after 1979, while CE showed a drop from 1980 to 1981 (see Figure 2.8).

\section{Natural Gas}

There are striking similarities in the trends of the NEA, CE and AGA data. AGA and NEA showed a relatively steady increase in natural gas consumption up until about 1970. After that both series exhibited an equivalent up

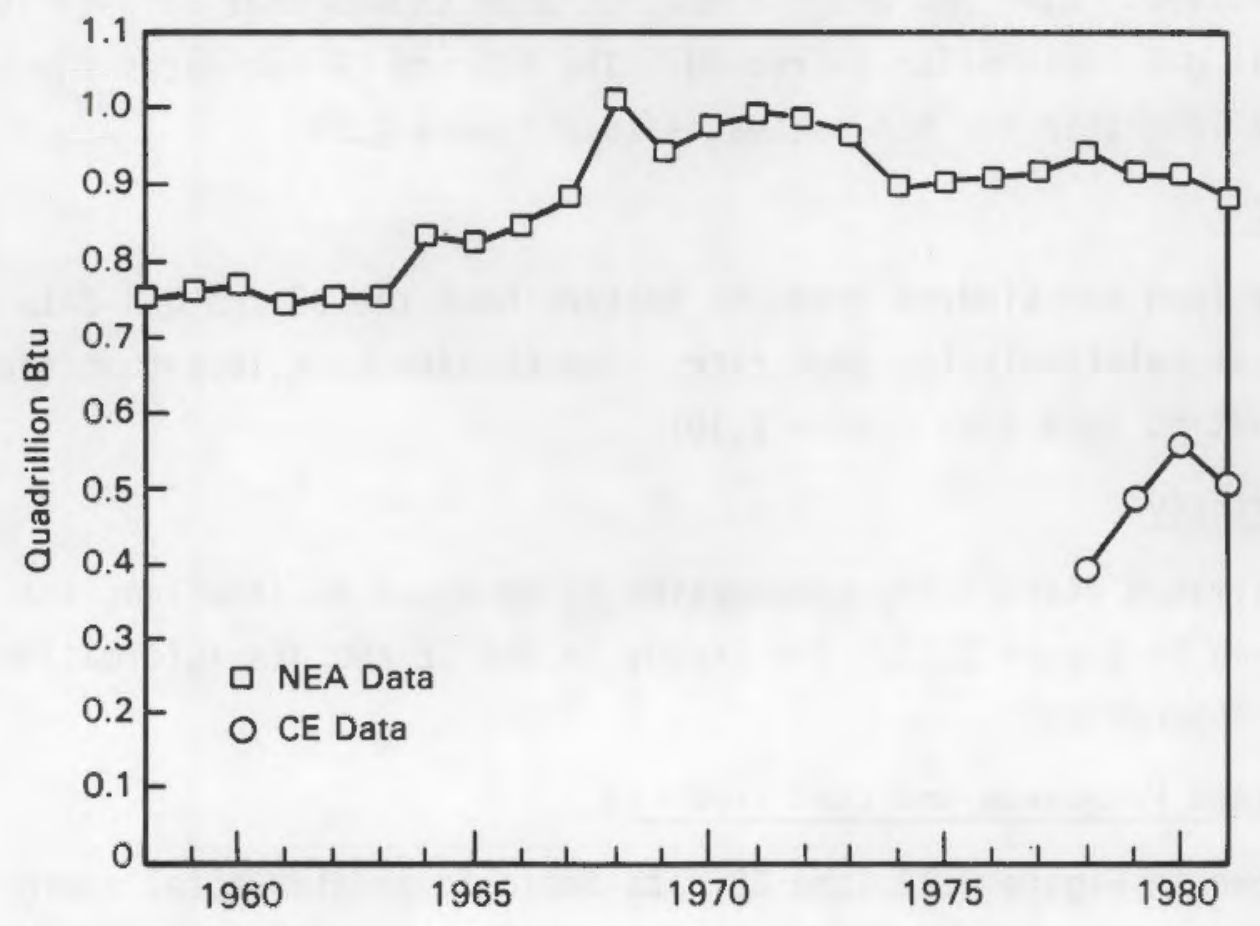

FIGURE 2.7. Total Energy Use in Food and Kindred Products 


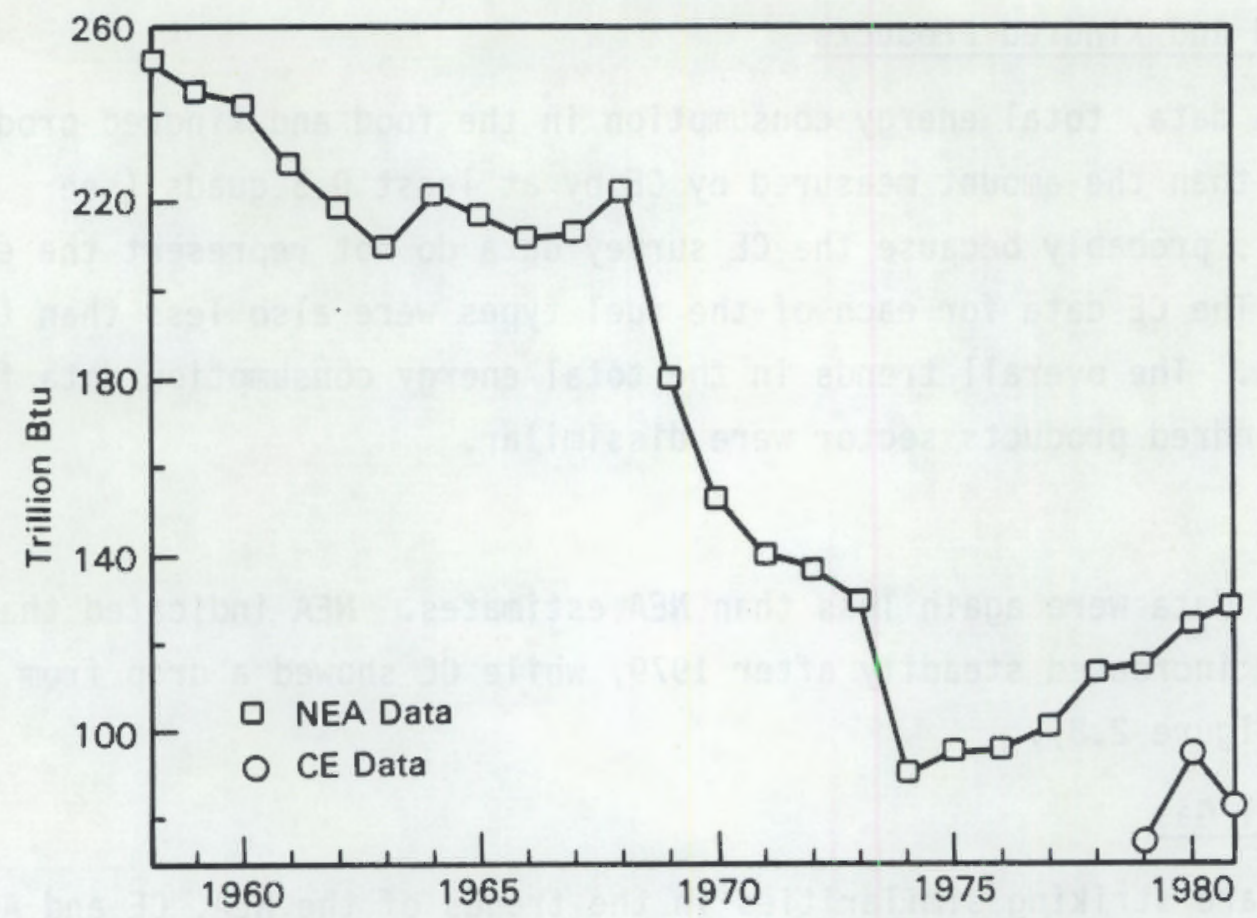

FIGURE 2.8. Coal Use in Food and Kindred Products

and down pattern. Like AGA and the NEA, CE also showed that between 1979 and 1981 natural gas consumption increased. The AGA and CE estimates for this sector were less than the NEA estimates (see Figure 2.9).

Fuel 0 il

In the food and kindred products sector, both the CE and NEA data decreased after 1979 at relatively the same rate. The CE data were less than the NEA data by about 50 TBtu (see Figure 2.10).

\section{Electricity}

CE estimated electricity consumption to be about 50 TBtu less than did NEA, as shown in Figure 2.11. The trends in the CE and NEA information show little correspondence.

\subsubsection{Refined Petroleum and Coal Products}

As shown in Figure 2.12, the CE data indicate greater total energy consumption by the petroleum and coal products industry than do the NEA data 


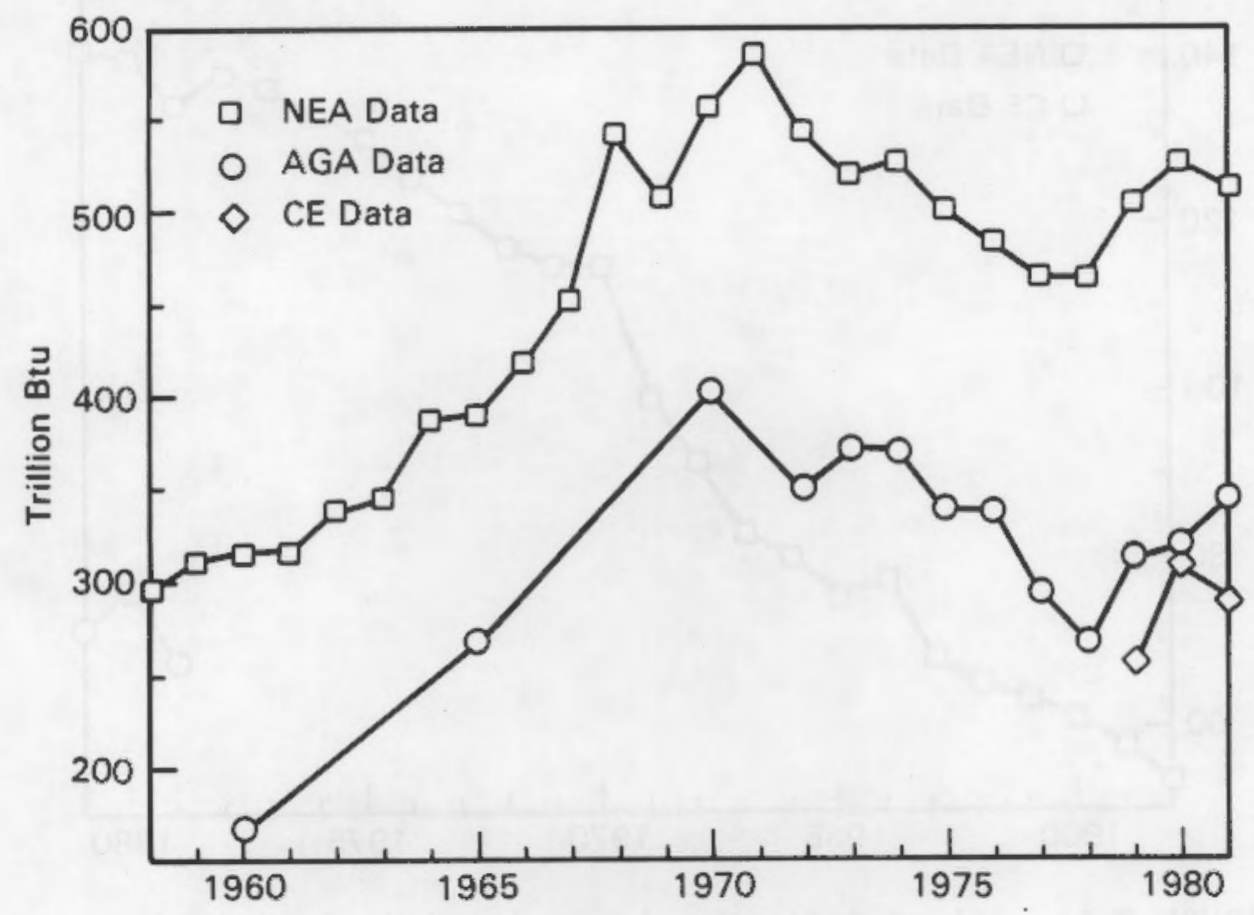

FIGURE 2.9. Natural Gas Use in Food and Kindred Products

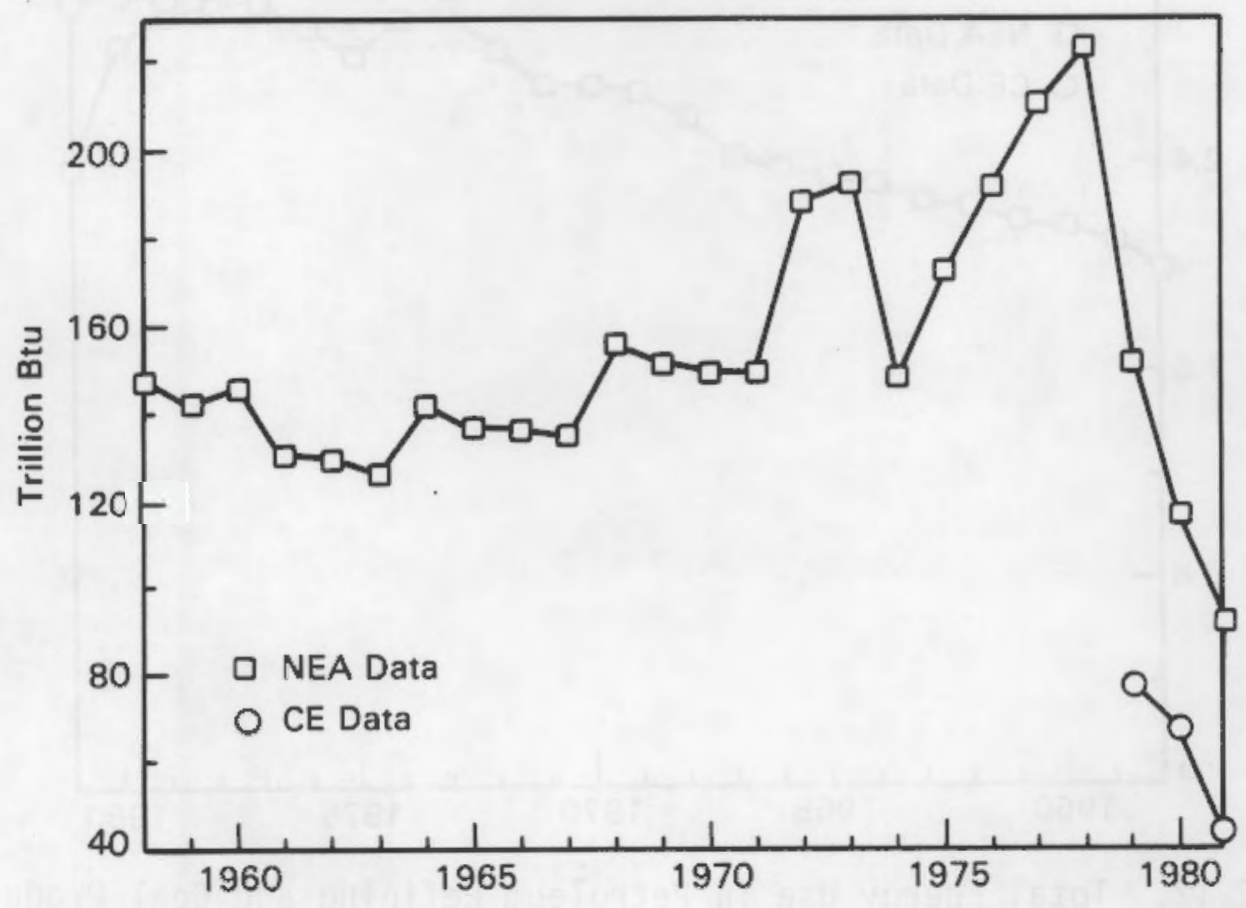

FIGURE 2.10. Fuel $0 i 1$ Use in Food and Kindred Products 


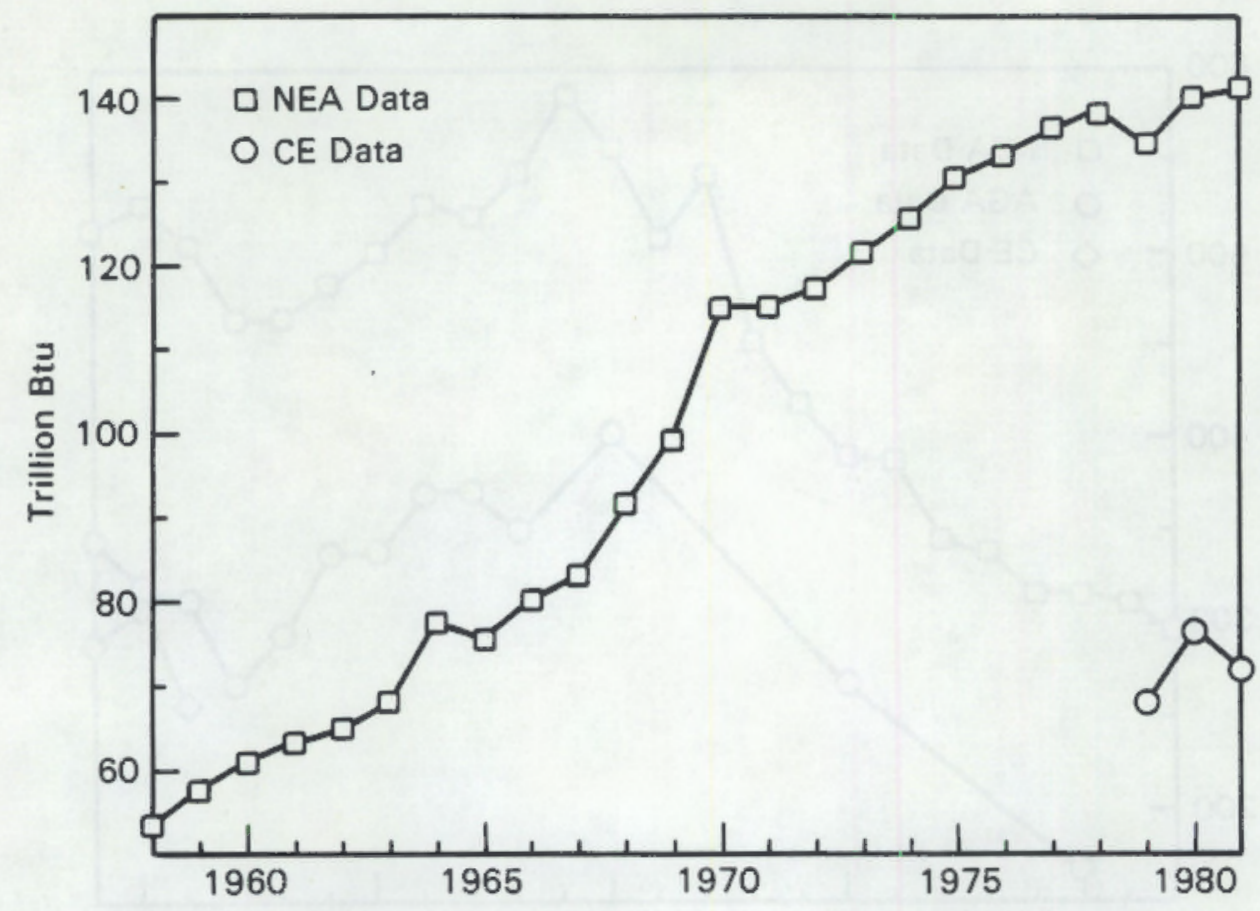

FIGURE 2.11. Electricity Use in Food and Kindred Products

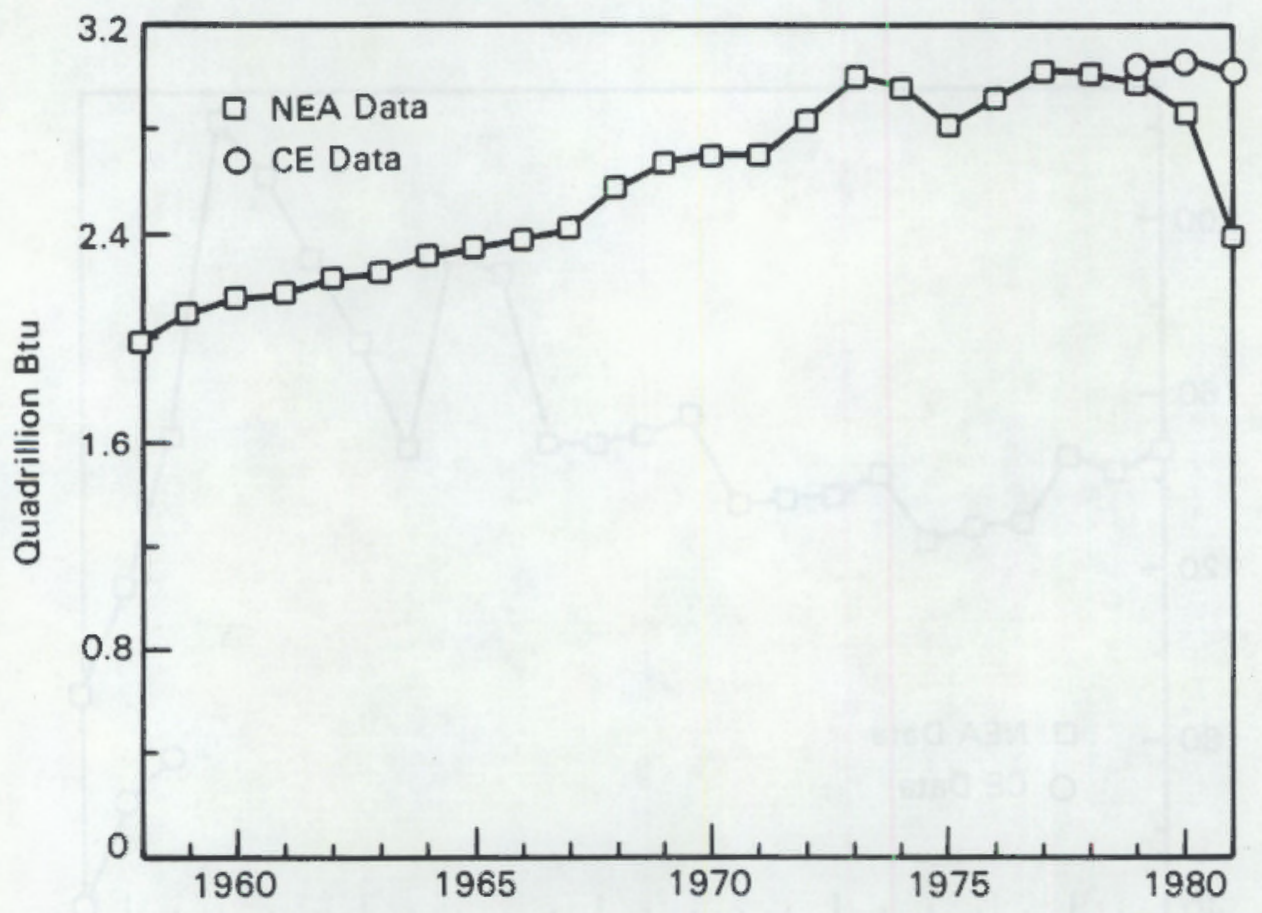

FIGURE 2.12. Total Energy Use in Petroleum Refining and Coal Products 
for the years 1979 through 1981. The reason for this discrepancy may be definitional, but why the definitions are different is not clear. Both should include all the energy consumed in SIC 29. Moreover, Figure 2.12 shows that the trends in energy consumption between 1979 and 1981 were also dissimilar for the two data sets.

Coal

The CE survey found very little coal consumed in the production of refined petroleum and coal products (see Figure 2.13). NEA estimated that in recent years about 250 TBtu per year of coal was consumed in this sector.

\section{Natural Gas}

Both the NEA and AGA data series indicated that natural gas consumption in the production of refined petroleum and coal products increased between

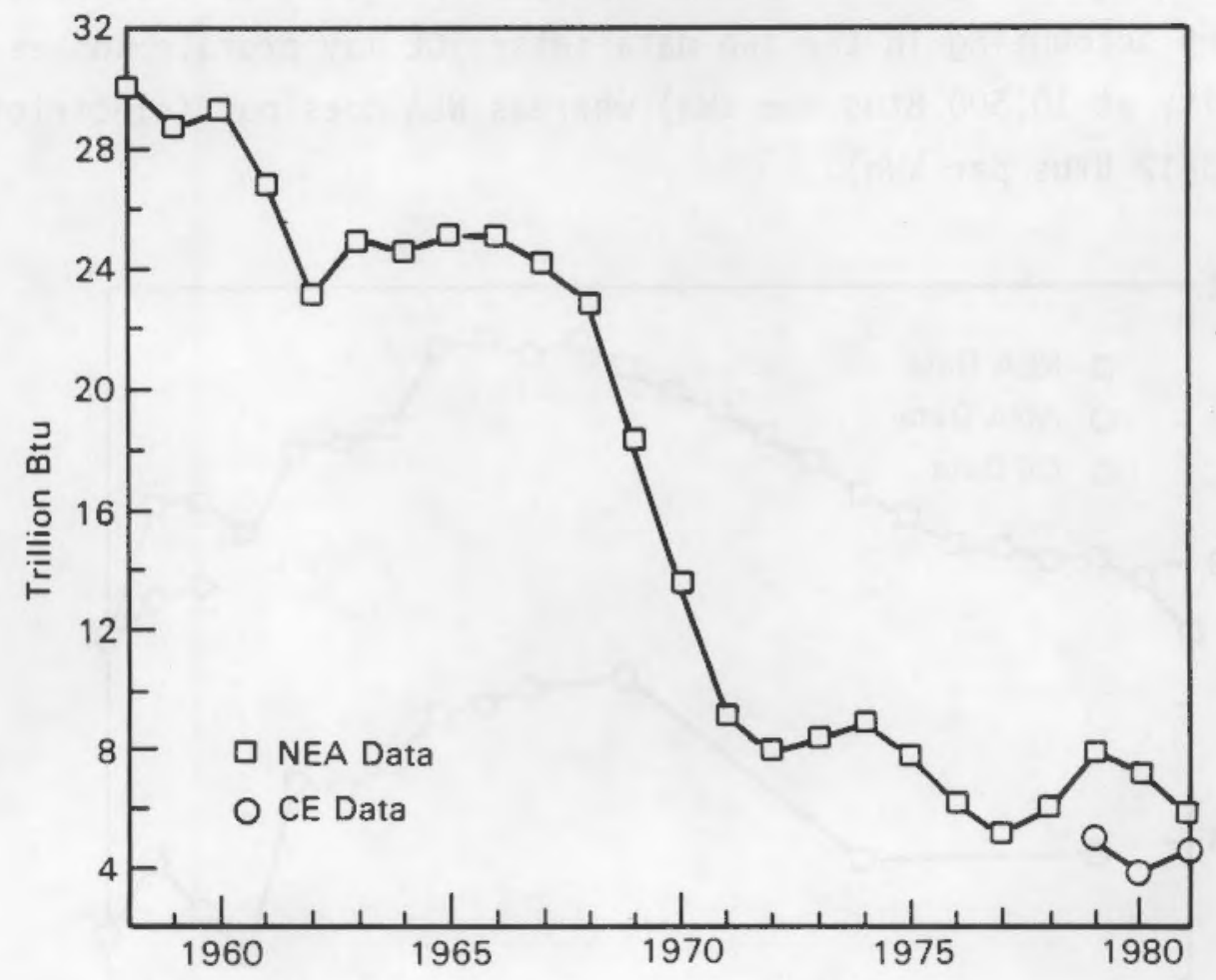

FIGURE 2.13. Coal Use in Petroleum Refining and Coal Products 
1958 and 1970, followed by an overall downward trend to 1981. The CE data for 1970 through 1981 also showed this decreasing trend.

In terms of magnitude, the CE data were somewhat similar to the NEA data and identical to NEA in 1981. The AGA data averaged about 0.5 quads less than the NEA data (see Figure 2.14).

\section{Fuel 011}

As shown in Figure 2.15, the CE data were similar to NEA data, especially for the years 1980 and 1981. However, for 1979, the data show different levels and the movement from 1979 to 1980 is quite different.

\section{Electricity}

CE estimated electricity consumption in the refined petroleum and coal products sector to be considerably higher than did the NEA, by a factor of more than 2 times (see Figure 2.16). This may be a result of a variation in electric energy accounting in the two data sets; CE may prorate losses (evaluate electricity at 10,500 Btus per $k$ Wh) whereas NEA does not (electricity is evaluated at 3412 Btus per $\mathrm{kWh}$ ).

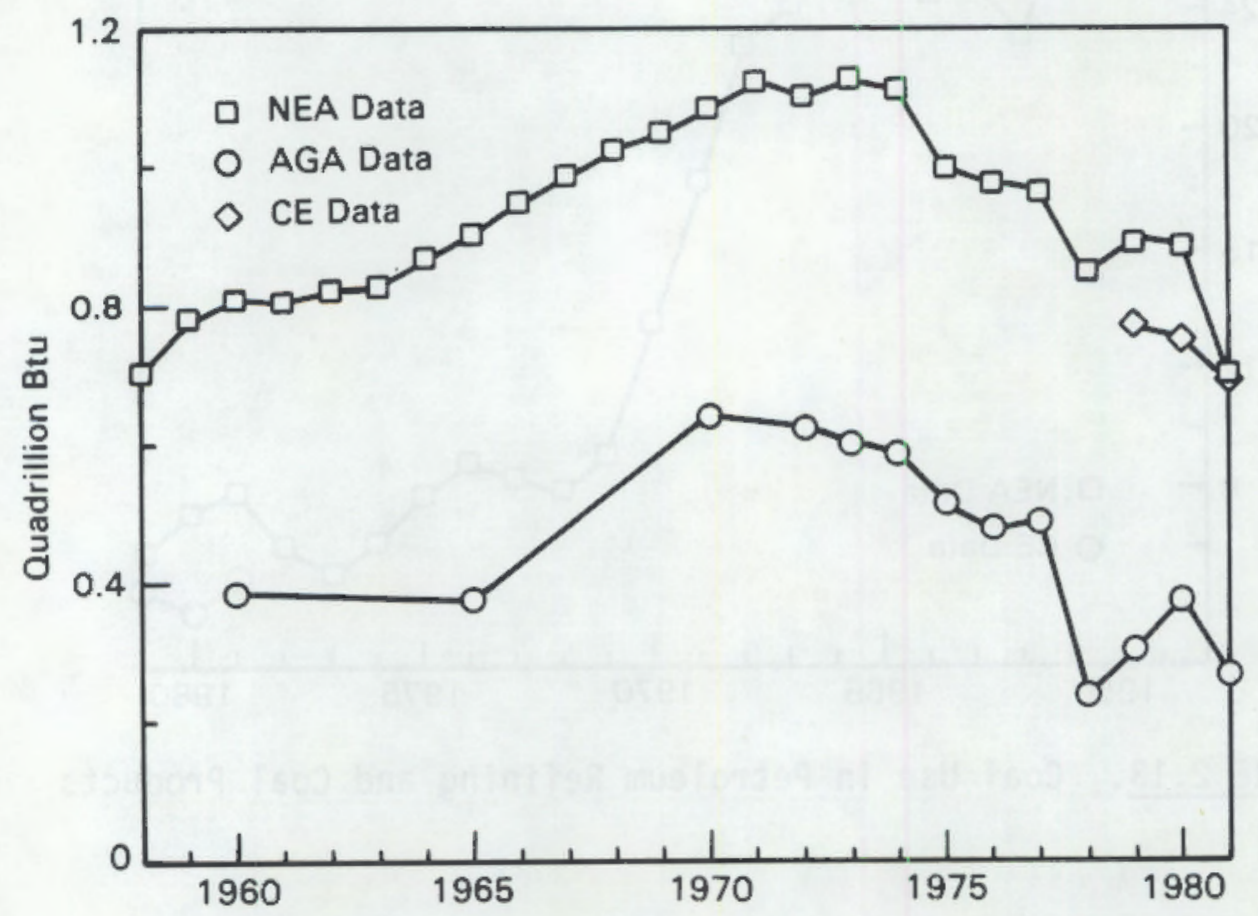

FIGURE 2.14. Natural Gas Use in Petroleum Refining and Coal Products 


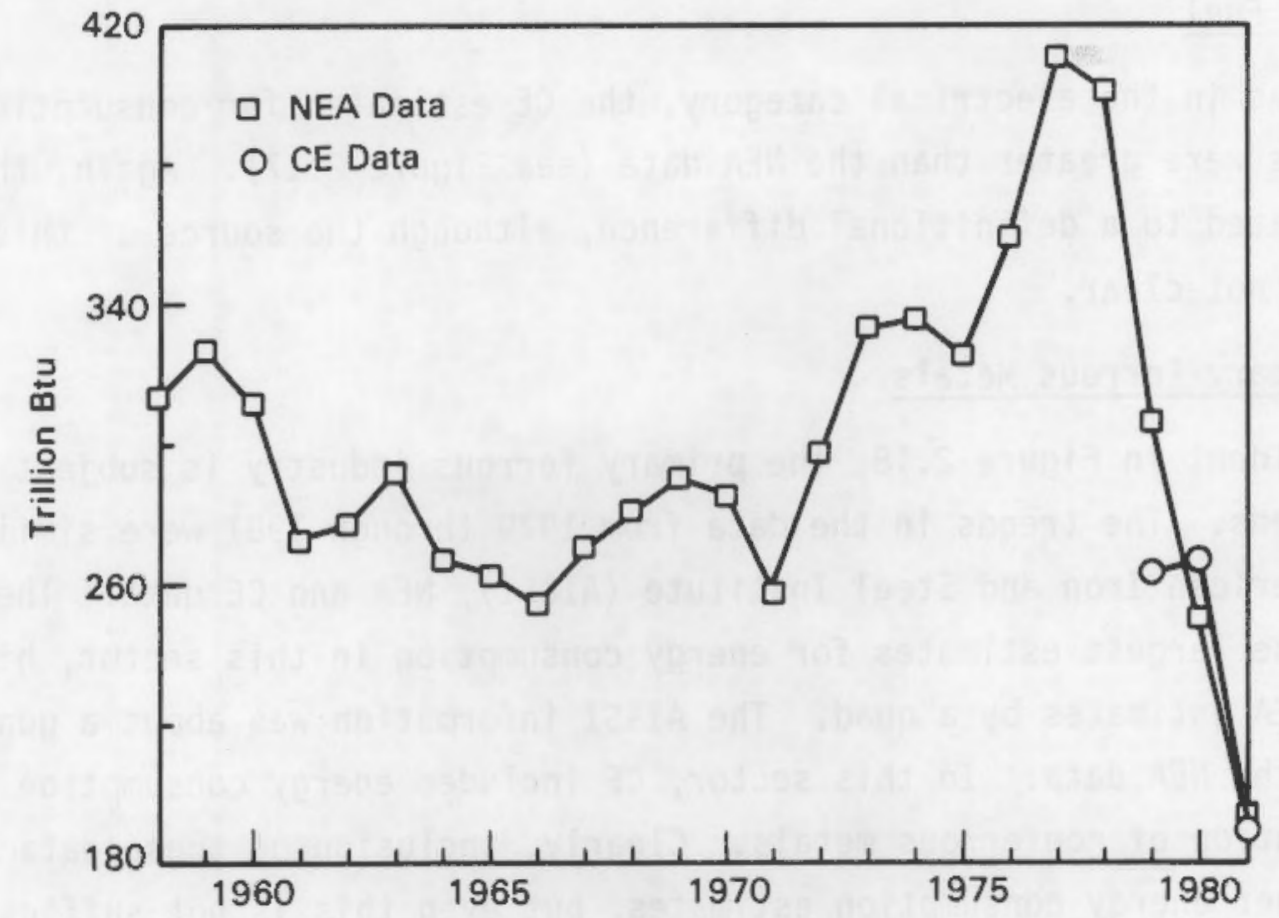

FIGURE 2.15. Fuel $0 i 1$ Use in Petroleum Refining and Coal Products

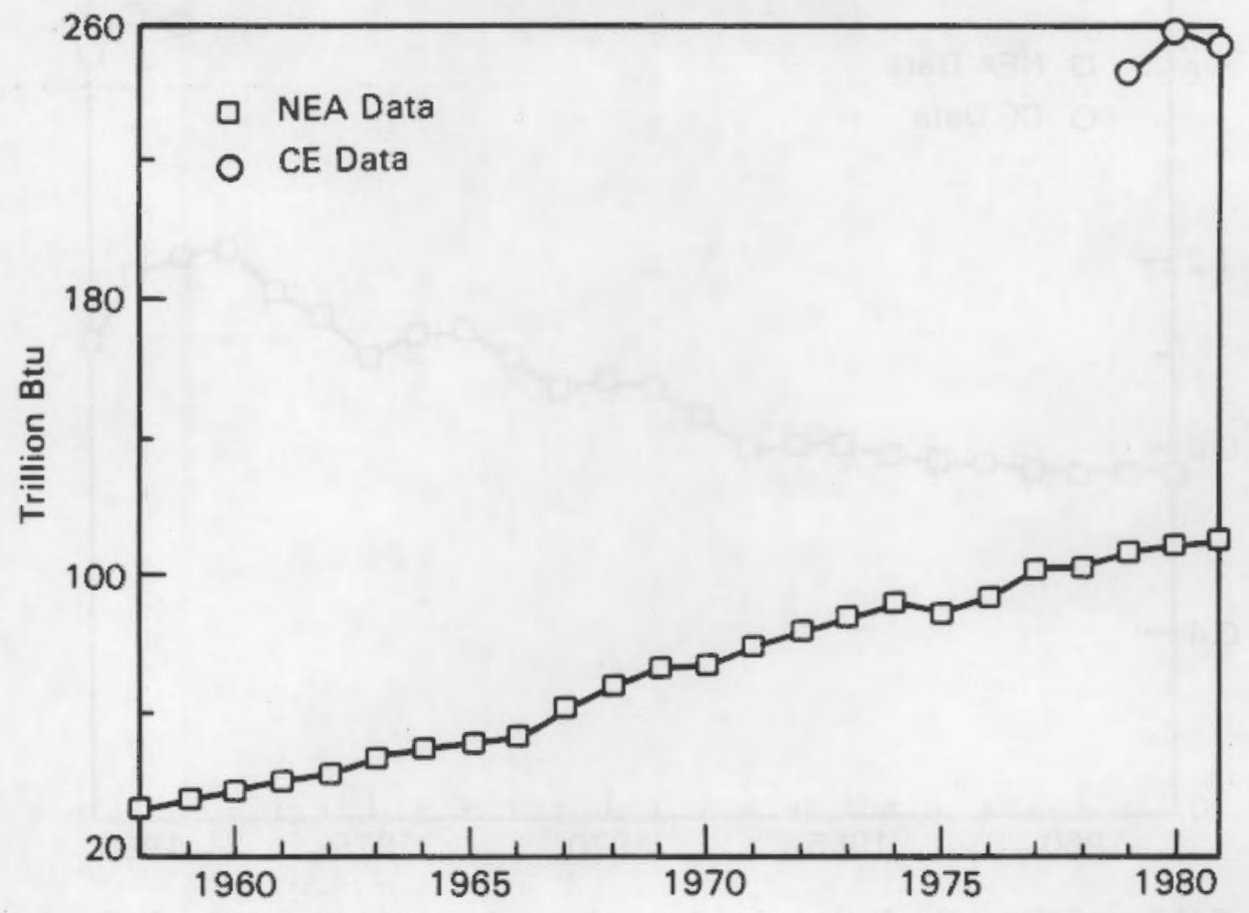

FIGURE 2.16. Electricity Use in Petroleum Refining and Coal Products 


\section{Other Fuel}

Just as in the electrical category, the CE estimates for consumption of other fuels were greater than the NEA data (see Figure 2.17). Again, this may be related to a definitional difference, although the source of this difference is not clear.

\subsubsection{Primary Ferrous Metals}

As evident in Figure 2.18, the primary ferrous industry is subject to cyclic trends. The trends in the data from 1979 through 1981 were similar for the American Iron and Steel Institute (AI\&SI), NEA and CE data. The CE data had the largest estimates for energy consumption in this sector, higher than the NEA estimates by a quad. The AI\&SI information was about a quad less than the NEA data. In this sector, CE included energy consumption for the fabrication of nonferrous metals. Clearly, inclusion of these data resulted in the higher energy consumption estimates, but even this is not sufficient to explain the differences in the totals.

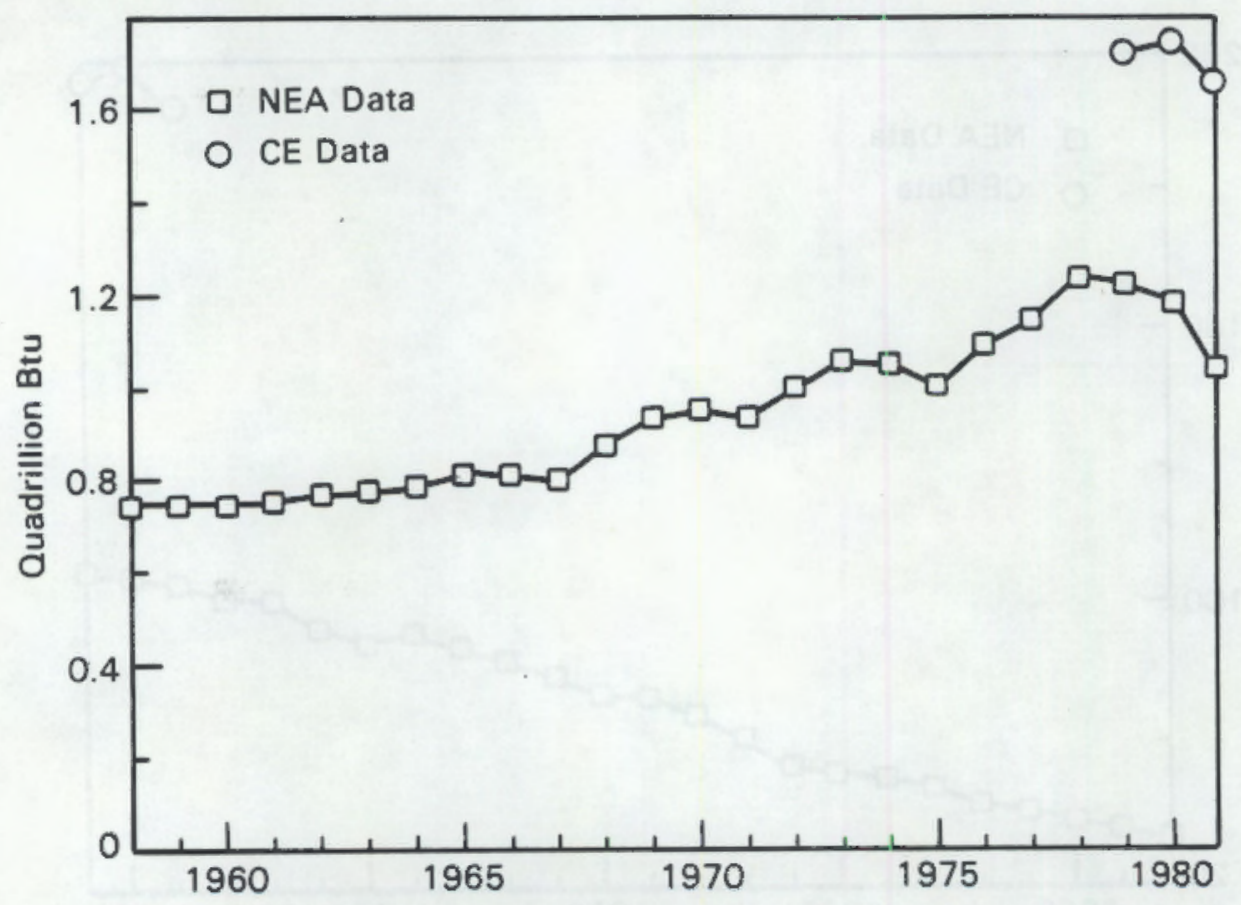

FIGURE 2.17. Other Fuel Use in Petroleum Refining and Coal Products 


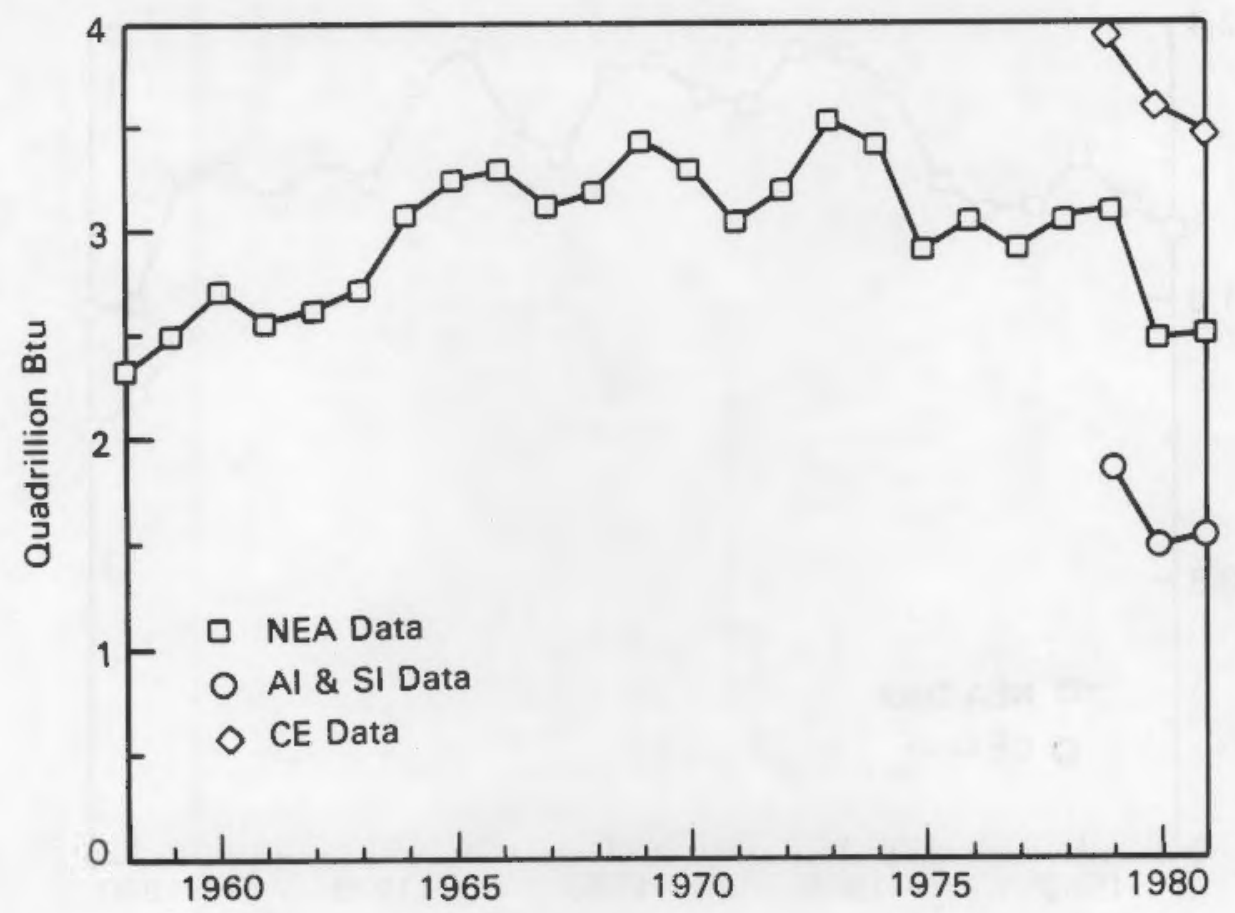

FIGURE 2.18. Total Energy Use in Primary Ferrous Metals

\section{$\underline{\text { Coal }}$}

As shown in Figure 2.19, the CE statistics were less than the NEA information by about 200 to $300 \mathrm{TBtu}$. Both CE and NEA estimated a decrease in the consumption of coal in the primary ferrous metals industry subsequent to 1979 . AI\&SI data did not contain an estimate for coal consumption in this industry. Rather, AI\&SI calculated coke and coke oven gas energy consumption which, in this analysis, was included in the "other fuels" category.

\section{Natural Gas}

NEA and AGA data for natural gas consumption were, for the most part, identical from 1960 to 1981 . The available AI\&SI data were also essentially identical to the NEA data. Only the CE data varied significantly (see Figure 2.20), and by a greater amount than would be warranted based on energy use in primary ferrous fabrication. 


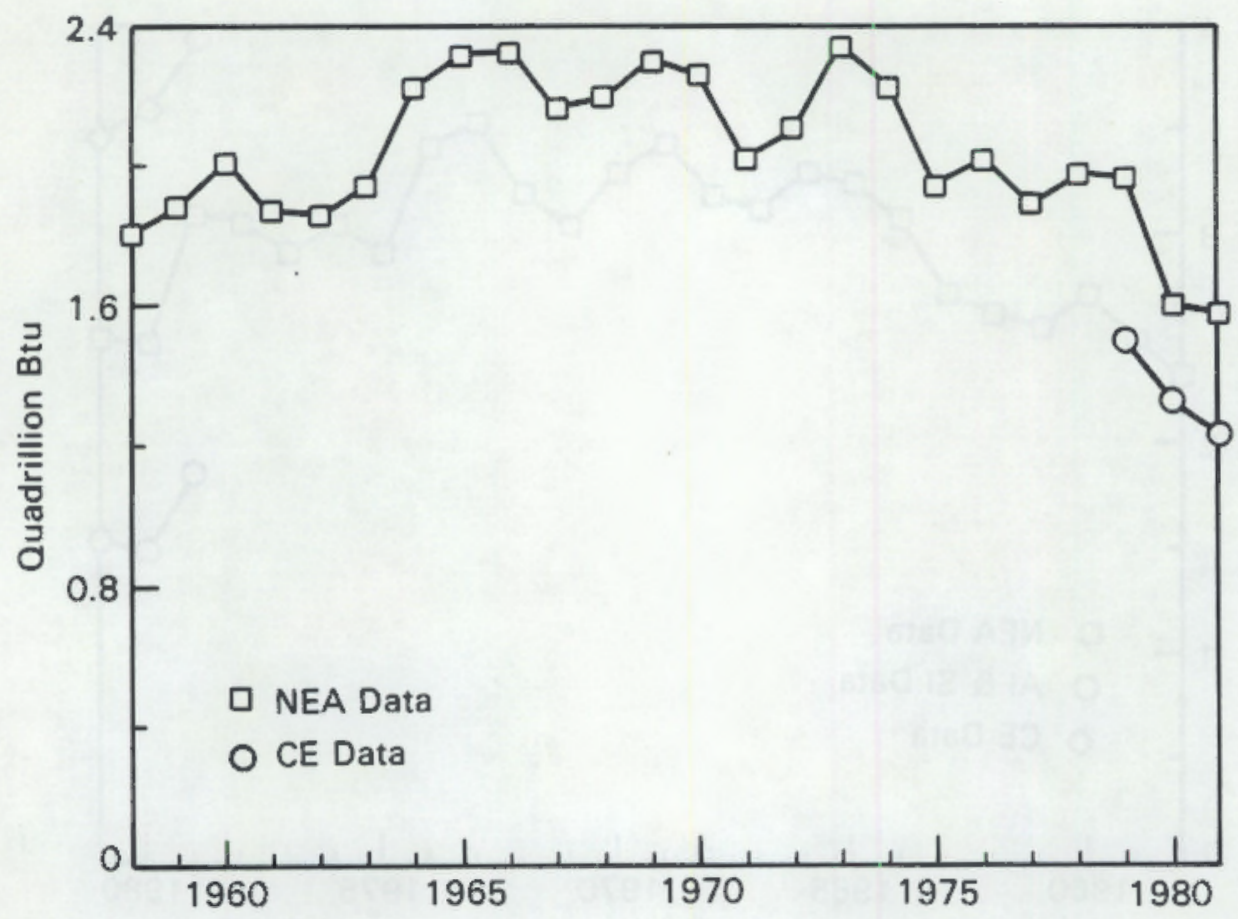

FIGURE 2.19. Coal Use in Primary Ferrous Metals

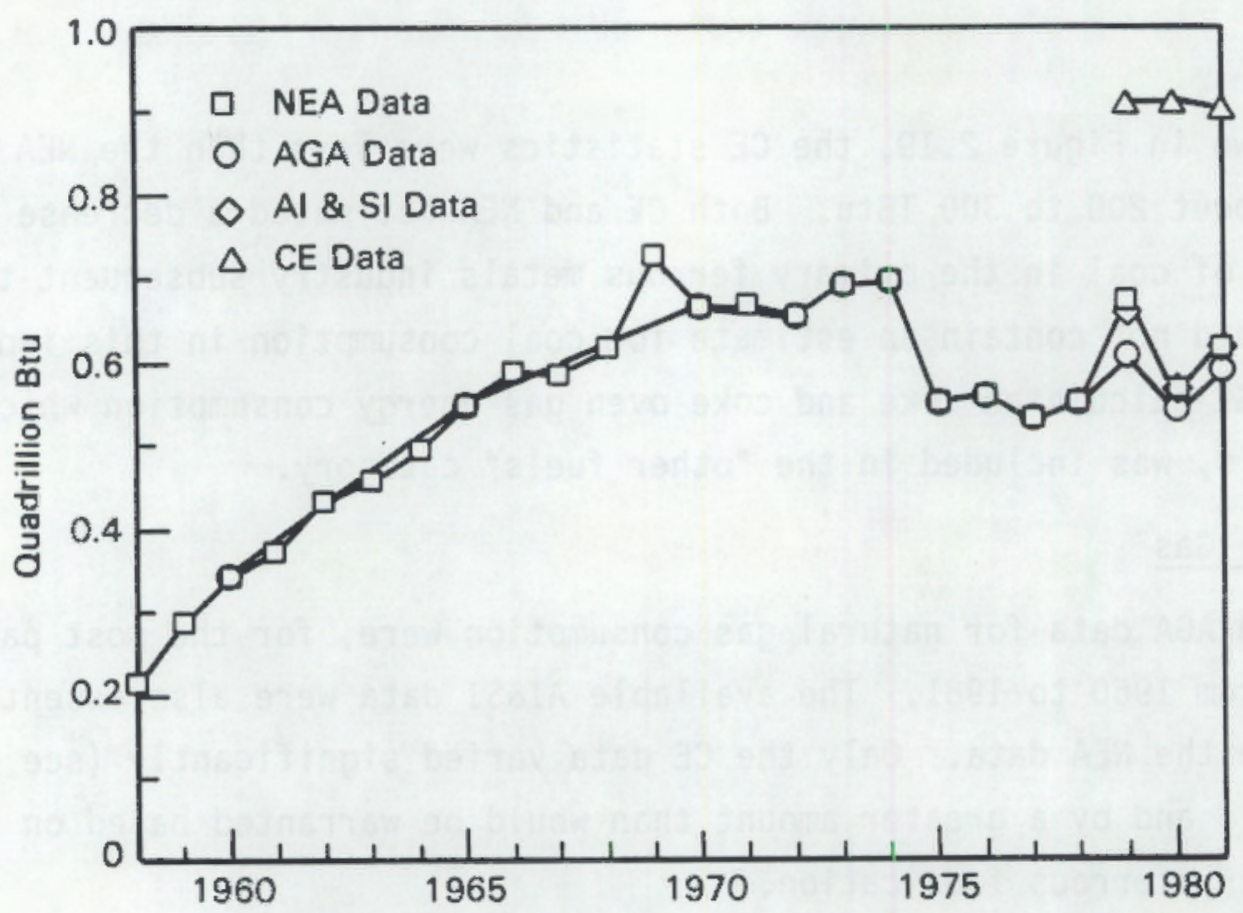

FIGURE 2.20. Natural Gas Use in Primary Ferrous Metals 


\section{Electricity}

The AI\&SI data, available for 1979 to 1981, almost exactly matched the NEA data (see Figure 2.21). Because of the aforementioned definitional differences, CE estimates for electricity consumption were significantly higher than the NEA/AI\&SI data.

\section{Fuel $0 i 1$}

Just as for the other fuels, the CE estimates for fuel oil consumption were high, though in this category the trend in the CE estimate for oil consumption was similar to the trends in the NEA and AI\&SI data. The AI\&SI and NEA information showed only slight variance (see Figure 2.22).

\subsubsection{Stone, Clay and Glass Products}

As shown in Figure 2.23, the CE data indicate total energy consumption that is less than the NEA data by at least a 100 TBtu. That the CE data are

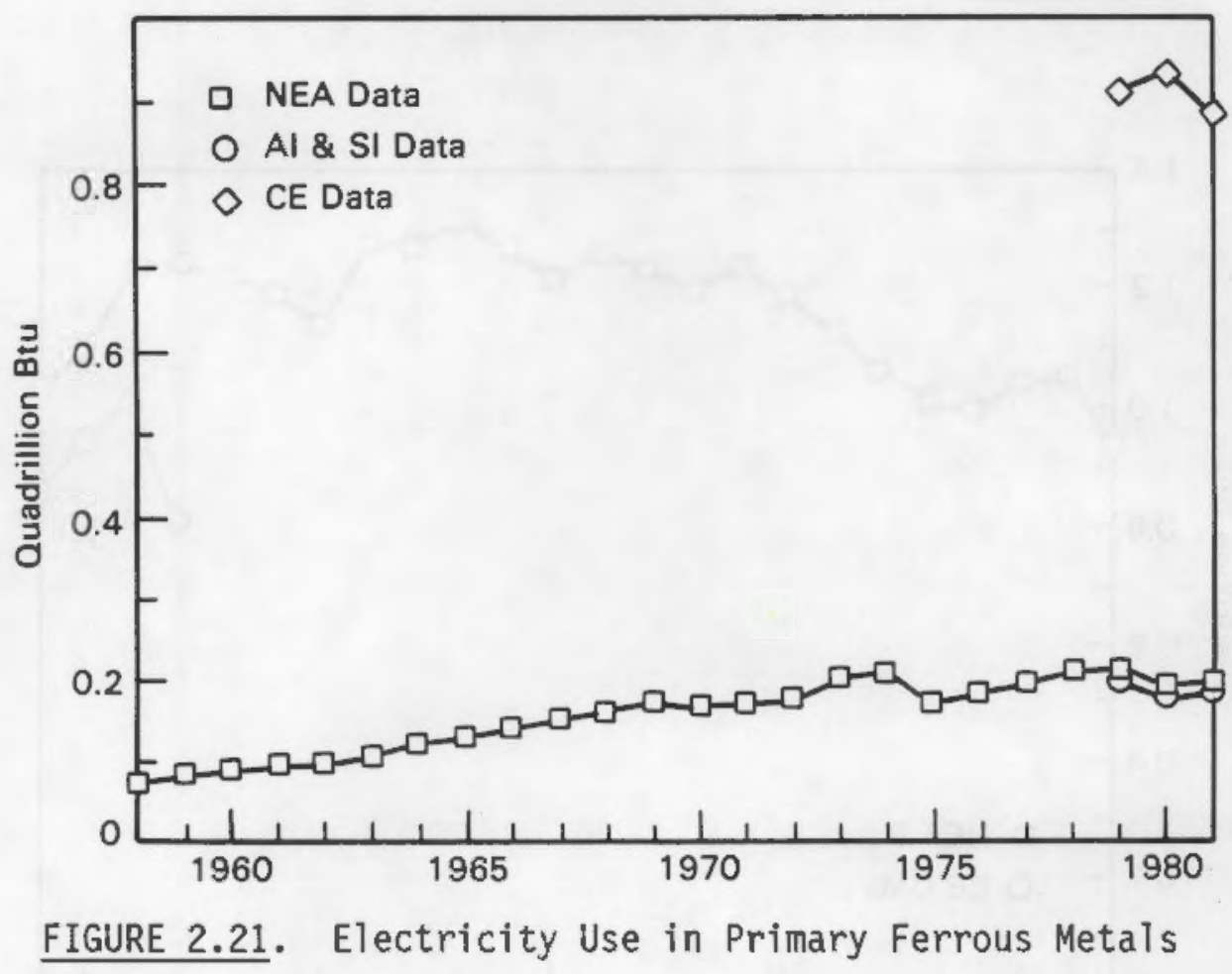




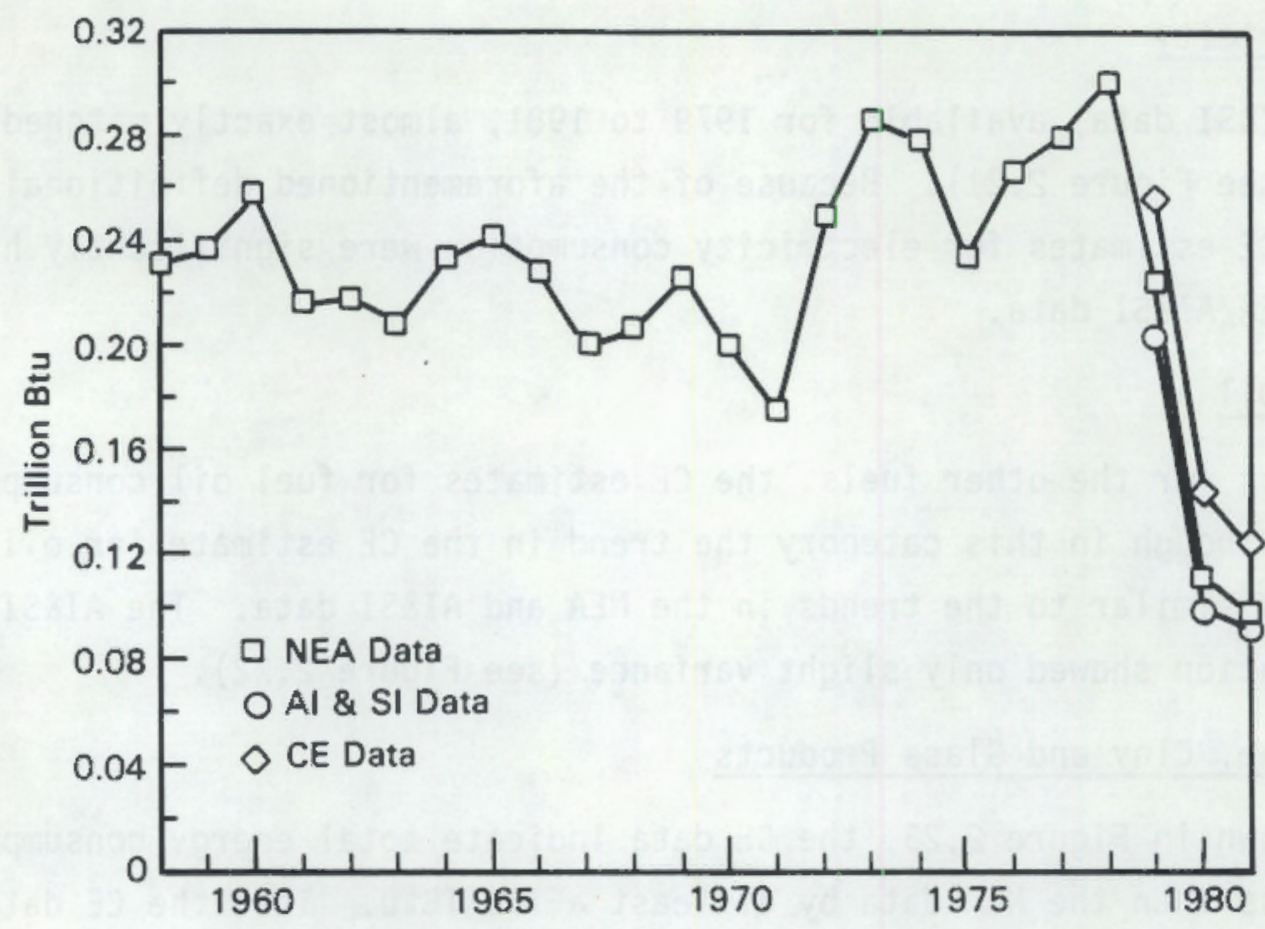

FIGURE 2.22. Fuel $0 i 1$ Use in Primary Ferrous Metals

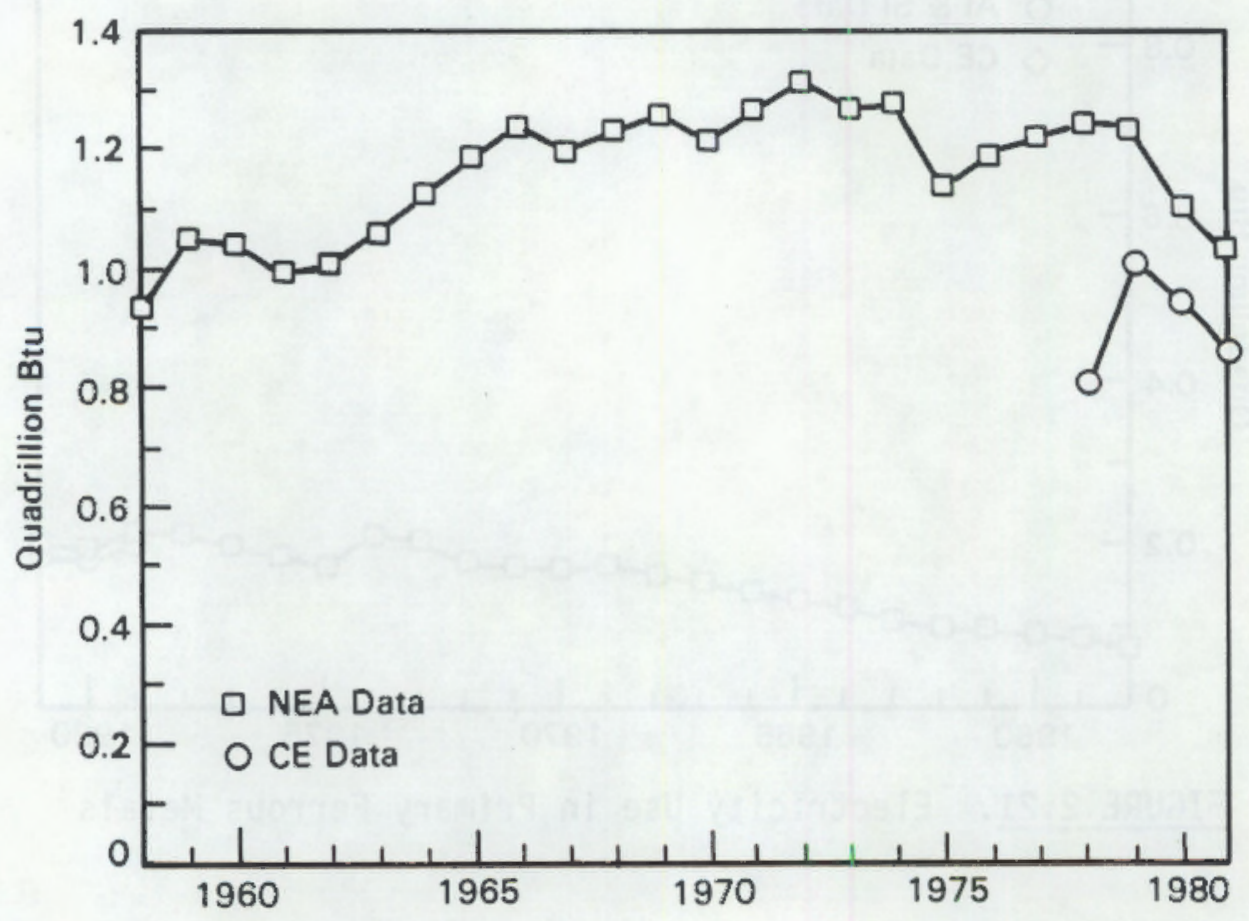

FIGURE 2.23. Total Energy Use in Stone, Clay and Glass Products 
lower is not surprising, since CE data are not enumerative of the industry. There is, however, a substantially greater difference in the CE and NEA data for 1978 than for the other years. Both the CE and NEA data indicated a decreasing trend in energy consumption in the production of stone, clay and glass starting in 1979.

Coal

Coal consumption in this sector decreased from 1978 to 1979 . In 1980, the consumption of coal rebounded slightly as shown by both the NEA and CE data. The trends in the CE data were slightly more conservative than the NEA, with the CE data less by 50 about TBtu (see Figure 2.24).

\section{Natural Gas}

Natural gas consumption in the stone, clay and glass sector appeared to have increased almost steadily until the energy crisis in 1973 according to statistics from NEA and AGA (see Figure 2.25). After 1973, the NEA, AGA and CE data indicated a cyclical decreasing trend. Throughout the entire time

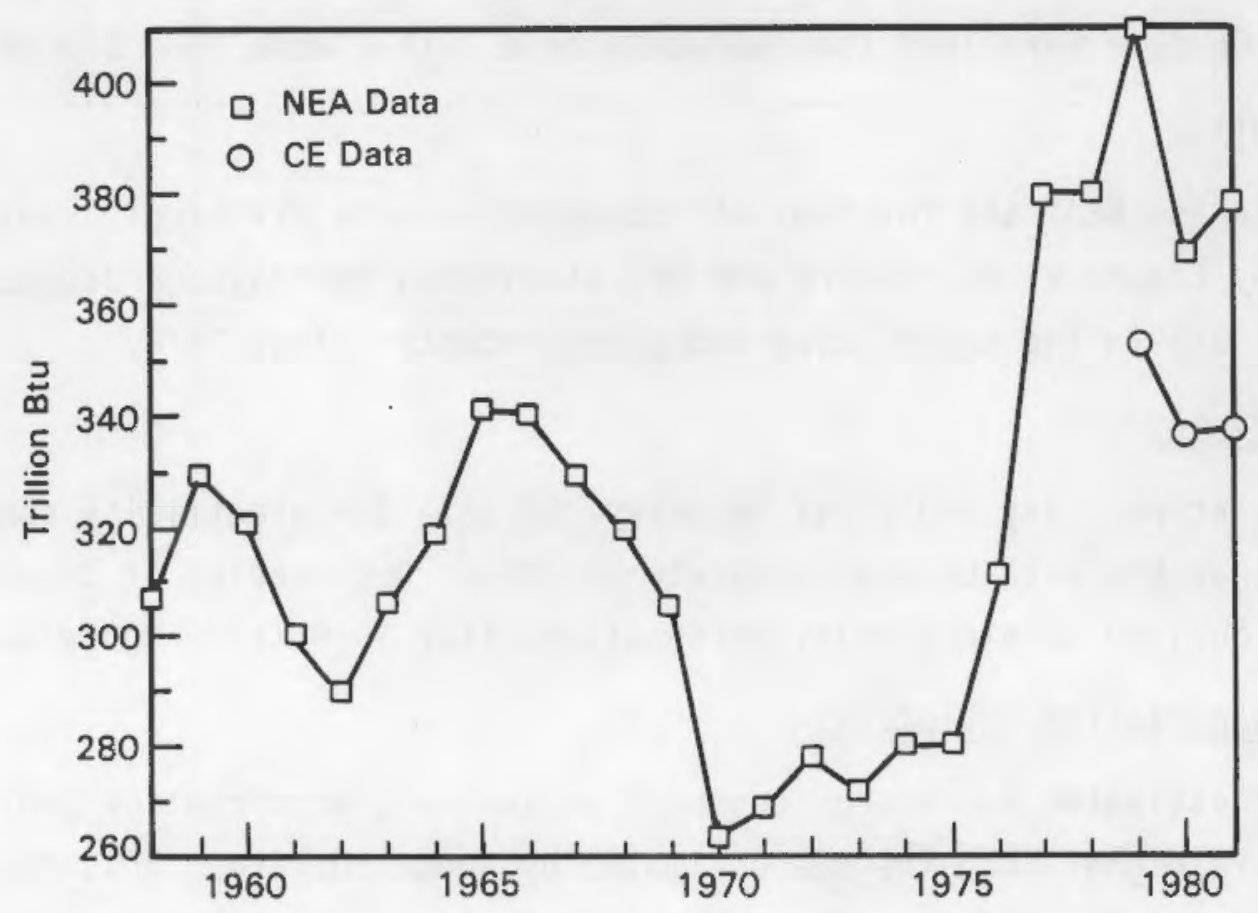

FIGURE 2.24. Coal Use in Stone, Clay and Glass Products 


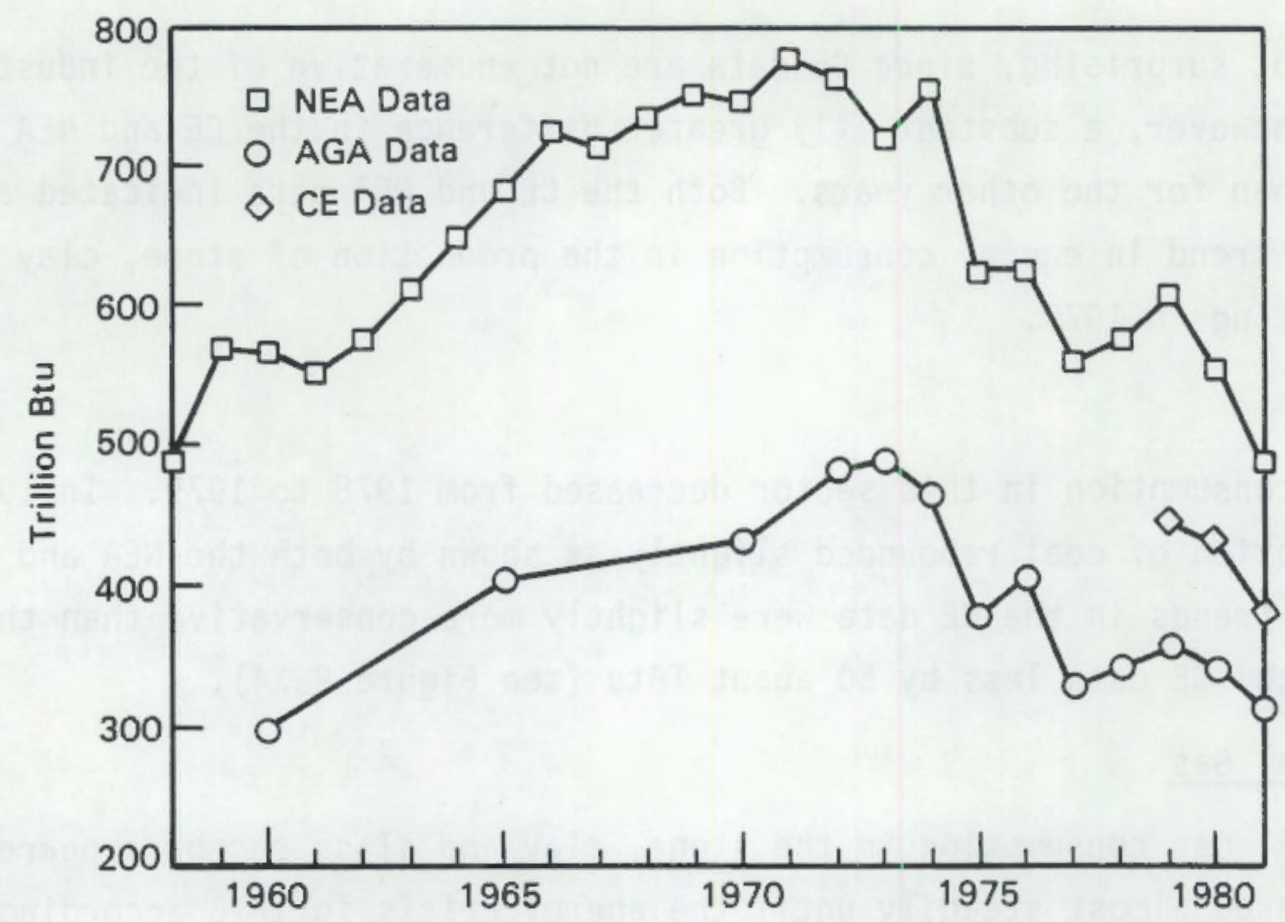

FIGURE 2.25. Natural Gas Use in Stone, Clay and Glass Products

series from 1958 to 1981 , the AGA statistics were less than NEA data by 200 TBtu. The CE data were less than NEA data by a little more than 100 TBtu.

Fuel 0 il

CE data and NEA data for fuel oil consumption were strikingly similar, as indicated by Figure 2.26. The CE and NEA statistics portrayed a decreasing use of fuel oil in the stone, clay and glass industry after 1978.

\section{Electricity}

In the stone, clay and glass industry, CE data for electricity consumption were less than NEA data by approximately 20 TBtu. Both series of data showed an overall decline in electricity consumption after 1979 (see Figure 2.27).

\subsubsection{Transportation Equipment}

The CE estimates for energy consumption in the transportation equipment industry were higher than the NEA estimates by about 50 TBtu. This had not been the case with estimates from other industries. Typically, the CE data were less than the NEA data since the NEA data represented consumption for the 


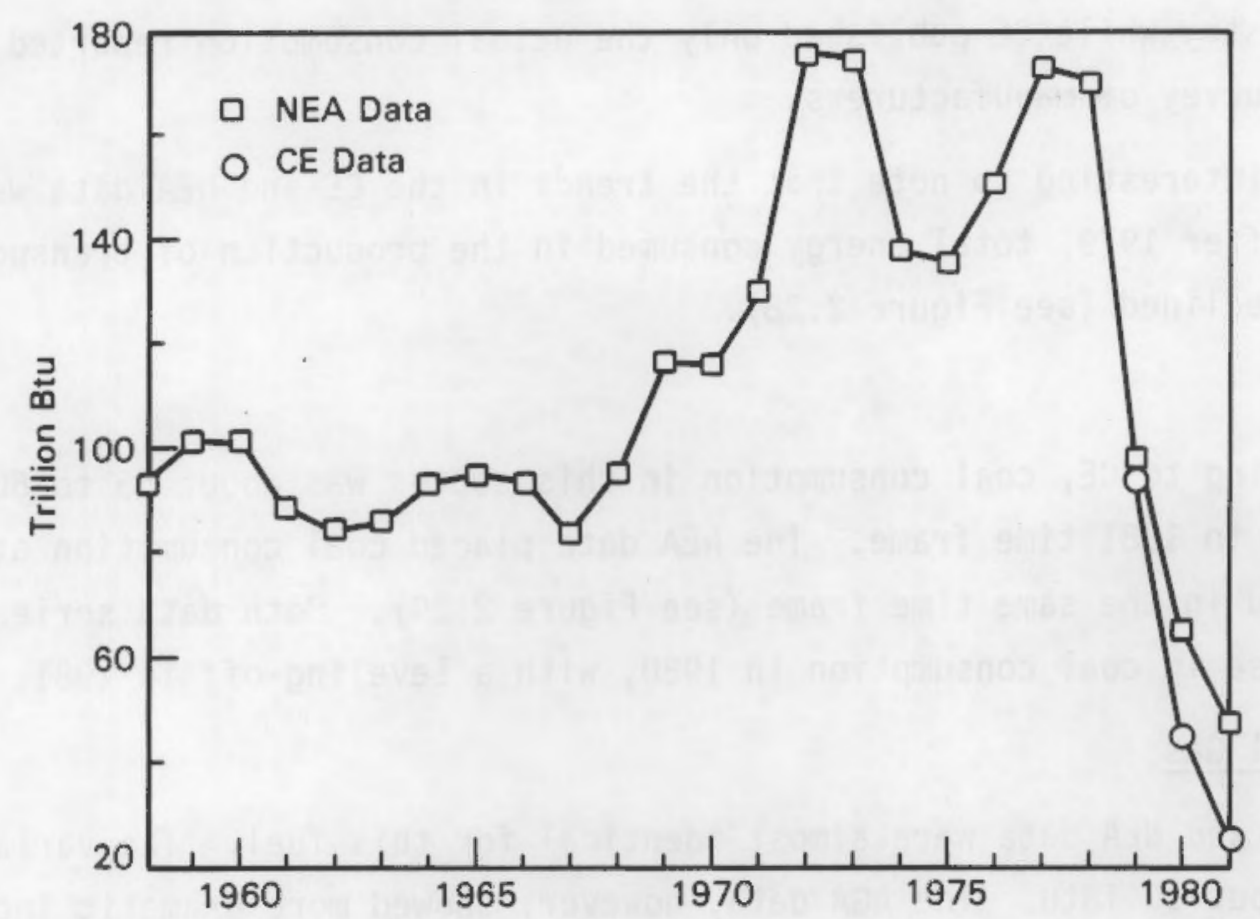

FIGURE 2.26. Fuel 011 Use in Stone, Clay and Glass Products

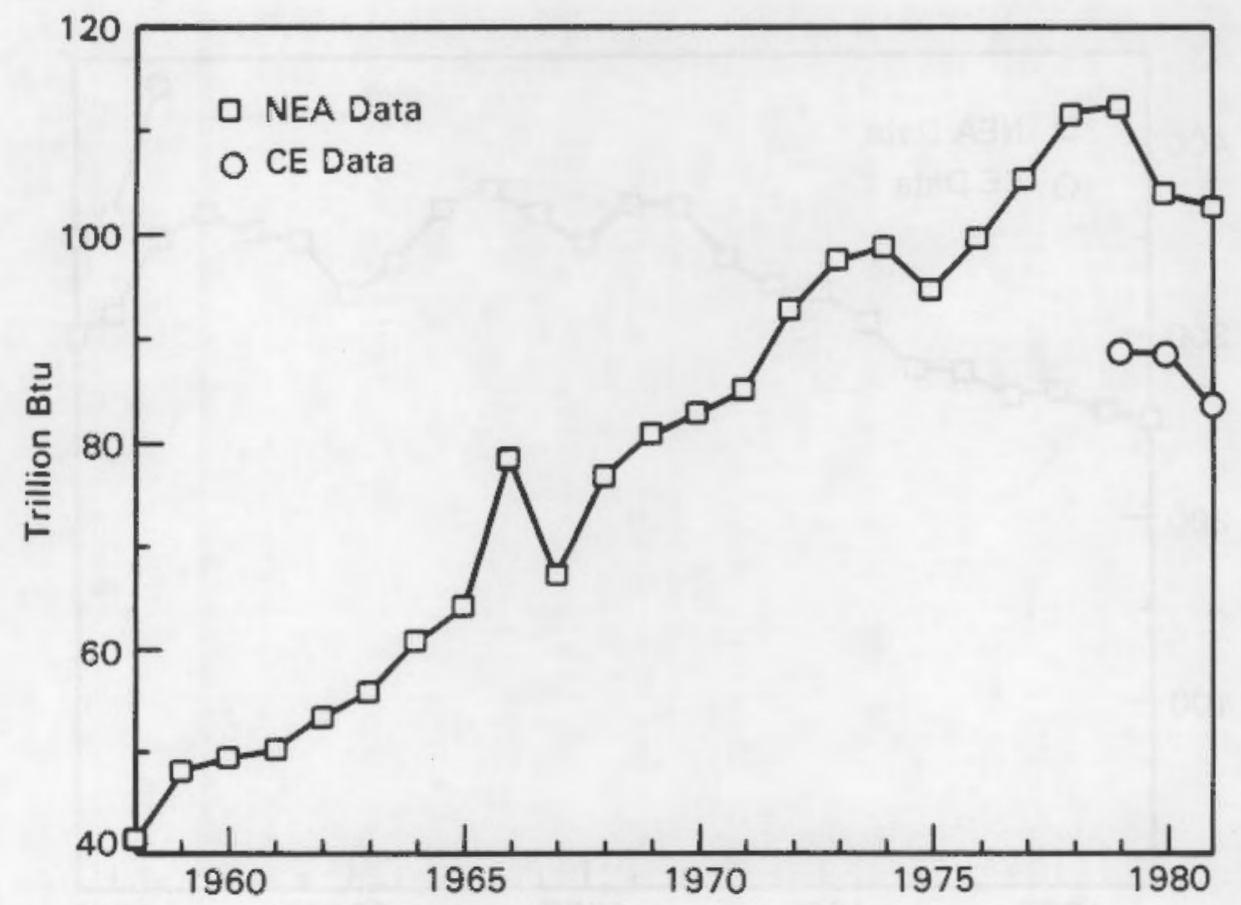

FIGURE 2.27. Electricity Use in Stone, Clay and Glass Products 
entire industry while CE published only the actual consumption reported in a voluntary survey of manufacturers.

It is interesting to note that the trends in the CE and NEA data were similar. After 1979, total energy consumed in the production of transportation equipment declined (see Figure 2.28).

\section{$\underline{\text { Coal }}$}

According to CE, coal consumption in this sector was about 55 to 60 TBtu in the 1979 to 1981 time frame. The NEA data placed coal consumption at only 45 to $55 \mathrm{Btu}$ in the same time frame (see Figure 2.29). Both data series picked up a decrease in coal consumption in 1980, with a leveling-off in 1981 .

\section{Natural Gas}

The CE and NEA data were almost identical for this fuel. The variance was only about 10 TBtu. The AGA data, however, showed more dramatic increases in natural gas in the 1970 to 1974 time frame and decreases after 1977 (see Figure 2.30).

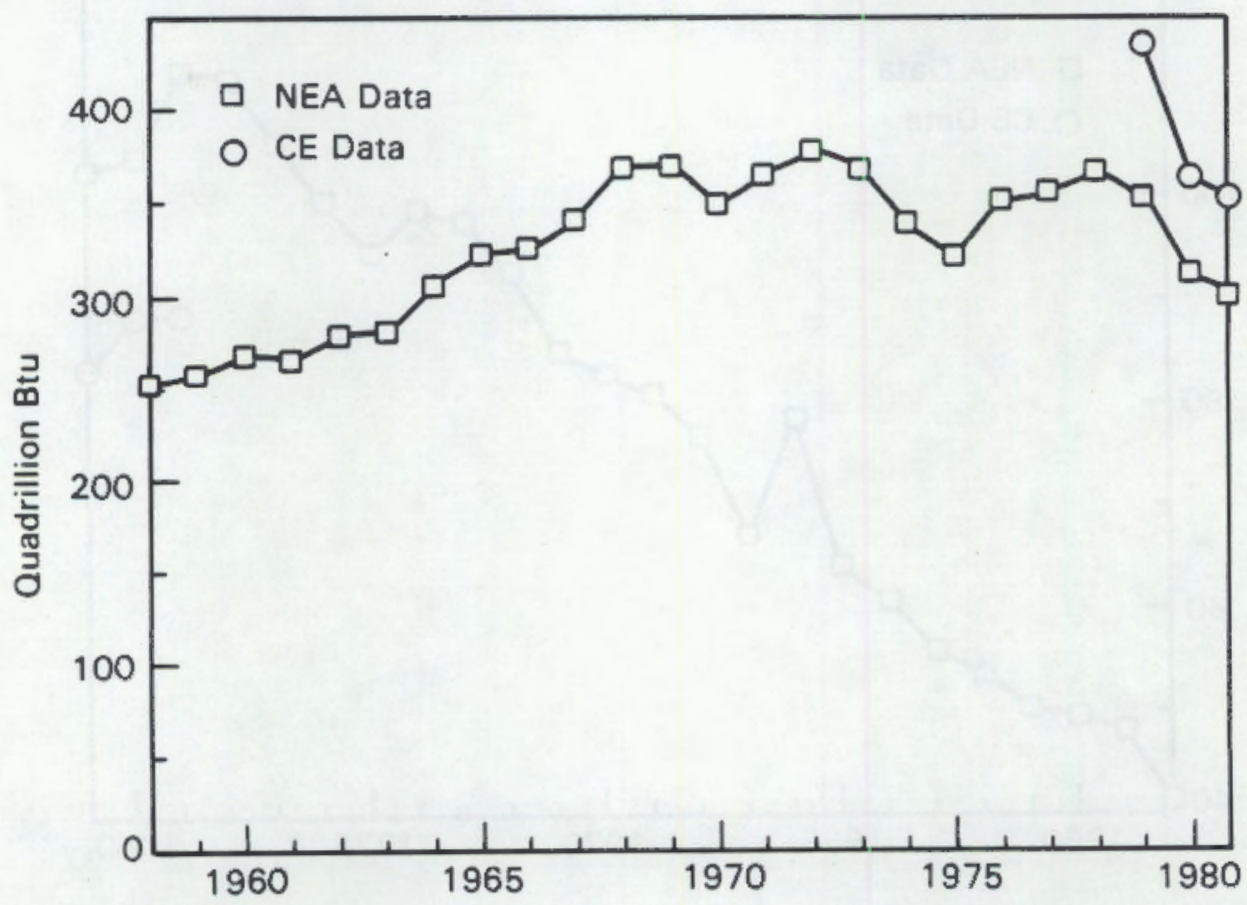

FIGURE 2.28. Total Energy Use in Transportation Equipment 


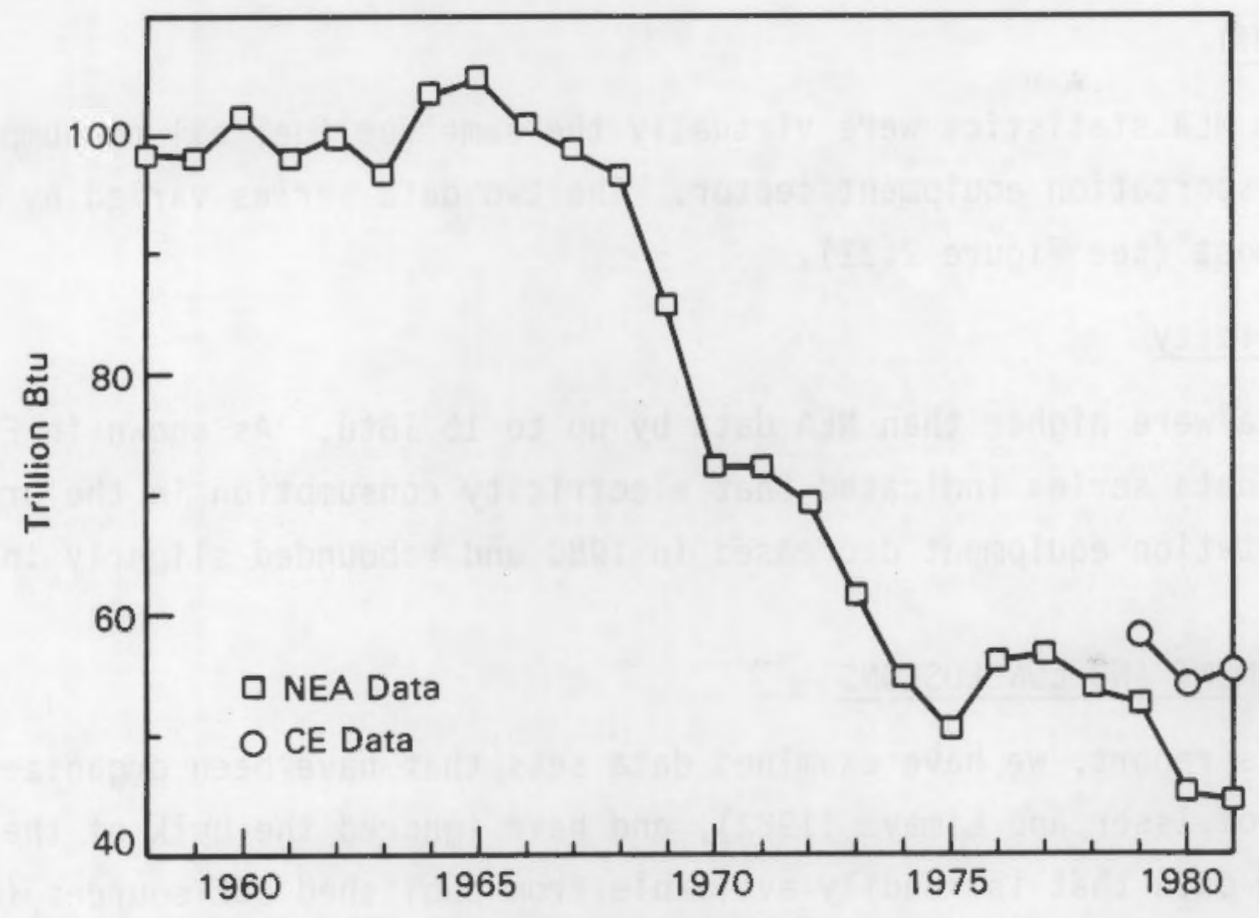

FIGURE 2.29. Coal Use in Transportation Equipment

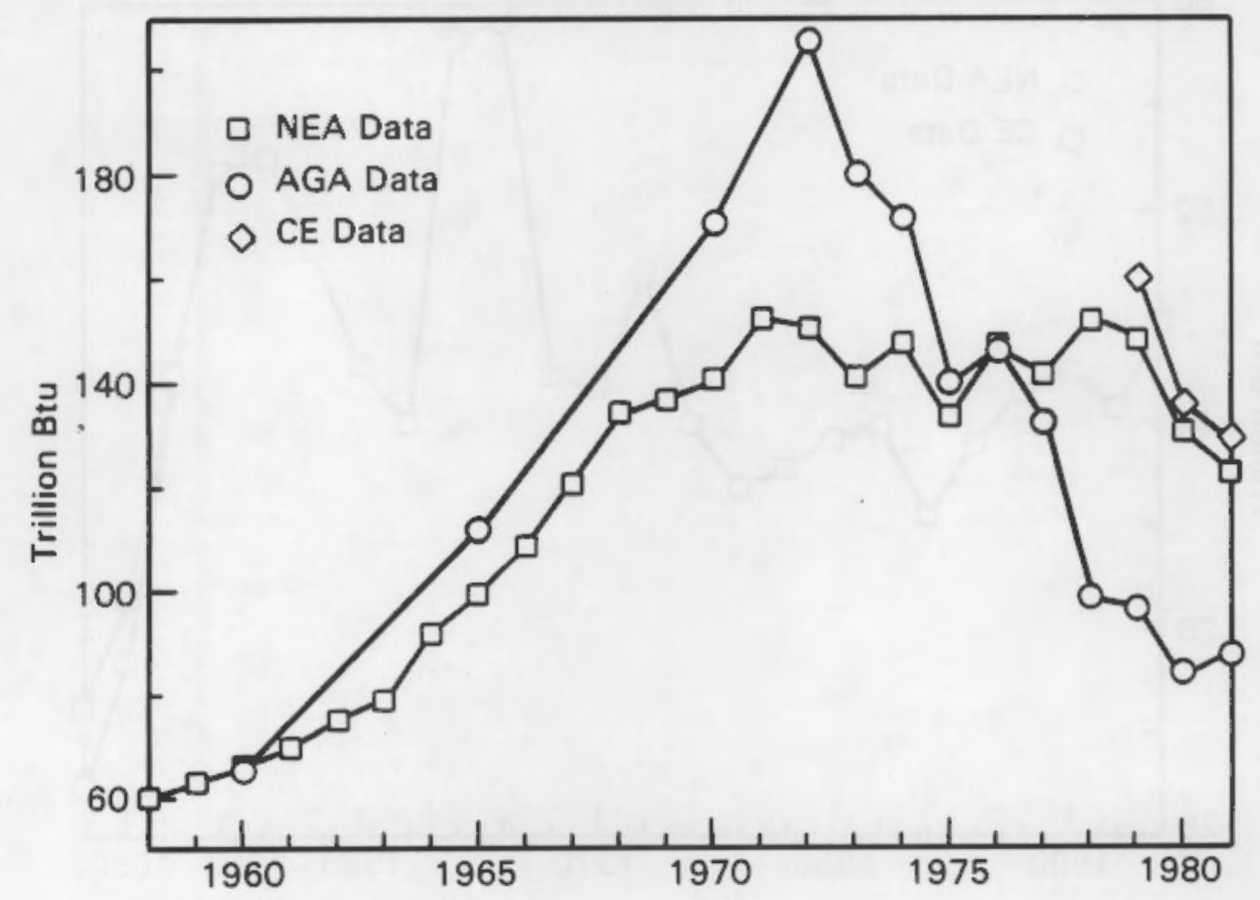

FIGURE 2.30. Natural Gas Use in Transportation Equipment 


\section{Fuel 0 il}

CE and NEA statistics were virtually the same for fuel oil consumption in the transportation equipment sector. The two data series varied by only 4 TBtu at most (see Figure 2.31).

\section{Electricity}

CE data were higher than NEA data by up to 15 TBtu. As shown in Figure 2.32, both data series indicated that electricity consumption in the production of transportation equipment decreased in 1980 and rebounded slightly in 1981.

\subsection{ASSESSMENT AND CONCLUSIONS}

In this report, we have examined data sets that have been organized since the survey of Isser and Limaye (1982), and have ignored the bulk of the supply-side data that is readily available from published DOE sources (mainly Energy Information Agency). The coverage, sources, time periods, unit of

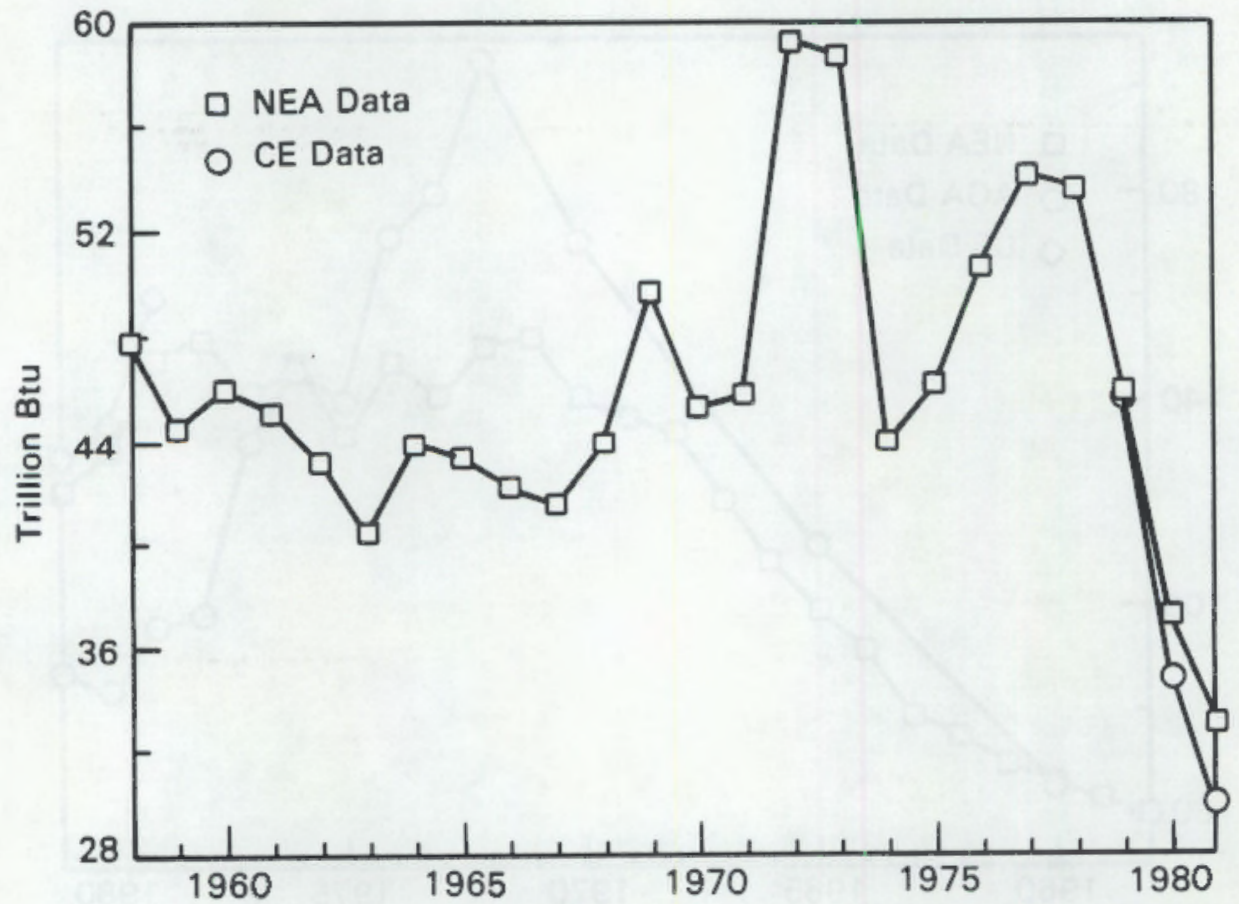

FIGURE 2.31. Fuel 0 il Use in Transportation Equipment 


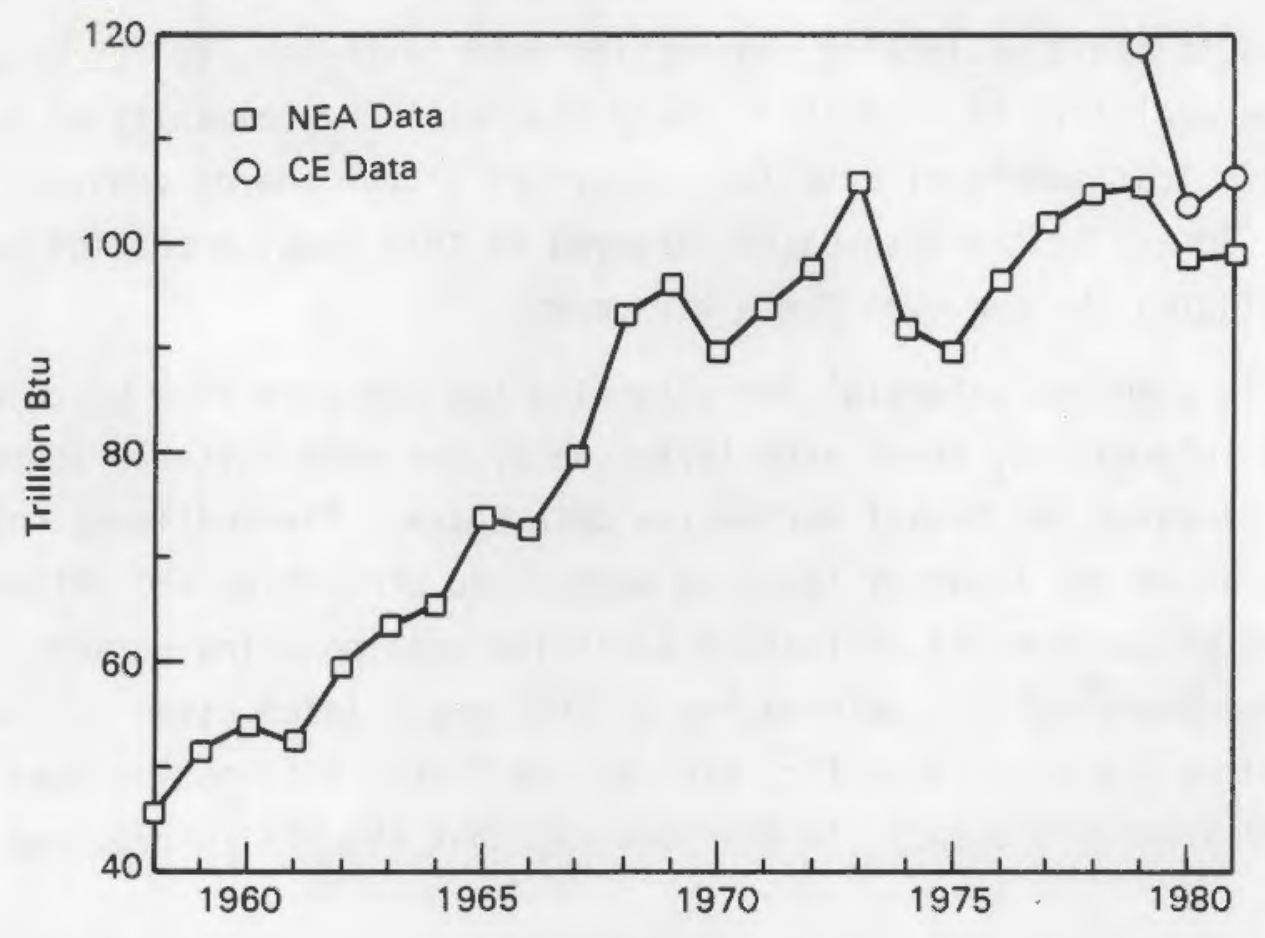

FIGURE 2.32. Electricity Use in Transportation Equipment

analysis, method of collection and reliability of these relatively new data sets have been examined and our findings are summarized for the entire industrial sector.

\subsubsection{Assessment}

One of the primary sources of industrial sector energy consumption data, the purchased fuel and power questions that were part of the Annual Survey of Manufacturers, have not been collected since 1981. If the Manufacturers Energy Consumption Survey (MECS) begins sampling on schedule (Spring, 1986), there will be a hiatus of only three years in which the data were not collected. Full enumeration of the use of fuels and power in manufacturing will not occur until the 1987 Census. Without these data, there is no source that can be used to validate any of the data bases that focus on consumption. The consequences of this dearth of industrial sector energy consumption data for policy analysis are mixed. On the one hand, there is no statistically reliable information against which policy analysis can be benchmarked or validated; on the other hand, no policy prescription can be proved false. 
MECS is to begin collecting consumption data next year, so the data are likely to be available in late 1987. Only then will the community of analysts have a statistical sample of data for industrial sector energy consumption past 1981. Do any of the data bases surveyed in this section provide some hope for bridging the gap over these six years?

There is a modest potential for extending the NEA past 1981 based on DOE supply-side information, trade association data, and some suitable aggregation of industries using the Drexel derivative data bases. The continued collection of information at the industry level on output and production and reliable data on fuel prices provide at least a basis for interpolating between sampled periods. Benchmarking this information to the supply information collected and reported at the end-use sector level by the Energy Information Agency would assure some consistency, in the same way that the NEA is required to be consistent.

Absent this exercise of projecting energy consumption data past 1981, policy analysis has little to rely on except the supply-side information published routinely by DOE--i.e., information that uses as its basic source reports from firms that supply the energy to customers. For many policy purposes, this information is adequate. Data are reported for the industrial sector by fuel type in considerable detail, and in both physical units and Btu. Moreover, price information is available from these sources. When no more detailed disaggregation of industries is required and there is no significant potential for inventory accumulation, this reporting scheme is adequate and reliable. Moreover, this supply-side reporting provided some detail--state disaggregation, specifically--that has never been available reliably from the consumption oriented data bases.

To summarize, although consumption data derived from surveys of the industrial sector are not available past 1981, the potential exits for extending past data through the periods when new data will not be available. Data on the supply of energy to the industrial sector are available annually, and for many purposes, these data suffice. What then can be said about the data sources examined in this section? 
The NEA are constructed to assure consistency between supply and use, are benchmarked to the Annual Survey of Manufactures, and exploit as much information as was available when the data base was constructed. Faults can be found for any particular industry, but for the industrial sector as a whole, this is unquestionabiy the best source of consumption data by industry. For historical analysis, this is clearly the preferred set of data to use when industry detajl is required. The major weakness of this data base is that the data end in 1981 and are not likely to be extended for quite some time.

The Orexel derivative data bases may prove useful for extending the NEA past 1981 and are valuable when specific industry or process detail is required. However, they are generally less useful than the NEA as indicators of industrial energy consumption. PNL's INDUST data base has been calibrated to 1980 energy use for purchased fuels and power, but not for total industry energy consumption. An extensive calibration would be required, if INDUST were to be used as a basis for projecting energy use past 1981. The Dun and Bradstreet data base has not and cannot be calibrated to any consumption data since it begins in 1983 after the termination of the NEA. When the MECS becomes available, this calibration will be possible. The major drawback of the D\&B data base is its cost.

of the supplemental data bases, only the trade association data hold much hope as a reliable source for augmenting or extending other data bases. CE's Energy Efficiency Improvement Program data only rarely demonstrate the corresponding movements that would allow it to be used as a source for updating other data bases. ATso, CE consumption data frequently exceed even the trade association data. Of the trade associations, the industry-specific data sources, such as the American Paper Institute, appear the most reasonable as a source of additional information.

\subsubsection{Conclusions}

For the next several years, policy analysis at the industrial sector level of aggregation will have to depend on the supply-side data sources provided by $\mathrm{DOE}$, or will have to pursue an extension of the consumption data base provided by the NEA. The projected publication of MECS in 1987 and the publication of the 1987 Census in 1989 will again allow a benchmark for the 
consumption data that currently end in 1981. Until then, however, the best source of data for policy analysis is the information available from the Energy Information Agency.

The loss of energy consumption information will interject uncertainty into the policy arena that will be especially noticeable when industry-specific questions arise. For broad policy questions that can be handled at the level of the industrial sector, this uncertainty will not be a major drawback to effective policy analysis. 


\subsection{AN ASSESSMENT OF COMMERCIAL SECTOR DATA BASES}

Compared to the industrial sector, there has been a dearth of information related to the use of energy in the commercial sector. Until the 1980s, energy data related to the commercial sector have come from two general sources. The first source is the aggregate consumption data published by the Energy information Administration as part of the State Energy Data System (SEDS). The primary source of this information is the federal regulatory agencies. Although this data set provides historical trends on total consumption, by itself it offers no insights as to how shifts in the structural or operational characteristics of the building stock may be responsible for changes in energy use.

The second source of information includes several limited, special surveys of commercial buildings. Although these surveys, together with building energy simulations, can provide some information on common metrics such as energy per square foot or energy per employee, they do not provide any type of characterization of the national building stock as a whole.

The information base on commercial building characteristics and energy consumption changed dramatically with the publication of EIA's 1979 Nonresidential Buildings Energy Consumption Survey (NBECS) in 1981. This was the first comprehensive statistical sample of nonresidential buildings ever to be conducted in the United States. In 1983 EIA conducted a second survey of commercial buildings, the first results of which were published in 1985 . As the most important source of commercial buildings data now in existence, the two NBECS will receive most of the attention in this assessment.

Besides NBECS, two other data bases related to the commercial sector merit discussion. The first of these is the data collected by F.W. Dodge on building construction. Although not an energy data base, these data have been used in the past to support the development of commercial sector energy models. The Dodge information is important since it can provide up-to-date information on the distribution of new construction by region or building type, on factors that influence the trends in total energy consumption, and on consumption by fuel type. A second, more limited data base, is represented by the information appearing in the issues of the Experience Exchange Report, published by the Building Owners and Managers Association (BOMA). Although this information 
is primarily limited to office bujldings, data on energy costs have been published since the 1930s. As a reasonably consistent set of data collected over a long period of time, these data may be able to answer some questions that cannot be addressed by any other source. Overviews of each of these data bases are presented in Section 3.1 below.

\subsection{OVERVIEW OF DATA BASES}

The three major commercial sector data bases will be introduced in this section, followed in later sections by a more detailed characterization. 3.1.1 Nonresidential Building Energy Consumption Surveys (NBECS)

The EIA has conducted two comprehensive surveys of nonresidential buildings for the years 1979 and 1983. Tbese surveys represent the first time that either the public or private sector has collected data on a statistical sample of nonresidential buildings in the U.S. As with the residential surveys conducted by EIA, the NBECS surveys were initiated to provide information on the energy-related characteristics of nonresidential buildings that would be useful in formulating federal energy policy.

The NBECS data base includes data on 1) energy consumption and expenditure by fuel: electricity, natural gas, fuel oil, LPG, and purchased steam; 2) building structural characteristics, including information on the HVAC system; 3) occupancy schedules; 4) recent conservation retrofit activities; and 5) weather.

Data for 1979 NBECS were presented in a series of four reports, the first two dealing with building characteristics and conservation practices and the second two covering fuel consumption (EIA 1983a and 1983b). A public use tape was also produced. The building characteristics information from the 1983 NBECS was published in August of 1985, with consumption data scheduled for release in late 1986 .

The 1979 NBECS comprised approximately 6,200 buildings that had been selected by a multistage probability sampling procedure (see Section 3.3 .1 ). The 1983 NBECS (or NBECS II) "revisited" the original sample buildings to determine what structural and operational changes had been made since January 1980. In addition, information is provided for some 1200 new buildings that 
were constructed between 1979 and 1983. The samples provide a basis for comparing energy consumption patterns across various building classifications, including size, age, census region, climate zone, type of heating system, and type of building.

As the first probability sample of the U.S. nonresidential building population, NBECS has been used extensively by researchers to analyze various aspects related to energy consumption in the commercial sector. EIA has developed an econometric model of energy consumption for six broad building categories using the 1979 NBECS (EIA, 1984). NBECS has also been used to calibrate commercial sector energy forecasting models (COMMEND) maintained by the Electric Power Research Institute and by Pacific Northwest Laboratory for the Commercial Energy End Use Model. Pacific Northwest Laboratory used information provided on building retrofit activity over the post-embargo period to estimate energy savings attributable to retrofits from 1973 through 1979 (Adams, et al., 19B5). Several organizations have reformatted and summarized information from the NBECS data in separate reports designed to aid internal planning activities. The Gas Research Institute (GRI, 1986) sponsored the preparation of a report with heavy emphasis on graphical presentation of various aspects of the NBECS data base. Pacific Northwest Laboratory incorporated NBECS data into its Residential and Commercial Building Data Book, a publication designed to communicate key aspects related to building energy consumption to program managers within DOE's Office of Buildings and Community Systems (DOE 1984).

\subsubsection{Dodge Construction Data}

The F. W. Dodge Division of MCGraw-Hill Information Systems Company has collected building construction data in the U.S. for over fifty years. F. W. Dodge uses a field staff of about 1,500 persons to collect building information in a designated area. This information primarily covers square footage, type of construction, and estimated construction cost.

The construction data collected by $F$. W. Dodge are proprietary. The data are used by many companies to assess market potentials of construction-related goods and services. The complete data base is expensive; computer tapes of 
project Tevel data for the entire U.S. currently cost about $\$ 35,000$ per year. Dodge does, however, publish aggregate figures that are used in government publications such as the Statistical Abstract of the U.S. and Business

Statistics.

The time series aspect of the Dodge data, plus its substantial geographic and building type disaggregation, has made this information valuable in the development of economic and energy models of the commercial sector. In 1977-78 Oak Ridge National Laboratory used the Dodge data to estimate the building floorspace for the Commercial Energy End Use Model of the U.S. In the early 1980s Pacific Northwest Laboratory used the Dodge data base to develop the construction component of the Metropolitan and State Regional (MASTER) model.

\subsubsection{Building Owners and Managers Association (BOMA) Experience Exchange Report}

The Experience Exchange Report (EER) annually reports various income and operating expenses for a large number of office buildings in the U.S. Data in the EER are obtained through a majl survey conducted by BOMA staff. As a key component of total operating expenses, energy costs have been treated as line items in the report since its inception in the 1920s. Special analyses of energy costs have been produced in a number of historical years, including 1921-25, 1931-33, 1957-68, 1970-73, 1975, and 1978-79.

The EER provides a valuable source for time series analysis because the basic data preparation procedures have remained essentially unchanged since 1934. The number of respondents grew slowly from the 1940s through the mid1960s, rising from 480 buildings in 1940 to 547 buildings in 1966. Since 1970, the sample has grown rapidly, and by 1983, nearly 3000 building owners or managers responded to the BOMA survey.

\subsection{SCOPE AND METHOD}

In this section, the technical information reiated to scope and method is used to characterize each of the commercial sector data bases. Each data base will be characterized as to how well it represents the sector as a whole, and its timeliness, reliability, and applicability to policy analysis. The characterization proceeds with each of these data bases considered in sequence. 


\subsubsection{NBECS}

The data for NBECS were collected through personal interviews with building representatives. The building questionnaire, administered by survey personnei from WESTAT, Inc., covered building characteristics and the types and uses of energy associated with the building. After the interviews were concluded, respondents were asked to sign waivers releasing energy consumption and expenditure data for the building. The building's fuel suppliers were then contacted and asked to provide information on energy consumption and bills for the buildings.

\section{Geographical Coverage}

The building samples employed in both the 1979 and 1983 NBECS surveys covered the 48 contiguous states plus the District of Columbia. The sample size precluded putting state identification codes to correspond with individual buildings. Regional information on NBECS is broken out to the four major census regions: Northeast, South, North Central, and West.

Sampling Methods

The 1979 NBECS sample was selected by standard area sampling techniques, supplemented by samples of individually compiled lists of large buildings. A multi-stage approach was followed. In the first stage, 79 primary sampling units (PSU) were chosen from a population of some 1900 PSUs developed by the Census Bureau. of these 79 PSUs, 25 were chosen as self-representing (i.e., key ones were chosen with certainty); these 25 PSUs all had a 1970 population greater than 1.85 million. The remaining non-self-representing PSUs were chosen on the basis of region, rate of growth from 1960 to 1970, percentage of black population, and a measure of social economic status. They were selected with probabilities proportionate to their 1970 population.

The second stage units were zip codes. Zip codes were used since the Census County Business Patterns contained the number, type, and size of nonresidential establishments by zip code. Each zip code was assigned a measure of size based on the County Business Patterns data combined with proprietary commercial data related to office machines population. Segments (approximately 400) and individual buildings were selected in the third and fourth stages of the procedure. 
In addition to using the multi-stage procedure described above, a segment of the final sample buildings was taken from separately compiled lists of large buildings. These lists included buildings over 250,000 square feet in Standard Metropolitan Statistical Area (SMSA) PSUs and 100,000 square feet in non-SMSA PSUs. About 3,200 buildings were included in this special building 1ist, and approximately 1,200 were included in the final sample. Large buildings from the area sample list (generated in the fourth stage described above) were checked against the buildings on the special list to identify duplicates and assign them appropriate selection probabilities.

The final sample consisted of 7,322 buildings; for a variety of reasons, 549 buildings were determined not to be eligible for an interview. Interviews were completed for over 90 percent of the approximately 6,700 eligible buildings, resulting in a final sample size of 6,222 .

The NBECS II sample was developed by recontacting buildings in the 1979 survey and by constructing a new sample for those buildings built from 1980 through 1983. The new building sample was put together by sampling the construction records of new building projects maintained by the $F$. W. Dodge Division of MCGraw-Hill Information Systems Company. Sampling from the Dodge lists of projects was done within the PSUs selected for the original sample. The sampling rates employed by EIA were approximately twice as high as for the originial 1979 sample. This oversampling was performed to facilitate special types of analyses related to this cohort of buildings. The number of new buildings for which interviews were conducted was $t, 457$.

\section{Time Period Covered}

The building interviews for the first NBECS were conducted between 0ctober 1979 and January 1980. Data on fuel consumption were collected from the sample bufldings' fue? suppliers. From this information, calendar year 1979 consumption was estimated. In the case of fuel oil, suppliers were asked to estimate inventory levels in storage tanks, so that actual use during calendar year 1979 could be more accurately assessed.

The 1983 NBECS was conducted in essentially the same manner. Interviews were conducted over the period October 1983 through January 1984. Fuel consumption estimates were provided for calendar 1983. 


\subsubsection{Dodge Construction Data}

Information about $F$. W. Dodge was obtained from several sources, including the documentation of the data tapes that are included when the data base is purchased.

Source of Data

F. W. Dodge has a field staff of approximately 1,500 persons spread throughout the United States. Each member of this staff is responsible for collecting information on building construction in a designated area. Sources of information are architects, building planners, permit and licensing boards, and construction companies. Dodge lists a construction project in its files when construction is scheduled to begin within 60 days. The data file is later adjusted if a project is delayed, cancelled, or modified in value. Currentiy, Dodge collects data only on projects that are valued at more than $\$ 25,000$.

\section{Geographical Coverage and Time Period}

Since 1969, Dodge construction data have covered 50 states and the District of Columbia. In the period 1956-68, the data covered the 48 contiguous states and the District of Columbia. Prior to 1956, 13 western states were excluded from coverage; these states comprise what is now the western census region. Data have been available at the county level since 1960 .

\subsubsection{MA Experience Exchange Report}

Information on EER is obtained primarily from Penz (1984). More detail is available from BOMA.

\section{Source of Data}

The EER is based on a survey form that requests information on income and operating expenses for office buildings. At the end of each year data are requested for that calendar year or for the most recently concluded fiscal year. Although most of the respondents are members of BOMA, some are not, and the report reflects the operating experience of a wide variety of buildings.

No particular sample design is embodied in the BOMA survey. Rather, the process is generally one of seeking any and all willing participants. In 
1983 some 8,000 surveys were mailed, with just uncler 3000 responding. Response rates were influenced by varying levels of follow-up calls by staff in some of the local BOMA associations.

\section{Geographical Coverage}

Since 1978 data published in the EER have been disaggregated by city, downtown versus suburban, private versus government, and U.S. versus Canada. For most years prior to 1978, the principal regional disaggregation was by city.

\section{Sample Methods}

As mentioned above, no particular sampling design underlies the EER. BOMA's general approach has been to assume that simple addition of more reporting buildings will help make the overall sample more representative of the office sector as a whole.

The turnover rate from year to year among EER respondents has been relatively high. Over the past 10 years or so, between 20 and 50 percent of the respondents in any year have not responded the following year. This turnover has the effect of helping to assure that the reported data are more representative of the total stock and that the same biases do not show up repeatedly. Unfortunately, this instability in the sample makes it more difficult to inter-

pret short-term (year-to-year) changes in the sample averages. To help overcome this problem, the current reports have included tables that present data for identical samples ejther for two- or five-year time spans.

\section{Time Period Covered}

The first EER was published by BOMA in 1920 and covered 90 buildings. In 1934 a major reorganization of the data was instituted; many of the tables have remained consistent from this point forward. By the 1970 s the number of reporting buildings had increased to over 1,000. This allowed publication of energy costs for more detailed categories such as building height, age, and fuel type. 


\subsection{CHARACTERIZING THE DATA BASE}

Each of the data bases will be characterized by reference to a number of attributes, such as its usefulness in describing the sector, and its timeliness, reliability and applicability to policy analysis.

\section{$3.3 .1 \quad$ NBECS}

Maintaining the same order of treatment, the characterization begins with NBECS.

\section{Usefulness for Characterizing Sector}

As the first national area probability sample of commercial buildings, one of the greatest strengths of NBECS has been to provide a broad characterization of this sector. To the extent that EIA set out with this goa in mind, NBECS has become the definitive data base regarding the commercial sector in the U.S. Both EPRI and AGA have sponsored studies that have used NBECS information to produce graphical overview reports about commercial sector building stock and consumption.

The NBECS has several features that limit its ability to characterize the commerical sector. First, geographic information is very limited. Regional data are presented for only four census regions. Although the data are also presented by climatic region (five weather zones as defined by the American Institute of Architects), these zones do not translate into state boundaries, and only roughly into county boundaries.

The NBECS' characterization of heating and cooling systems within commercial buildings is a second limitation. For instance, NBECS asks only two questions about the heating conversion and distribution system. Further, with respect to the former, NBECS only delineates between central systems and self-contained units. For heat distribution, the survey picks up whether forced air or radiant systems are employed. (For radiant heating, some more detailed data are collected as to the exact nature of the system.) More detailed information in this area would enhance the ability to calibrate energy simulation models to the NBECS data set. Using the simulation models in this way would allow the NBECS data to be extended to include estimates of energy consumption by specific end use. 
Finally, it should be noted that NBECS provides information on commercial buildings, not the entire commercial sector as defined by the Energy Information Administration. Energy consumption outside of bui dings pertains to such uses as public and street lighting and operation of public, nonbuilding facilities (e.g., sewage treatment).

\section{Timeliness}

The scope of NBECS requires substantial processing and review after primary data have been collected. A substantial effort is devoted to imputation of missing values. For the 1983 NBECS, the building characteristics information was published some 18 months after the survey was completed. Publication of building fuei consumption data is expected about 12 months later. For both cases, public use tapes can be expected from two to four months after the publication of the summary data.

\section{Reliability}

The reliability aspect of NBECS concerns both the quality of the individual building data as well as the statistical validity of population parameters. Quality of the individual building data is high, since elaborate procedures were instituted to ensure quality of the field data. These procedures involved in-depth training of interviewers, individual screening by field supervisors, and machine edits to check for reasonable values, proper slip patterns, and logical inconsistencies. Additional edit checks were performed on the consumption and expenditure data received from the buildings' energy suppliers.

The procedures described above, however, could not make up for the lack of information on the original questionnaire. The overall amount of the data was reduced by two types of nonresponse: unit nonresponse (e.g., no interview) and nonresponse to particular items in an otherwise completed interview. The first type of nonresponse was handled by adjusting the sampling weight of responding buildings. Item nonresponse for selected building characteristics was handled by a "hot deck" procedure for each item. This procedure imputes the missing value from another building in the sample selected on a random basis, a building that has similar values for characteristics related to the missing item. The effect of this imputation procedure does not substantially affect the population averages. The number of buildings requiring imputations 
was very low, with only few characteristics for which missing values exceeded three percent of the total sample (e.g., 7.5 percent for hours of operation, 3.? percent for year built).

Apart from considering the reliability or validity of individual building data, a second issue involves the sampling error of the survey as a whole. Unfortunately, the complex multi-stage, multi-frame design of a survey such as NBECS does not permit the computation of exact algebraic variance estimators. Nevertheless EIA does compute estimates of sampling error based on a method known as balanced multi-sample replication. Using this method, relative standard errors (at the 0.05 level of significance) were estimated for the sample values for each of the published characteristic and consumption figures.

The magnitude of the published relative standard errors, of course, is highly related to the size of the particular subsample chosen. For the total number of commercial buildings, the estimate of the relative standard error (RSE) is 5.3 percent; for the associated square footage, the estimate is 6 percent. The uncertainty associated with the population (number of buildings) of any particular building type is, of course, larger; RSEs range from 6.1 percent for office buildings to 16.5 percent for health care. NBECS reports RSEs in a way that can be easily related to each of the published statistics.

\section{Application to Policy Analysis}

The NBECS has been and continues to be used in a variety of ways for energy policy analysis. Since it provides the most comprehensive picture of commercial buildings available, one of its primary strengths has been to provide estimates of buildings (and square footage) population across various strata. This has been particularly useful for organizations such as GRI and EPRI who have used the data to aid in targeting various research programs.

NBECS has provided the empirical foundation for several commercial sector models sponsored by DOE. PNL has used the NBECS to update the national engineering-economic model of the commercial sector built by Oak Ridge National Laboratory in the late 1970s. NBECS was able to provide reliable estimates of total floorspace and shares of floorspace served by fuel type, variables for which only rough estimates could be made previously. In 1983 the EIA developed a complete econometric model (CSEM), using NBECS data. CSEM contains 
fewer building types and end-uses than the ORNL-PNL model, but the price elasticity parameters are directly based on NBECS. EIA uses CSEM as a component of its Integrated Future Forecasting System (IFFS).

\subsubsection{Dodge Construction Data}

The Dodge information provides a detailed look at key parameters related to commercial building construction activity. As such, it must be used in conjunction with other data sets to provide any sort of information about current or projected energy use in the commercial sector.

The most valuable aspect of the data base stems primarily from its historical and geographic disaggregation. Since 1969 the data have covered a 11 50 states and the District of Columbia. The historica1, county-levei disaggregation of the data have supported the development by PNL of a large-scale regional econometric model. MASTER. MASTER also exploits the substantial building classification code information contained in the data base; the mode? employs 10 building categories compiled from a total of over 200 identified in the standard data base.

\section{Timeliness}

One of the primary users of the Dodge information is building construction suppliers who wish to identify ongoing or nea"term building projects. For this application Dodge actually reports new projects on a daily basis. Complete tapes on a national or state basis can be obtained approximately three weeks after the end of each monthly reporting period.

For the building industry, the short turnaround between primary data collection and its availability to subscribers is the key component in defining the value of the data. This factor helps to explain the roughly $\$ 35,000$ price that Dodge charges for the most recent year's national data. Prior years are discounted heavily, priced at about 20 percent of the most recent year.

Application to Policy Analysis

The Dodge data can be used only indirectly to support energy policy analysis. Its primary use is in detailing recent trends in building activity by region and building type. No energy-related data (e.g., building shell characteristics) are collected by the field reporters. As a result, information 
from outside sources must be used in conjunction with Dodge to make any statements regarding energy-efficient building practices.

One data item collected by Dodge has relevance to the technoiogy transfer functions of DOE. Dodge assigns codes to each project to signify the plan and builders. Examples are 1) "Architect or designer with a General Contractor, and 2) "Private plans owned by a company, public agency, etc. with no general contractor." Ten such codes are delineated by Dodge. Analyzing this information could help to target information generated in building-related research and development funded by DOE's Office of Buildings and Community systems.

\subsubsection{BOMA Experience Exchange Report}

Usefulness for Characterizing Sector

Since the EER covers only office buildings, it cannot be used to characterize the commercial building sector as a whole. Nevertheless, office buildings comprise about one-sixth of total commercial floorspace, making the specialized information in the EER potentially valuable in studies related to the commercial sector.

Compared to the EIA's 1979 Nonresidential Building Energy Consumption Survey, the recent EER contains a fairly large sample of office buildings. From 100 to 300 office buildings were surveyed by NBECS for 1979, with perhaps several hundred added for the 1983 survey. By contrast, the EER for 1983 covered nearly 3,000 office buildings. However, the EER sample is heavily weighted toward the very large office buildings. NBECS reports that only about 4 percent of all office buildings contain more than 50,000 square feet. This category, however, makes up the majority of office buildings represented in the EER, over 75 percent in 1983. This implies that where the distribution of expenses is affected by office sizes, the aggregated figure reported in the EER is not representative of the office sector as a whole. However, the more recent EERs have shown most data according to building size and location. Thus, the problem may not be important unless one requires long time series information. 
Reliability

Insufficient documentation procedures have made it difficult to establish levels of integrity for the data and subsequent analyses. This concern carries more weight the farther back in time one looks at the EER. Any assessment of data older than the most recent years is essentially precluded since BOMA does not retain the building-specific data.

The EER data need to be checked thoroughly for inconsistencies. Currently, each survey form is checked manually for obvious errors, followed by computer checks in both data entry and table generation steps. A more complete data check would involve the use of a computer code that uses statistical and logical tests to screen abnormalities. In spite of the lack of this tool, the effects of data inconsistencies are probably not acute for the latest few years when the sample size has exceeded several thousand.

\section{Application to Policy Analysis}

The EER has potential value to energy policy analysis since it contains information on energy costs that is consistent over a number of years. In addition, the EER has published a number of special studies related to energy use that have appeared periodically since the beginning of the report.

The EER data have particular application to questions involving how energy consumption has changed over time and whether particular types of office buildings have made relatively more progress in reducing energy bills. Some preliminary analysis by BOMA showed that average energy savings between 1973 and 1981 was about 18 percent for reporting buildings. The analys is also indicated that agency-managed buildings responded to a lesser degree to the 1973 initial energy price rises than did several other types of offices. The tentative conclusion is that the data in the EER may be able to provide valuable insights into institutional behavior regarding building energy conservation that are not available elsewhere.

\subsection{DATA BASE EXAMPLES}

This section provides some tables and charts clerived from the three commercial data bases discussed in this assessment. In addition, some attention will be devoted to comparing similar data elements across data bases. 


\subsubsection{NBECS}

Tables 3.1 and 3.2 illustrate some basic data items from NBECS, and are taken from Pacific Northwest Laboratory's Building Energy Use Data Book. This report summarizes in tabular and graphical manner data from EIA's Residential Energy Consumption Survey (RECS) and NBECS. Table 3.1 presents buildings population and square footage by the major building types used in the NBECS reports. Office and retail/service are the largest categories accounting for approximately one-third of all commercial floorspace. Table 3.2 provides information on the distribution of buildings using particular fuels for major end uses. Natural gas is used in nearly half of all commercial buildings that are heated.

Figure 3.1 is also taken from the Data Book and $i 1$ lustrates the energy consumption information contained in NBECS. As the first key finding under the chart states, in 1979 commercial buildings used more gas (0.43 quads) than any other type of energy. NBECS also reports purchased steam by commercial buildings. In 1979 this energy source accounted for about 0.2 quads.

\subsubsection{Dodge Construction Data}

The full national Dodge data set obtained on computer tape represents a truly massive amount of data. Each individual building project is coded with building size and value descriptors as well as county identification. Table 3.3 illustrates several attributes, by size category, that are collected by Dodge. PNL used this information to develop the MASTER regional model in the early 1980s. For 1980, the latest year in which this information was used, some individual building records were processed. In support of MASTER, a number of summary tables and charts were prepared using data at five-year intervals. As the top row of the table indicates, over half the square footage of office buildings constructed in 1980 was in buildings of over 100,000 square feet. Nearly 80 percent of all office buildings are planned by an architect or designer and constructed by a general contractor. Over 95 percent of the new buildings reported by Dodge were privately owned.

Table 3.3 provides a fairly complete illustration of the type of data that is contained in the Dodge data base. The single attribute collected by 
TABLE 3.1. Square Footage by Type of Commercial Building, U.S. Total, 1979

\begin{tabular}{|c|c|c|c|}
\hline Building Trpe & $\begin{array}{l}\text { Total } \\
\text { Batldings } \\
\text { (Thoosenda) }\end{array}$ & $\begin{array}{c}\text { Tivenl } \\
\text { Square Feer } \\
\text { (Miltong) }\end{array}$ & $\begin{array}{l}\text { Average } \\
\text { Square Feet } \\
\text { per Budlding } \\
\text { (Thousands) }\end{array}$ \\
\hline All Comoretal Barldtrga & 3,879 & 47,330 & 12.2 \\
\hline lade $-\mathrm{bly}$ & 443 & 5,020 & 11.3 \\
\hline Autometre Sales a Serrice & 400 & 1,820 & 4.6 \\
\hline Education & 161 & 5,851 & 36.2 \\
\hline Food Seled & 366 & 1,864 & 5.1 \\
\hline Boalth Care & 46 & 1,687 & 38.5 \\
\hline Lodgtng & 101 & 2,012 & 19.9 \\
\hline offica & 599 & 8,183 & 13.7 \\
\hline Retad1/Ser Flees & 714 & 7,652 & 10.7 \\
\hline Wharehones \& Storage & 366 & 5,987 & 16.4 \\
\hline Othar & 230 & 3,112 & 13.6 \\
\hline Vecant & 108 & 1,026 & 9.5 \\
\hline
\end{tabular}

Source: Nonresidentlal Buildings Energy Consumption Survey: 1979 Consumption and Expenditures, Part 2, ETA, Ilecember, 1983. 
TABLE 3.2. Square Footage by End Use Fuel Type, U.S. Total, 1979

\begin{tabular}{|c|c|c|c|}
\hline End Use By Fuel Trpe & $\begin{array}{l}\text { Total } \\
\text { Buildings } \\
\text { (Thousands) }\end{array}$ & $\begin{array}{l}\text { Total } \\
\text { Square Feet } \\
\text { (M+1liong) }\end{array}$ & $\begin{array}{l}\text { Average } \\
\text { Square Feet } \\
\text { per Butlding } \\
\text { (Thousands) }\end{array}$ \\
\hline All Commerc1nl Butldings & 3,879 & 47,330 & 12.2 \\
\hline Beating FueI Ised & 3,563 & 45,449 & 12.8 \\
\hline Natural Gas & 1,922 & 25,886 & 13.5 \\
\hline Electricity & 985 & 11,313 & 11.5 \\
\hline Fuel 011/Rarosene & 762 & 10,724 & 14.1 \\
\hline LAquidd Petroleum Gas & 208 & 1,075 & 5.2 \\
\hline Wood & 94 & 604 & 6.4 \\
\hline Stean & 45 & 3,675 & 82.3 \\
\hline Coa1 & 42 & 728 & 17.3 \\
\hline Other & 8 & 357 & Q \\
\hline Yo gesetng Fuel Used & 316 & 1.881 & 6 \\
\hline A1 Conditloning Fuel Used & 2,543 & 37,465 & 14.7 \\
\hline Electricity & 2.415 & 35,172 & 14.6 \\
\hline Katirral Gas & 147 & 2,750 & 18.7 \\
\hline Othar & 26 & 1,346 & 51.9 \\
\hline No Air Condiltontng Fuel Used & 1,335 & 9,865 & 7.4 \\
\hline Weter Reacting Fuel Usad & 2,663 & 39,507 & 4.8 \\
\hline Natural Gas & 1.252 & 20.794 & 16.6 \\
\hline Electriejty & 1,223 & 14,600 & 11.9 \\
\hline Fuel 0il/herasene & 169 & 4,538 & 26.8 \\
\hline Oether & 109 & 3,120 & 28.6 \\
\hline No Water Heakiog Fuel Used & 1,216 & 7,823 & 6.4 \\
\hline Cooketrg Fuel Used & 1,324 & 23,923 & 18.1 \\
\hline Blectricter & $74 I$ & 13,253 & 17.9 \\
\hline Ratural Gas & 610 & 13,681 & 22.4 \\
\hline Llquidd Perroleum Gas & 108 & 185 & 11.0 \\
\hline Other & 20 & 885 & Q \\
\hline No Cook1ng Fuel Ised & 2,555 & 23,407 & 9.2 \\
\hline
\end{tabular}

Note: $Q=$ data whtheld because of a large variance.

Source: Nonregidential Buildings Energy Consumption Survey: 1979 Consumption and Expenditures, Part 2, EIA, December, 1983. 


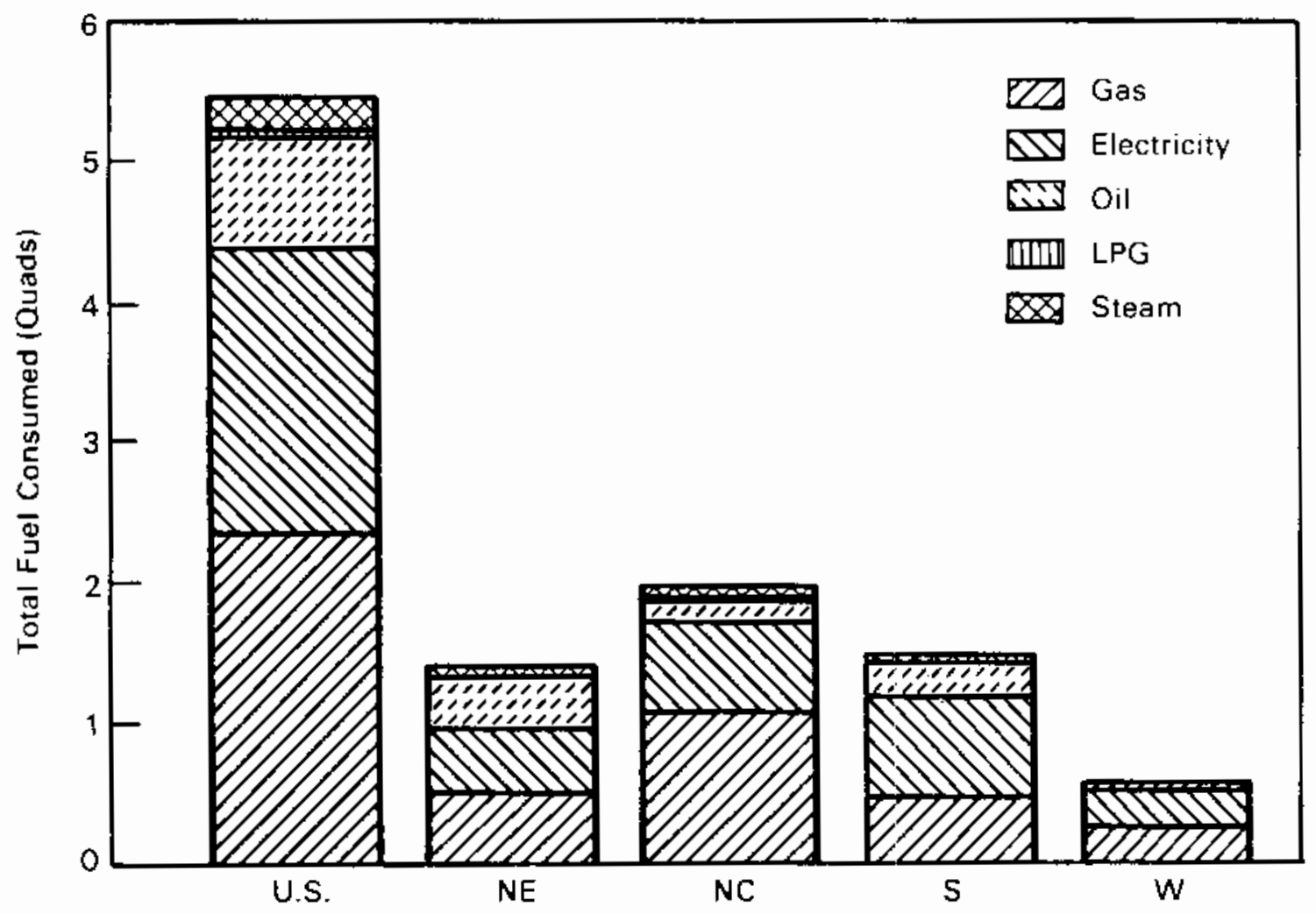

FIGURE 3.1. Fuel Consumption by Fuel Type, L.S. and Regions, 1979

Dodge but not shown in the table is the type of frame of structure. Key framecodes are 1) stee1, 2) wood, 3) reinforced concrete, and 4) pre-fabricated or pre-engineered.

The raw data files from Dodge classify some 200 separate building types. Most users, however, have aggregated this data into the ten building categories that Dodge itself uses for new releases and in its own forecast reports:

$\begin{array}{ll}\text { Retail/Wholesale } & \text { Health } \\ \text { Office } & \text { Public } \\ \text { Auto Repair } & \text { Relig"ous } \\ \text { Warehouse } & \text { Hotels/Motels } \\ \text { Education } & \text { Miscellaneous }\end{array}$

The categories above were used by Oak Ridge National Laboratory and PNL in modeling projects involving the commercial sector. In conjunction with the PNL model, tables similar to Table 3.1 were developed for each of the building categories listed above for the years 1965, 1970, 1975, and 1980 . 
TABLE 3.3. Characteristics of New Office Construction by Size Category of Building - 1980

TXPE CF

CONSTRUCTIO

\section{New}

Additions

Total

Number of stories:

1

2

4-10

10 or more

Unkrown

Plan \& Bullder:

$\omega \quad$ Arch./Dsgn. $w$ GC

Eng. wo $G$

Ower Arch./Eng. W $G C$

Omer Arch./Eng. wo GC

Co. Plans $w G C$

Co. Plans wo $G C$

Ind. Plans $w G C$

Ind. Plans wo $G$.

Unknown

amership:

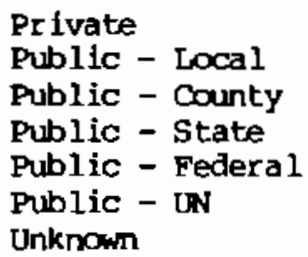

SOUAPE FOOTACE BY EUIIDING SI ZE CATEOORY (millions)

\begin{tabular}{|c|c|c|c|c|c|c|c|}
\hline $\begin{array}{c}\text { IASS THAN } \\
1,000 \\
\end{array}$ & $\begin{array}{l}\text { T,001- } \\
5,000\end{array}$ & $\begin{array}{r}5,001- \\
10,000\end{array}$ & $\begin{array}{l}10,001- \\
25,000\end{array}$ & $\begin{array}{l}25,001- \\
50,000\end{array}$ & $\begin{array}{r}50,001- \\
100,000 \\
\end{array}$ & $\begin{array}{r}100,000 \\
\text { and over } \\
\end{array}$ & Total \\
\hline $\begin{array}{r}.89 \\
.53 \\
1.42\end{array}$ & $\begin{array}{r}11.36 \\
3.46 \\
14.82\end{array}$ & $\begin{array}{r}12.92 \\
2.04 \\
14.95\end{array}$ & $\begin{array}{r}22.54 \\
2.96 \\
25.50\end{array}$ & $\begin{array}{r}25.38 \\
2.05 \\
27.43\end{array}$ & $\begin{array}{r}37.93 \\
1.84 \\
39.77\end{array}$ & $\begin{array}{r}116.14 \\
3.80 \\
120.02\end{array}$ & $\begin{array}{r}227.16 \\
16.76 \\
243.91\end{array}$ \\
\hline $\begin{array}{r}.86 \\
.02 \\
a \\
0 \\
a \\
.01\end{array}$ & $\begin{array}{c}9.50 \\
1.63 \\
.08 \\
.01^{\mathrm{a}} \\
0 \\
.14\end{array}$ & $\begin{array}{r}7.47 \\
4.62 \\
.34 \\
.04 \\
0 \\
.44\end{array}$ & $\begin{array}{r}7.77 \\
10.47 \\
2.56 \\
.68 \\
.02 \\
1.04\end{array}$ & $\begin{array}{r}4.79 \\
10.12 \\
7.08 \\
2.52 \\
0 \\
.87\end{array}$ & $\begin{array}{r}4.64 \\
8.61 \\
10.07 \\
13.78 \\
.15 \\
.68\end{array}$ & $\begin{array}{r}2.97 \\
6.55 \\
8.38 \\
33.79 \\
62.58 \\
1.87\end{array}$ & $\begin{array}{r}38.00 \\
42.02 \\
28.52 \\
50.82 \\
62.76 \\
5.04\end{array}$ \\
\hline
\end{tabular}

$\begin{array}{rr}.20 & 6.06 \\ .07 & 1.52 \\ \mathrm{a} & .23 \\ \mathrm{a} & .10 \\ \mathrm{~b} & .01 \\ 0 & \\ .29 & 1.76 \\ .12 & .79 \\ .07 & .25 \\ .07 & .31 \\ .07 & .33\end{array}$

$\begin{array}{rrr}8.06 & 15.19 & 16.55 \\ 2.45 & 4.55 & 5.93 \\ .37 & .46 & .65 \\ .18 & .30 & .10 \\ .010 & .02 & 0 \\ .01 & 0 & 0 \\ 1.15 & 1.20 & 1.12 \\ .42 & .64 & .87 \\ .04 & .08 & .07 \\ .08 & .06 & .07 \\ .14 & .04 & .02\end{array}$

26.25
8.91
.30
.21
.07
0
1.14
.99
.06
0
0

$\begin{array}{rr}102.74 & 175.06 \\ 9.30 & 32.74 \\ .70 & 2.73 \\ .10 & 1.00 \\ .12 & .23 \\ 0 & .02 \\ 1.68 & 8.34 \\ 1.48 & 5.33 \\ 0 & .58 \\ 0 & .59 \\ .02 & .54\end{array}$

$\begin{array}{rr}.86 & 10.83 \\ .01 & .20 \\ .01^{a} & .09 \\ \mathrm{a} & .14 \\ \mathrm{a} & .09 \\ 0 & 0 \\ .01 & .01\end{array}$

$\begin{array}{rr}12.31 & 21.16 \\ .25 & .56 \\ .08 & .35 \\ .21 & .26 \\ .06 & .21 \\ 0 & 0 \\ 0 & 0\end{array}$

36.81
.23
.20
.47
.22
0
0

216.45

2.20

1.19

6.05

1.26

0 


\subsubsection{BOMA Experience Exchange Report}

Table 3.4 presents an example of a typical table from the EER. The figures for each line item represent averages of all buildings that reported data for that item. Consequently, the sum of the various expense items do not necessarily add to the total (average) operating expense line.

The figures shown under the "mid range" heading correspond to values reported at 25 percent and 75 percent.

Table 3.5 reproduces a table presented in a paper by Alton Penz (1984) describing how the data in the EER could be exploited for energy analysis. Penz uses the State Energy Price and Expenditure Report 1970-81 (EIA, 1984) to define the percentage change in nominal cost for the commercial sector as a whole. As mentioned in Section 3.3.3, this changing of data from annual EERs provides some clues as to which building types have responded in greater measure to rises in energy prices.

For the building types shown in Table 3.5, medical buildings appear to have shown a rapid and more sustained response to higher fuel prices than other building types. On average, office buildings reported on by the EER achieved about an eighteen percent reduction in energy use between 1973 and 1981. Table 3.5 suggests the type of data that are available for analysis. of particular interest would be information covering more building types and more current data that might shed light on current behavior in the office sector following the trends in energy prices since 1981.

\subsubsection{Comparison of Dodge and NBECS Information}

A statistic of interest in the initial results of the 1979 NBECS was the estimate of the nonresidential building population. The number of buildings and the attendent amount of floorspace was substantially greater than had been estimated previously via more indirect methods. In response to questions and comments concerning the sampling procedure, EIA statistician Dwight French compared NBECS with other available sources of information (French, 1982). Table 3.6, based on a similar table in the French report, shows Dodge building construction estimates for the years 1974-1979 compared with NBECS estimates for the same period by building type and square footage. 


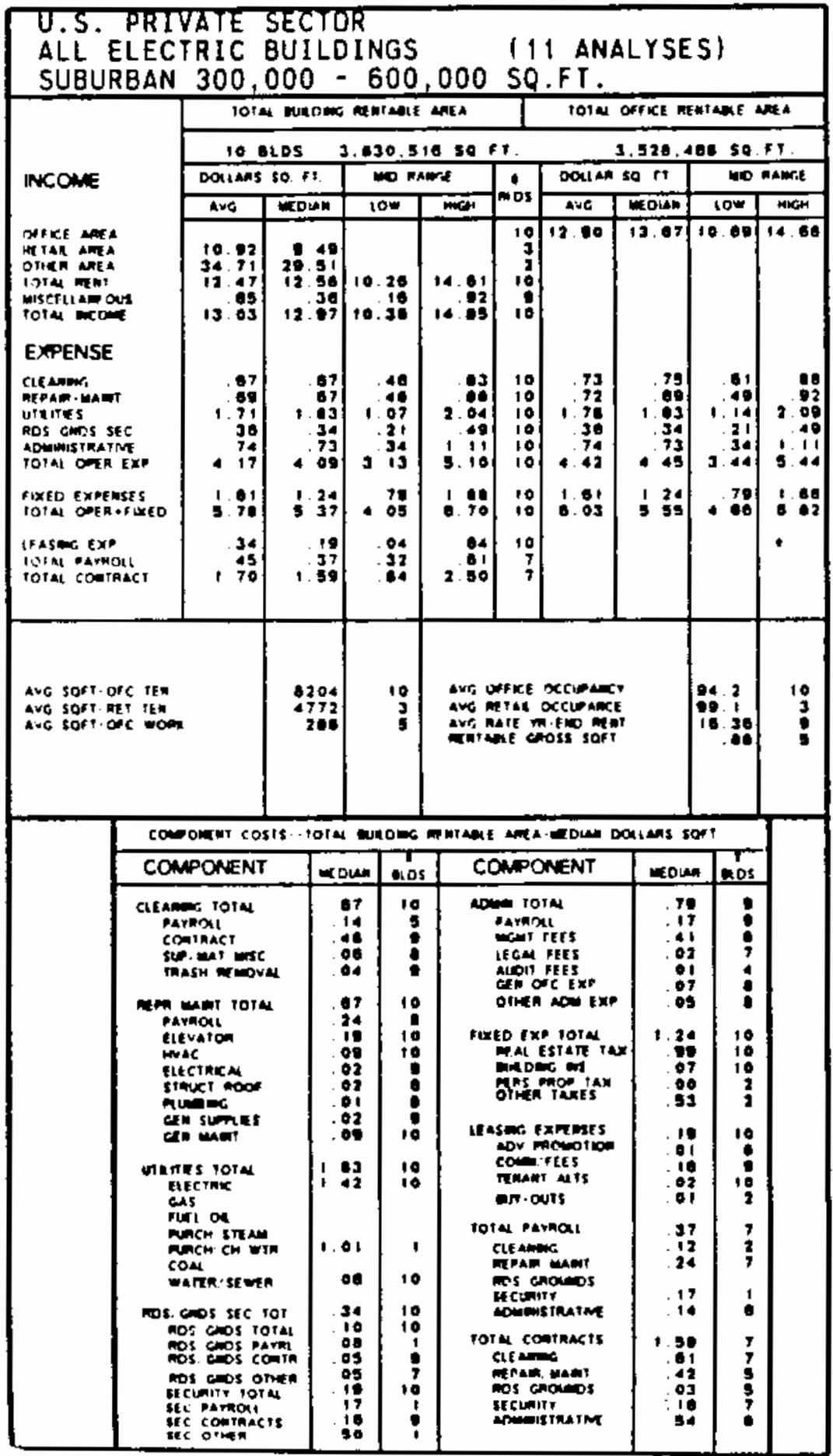


TABLE 3.5. Percent Change in Utility Bills, 1973-1981

U.S. Private Sector Office Buildings

\begin{tabular}{|c|c|c|c|c|c|c|c|c|c|}
\hline & $73-74$ & 74-75 & $75-76$ & $76-77$ & $77-78$ & $78-79$ & $79-80$ & $80-81$ & Cumul. \\
\hline All Bidgs & $32 \%$ & $20 \%$ & $17 \%$ & $12 \%$ & $5 \%$ & $11 \%$ & $12 \%$ & $10 \%$ & $119 \%$ \\
\hline $\begin{array}{l}\text { Same Smp T, } \\
\text { Both Yrs }\end{array}$ & 23 & 19 & 17 & 12 & 3 & 9 & 17 & 19 & 119 \\
\hline $\begin{array}{l}\text { Single } \\
\text { Purpose }\end{array}$ & 21 & 23 & 16 & 2 & 9 & 10 & 11 & 31 & 133 \\
\hline Medical & 46 & 11 & 13 & 13 & 14 & -7 & 22 & 10 & 112 \\
\hline $\begin{array}{l}\text { Agency } \\
\text { Managed }\end{array}$ & 31 & 29 & 9 & 17 & 2 & 12 & 16 & 4 & 120 \\
\hline $\begin{array}{l}\text { EIA Price } \\
\text { Index }\end{array}$ & 33 & 20 & 8 & 17 & 8 & 10 & 28 & 21 & 145 \\
\hline CPI Index & 15 & 16 & 11 & 13 & 9 & 11 & 17 & 15 & 107 \\
\hline
\end{tabular}

Source: Penz, 1984

As the first line of Table 3.6 shows, Dodge counts only about 75 percent of the buildings estimated by NBECS during this six-year period. Four building type categories account for most of the difference--automotive, food, office, and sales/service. Some of the difference can be explained in terms of Dodge's larger "other" classification. The remainder is due to Dodge's nonreporting of construction projects valued less than $\$ 25,000$, an unknown degree of undercounting by Dodge, and sampling variations in NBECS.

The figures under the square footage categories clearly show the impact of the $\$ 25,000$ minimum required for inclusion in the Dodge data set. The differences in the residential and bottom two size categories are weli outside the magnitude that might be explained by sampling error of the NBECS. The total difference across these size classes is some 115,000 buildings, making up a good proportion of the total difference of 147,000 . The Dodge figures are also lower than NBECS in the next two larger size categories. However, 
TABLE 3.6. Number of Buildings Listed by Dodge During 1974-1979, and NBECS Estimates of Number of Buildings Constructed from 1974 to the Time of the Survey, by Square Footage Class and Building Type

\begin{tabular}{|c|c|c|c|}
\hline $\begin{array}{l}\text { Type and Size } \\
\text { Category }\end{array}$ & $\begin{array}{l}\text { Dodge Building Counts } \\
\text { Excluding Residential }\end{array}$ & $\begin{array}{c}\text { NBECS } \\
\text { Estimate }\end{array}$ & $\begin{array}{c}\text { Estimated Standard } \\
\text { Error of NBECs } \\
\text { Estimate } \\
\end{array}$ \\
\hline All Building Types & 414,023 & 561,000 & 51,000 \\
\hline Assembly & 38,528 & 51,000 & 10,000 \\
\hline Automotive & 12,827 & 42,000 & 8,000 \\
\hline Education & 12,405 & 18,000 & 5,000 \\
\hline Food & 25,442 & 63,000 & 11,000 \\
\hline Health & 7,315 & 11,000 & 4,000 \\
\hline Industrial & 41,760 & 35,000 & 8,000 \\
\hline Lodging & 4,400 & 6,000 & 3,000 \\
\hline Office & 62,845 & 104,000 & 16,000 \\
\hline Sales/Service & 63,513 & 103,000 & 16,000 \\
\hline Warehouse & 52,775 & 70,000 & 12,000 \\
\hline Residential & - & 10,000 & 4,000 \\
\hline other & 92,213 & 47,000 & 9,000 \\
\hline \multicolumn{4}{|l|}{ Square Footage } \\
\hline$<1,000$ & 48,568 & 105,000 & 16,000 \\
\hline $1,001-5,000$ & 163,997 & 221,000 & 27,000 \\
\hline $5,001-10,000$ & 76,302 & 102,000 & 16,000 \\
\hline $10,000-25,000$ & 67,479 & 83,000 & 13,000 \\
\hline $25,000-50,000$ & 29,942 & 25,000 & 6,000 \\
\hline $50,000-100,000$ & 16,950 & 16,000 & 5,000 \\
\hline $100,001+$ & 10,785 & 8,000 & 3,000 \\
\hline
\end{tabular}


very few buildings of these sizes cost less than $\$ 25,000$. It appears that Dodge does miss some of the smaller construction projects that still meet the $\$ 25,000$ criterion.

Total floorspace is the more relevant statistic for use in energy models of the commercial sector. Since Dodge's undercounts apply primarily to smaller buildings, the discrepancy between total floorspace in the NBECS and that reported by Dodge should be smaller than that for the number of buildings. This is indeed borne out by reference to Figure 3.2. For the periods in the 1970s, the difference in total square footage between the two sources was less

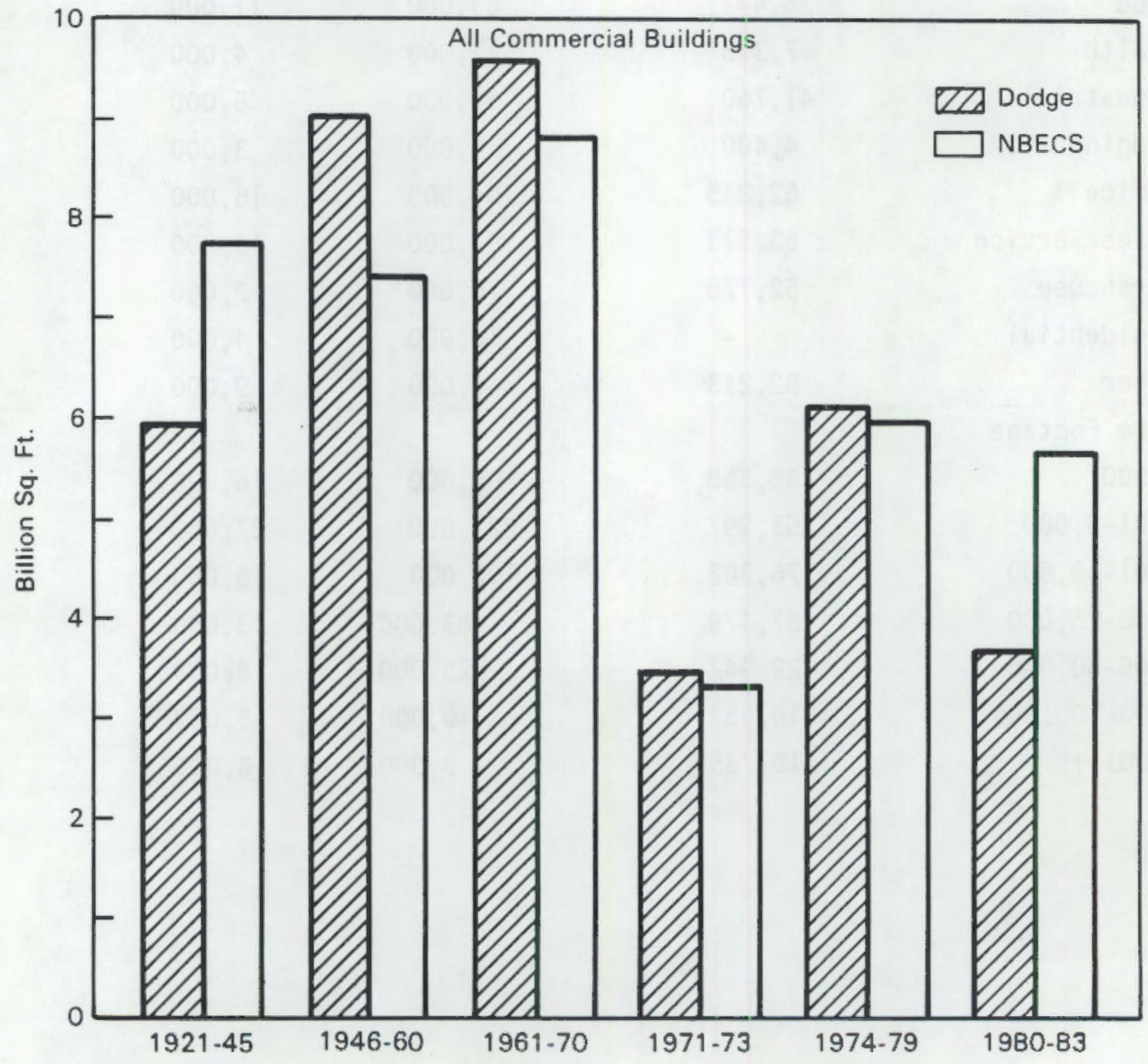

FIGURE 3.2. Dodge Additions Versus NBECS Floorspace Stocks by Vintage, 1921-1979 
than five percent. If we assume that few commercial buildings built since 1960 have been demolished or destroyed, the figure suggests that the Dodge reporting system has improved over the years. For the 1960s, the Dodge figure for new floorspace is nearly eight percent lower than the estimate reported by the 1979 NBECS. The comparisons prior to 1961 become more problematic. Since Dodge did not cover thirteen western states prior to 1955, the Dodge numbers reflected in the figure have included estimates by ORNL (ORNL, 1978) of western construction activity during these earlier years. If we assume that the ORNL estimates are roughly reflective of construction activity during this period, the comparison shows severe underreporting by Dodge prior to 1960. Given that some of these pre-World War II buildings have been demolished or destroyed by 1979, we would actually expect the Dodge estimates to be higher than NBECS. The implication of this finding is that it is very difficult to use the Dodge data in any type of perpetual inventory methodology to construct historical time series of commercial floorspace.

For the 1979-83 period, the correspondence between the square footage totals from NBECS and Dodge breaks down completely. NBECS reports nearly six billion square feet of commercial construction during 1979 through 1983. The Dodge total, on the other hand, is less than two-thirds of that. If we look at the size distribution of buildings in the latest NBECS sample, we get some clue as to the source of this discrepancy.

As mentioned in Section 3.2.1, the sample of post-1979 buildings in NBECS II is derived from the Dodge lists of building projects. Thus, we might expect the (unobserved) biases related to building size and category to be similar to those implied in Table 3.6. The results of the sampling from the Dodge lists, however, suggests a far greater percentage of large buildings constructed over the most recent four years. Table 3.7 illustrates this result by normalizing the 1974-1979 sets of size distributions from both Dodge and NBECS to be consistent with the total number of buildings published by NBECS for the 1980-1983 sample.

The most glaring difference is in the number of buildings over 100,000 square feet. Using the size distribution from Dodge for the 1974-1979 period, we would expect less than 4000 buildings over 100,000 square feet to have been constructed from 1980 to 1983 . Yet, from NBECS II, an estimated 10,000 
TABLE 3.7. Number of Buildings by Size Class Listed by Dodge During 1974-1979 and by NBECS for 1974-1979, Normalized to Total 1980-1983 NBECS New Building Count

\begin{tabular}{|c|c|c|c|}
\hline Square Footage & $\begin{array}{l}\text { 1974-79 Dodge Bldg. (a) } \\
\text { Counts, excluding } \\
\text { Resident, Normalized } \\
\text { to } 1980-83 \text { NBECS } \\
\end{array}$ & $\begin{array}{l}1974-79 \text { NBECS }(a) \\
\text { Normal ized to } \\
1980-83 \text { NBECS } \\
\end{array}$ & $\begin{array}{l}1980-83^{(b)} \\
\text { NBECS II }\end{array}$ \\
\hline$<5,000$ & 71,900 & 81,500 & 49,000 \\
\hline $5,000-25,000$ & 48,700 & 46,300 & 55,000 \\
\hline $25,000-50,000$ & 10,100 & 6,200 & 14,000 \\
\hline $50,000-100,000$ & 5,700 & 4,000 & 12,000 \\
\hline $100,000+$ & 3,600 & 2,000 & $\underline{10,000}$ \\
\hline TOTALS & 140,000 & 140,000 & 140,000 \\
\hline
\end{tabular}

(a) Square footage to be normalized was taken from Table 3.6

(b) Excludes industrial buildings

such buildings were built. At the other extreme, NBECS II for 1980-1983 suggests roughly 35 percent of new buildings were less than 5,000 square feet. This compares to over 50 percent for 1974-1979 based on the total Dodge buildings count and over 60 percent for NBECS based on the area probability sample.

These substantial differences in the size distributions of buildings between 1974-79 and 1980-83 are reflected in the average size. In the 1974-79 period, the average size of new commercial buildings reported in NBECS I was 12,500 square feet. NBECS II, however, reports a jump to over 40,000 square feet per building.

Sampling from the Dodge building lists appears to be the principal reason for so many more large buildings in the 1980-83 period compared to the 1974-79 period. It is possible, however, that the early 1980s did, in fact, see disproportional building activity in those building types that are larger than the average commercial building. One could speculate that the office building boom, which drove up vacancy rates in nearly all major U.S. cities in the early 1980s, could be pushing up the average building size. However, the percentage of new buildings that were office buildings rose only one percentage point (to 20 percent) from that observed in 1974-79. The percentages 
of all buildings accounted for by schools and hospitals declined sharply in the latest NBECS vintage; buildings in both of these categories are generally much larger than average. Further analysis of the role of compositional influences on overall building size must await release of the individual building observations in the NBECS II sample.

Another source of bias toward large buildings (and why NBECS II reports more aggregate floorspace than Dodge for 1980-83) may be simply because of sampling variation in the 1983 "survey." The breakdown by size classification for Dodge in column 1 of Table 3.7 is based on the entire national Dodge building file. NBECS II, on the other hand, is based on sampling from the Dodge building lists only for the approximately 80 primary sampling units as used in the original NBECS. Because only a limited number of geographical areas were included in the initial sample, we might expect to find the size distribution of buildings based on these chosen sampling areas differing from a similar distribution based upon the entire national Dodge data set. Thus, if the bias toward large buildings were, in fact, larger in these selected areas than for the nation as a whole, the estimate of total-floorspace would be larger than that obtained by summing all projects in the Dodge data set. The sampling variances associated with the NBECS II new building sample suggest that this may be what has happened. For example, NBECS II reports some 10,000 buildings over 100,000 square feet built between 1980 and 1983. Using EIA's generalized variance equation, the relative standard error associated with this figure is estimated to be 26 percent. The 95 percent confidence interval implied by this estimate is roughly 5,000 to 15,000 buildings. A building count estimate at the low end of this range for 1980-83 would at least approach the hypothetical estimate of 3600 buildings based on the size breakdown from the 1974-77 Dodge 1ists (see Table 3.7).

Leaving aside the issue of the 1983 NBECS and the historical Dodge information, the Dodge estimates of the 1970s appear to have improved to the point where these data could be used in conjunction with NBECS to extrapolate floorspace estimates. Figure 3.3 expands upon this point by comparing the 1974-79 floorspace estimates for five major building categories. Note that while Dodge reported less than two-thirds of the NBECS office building count 


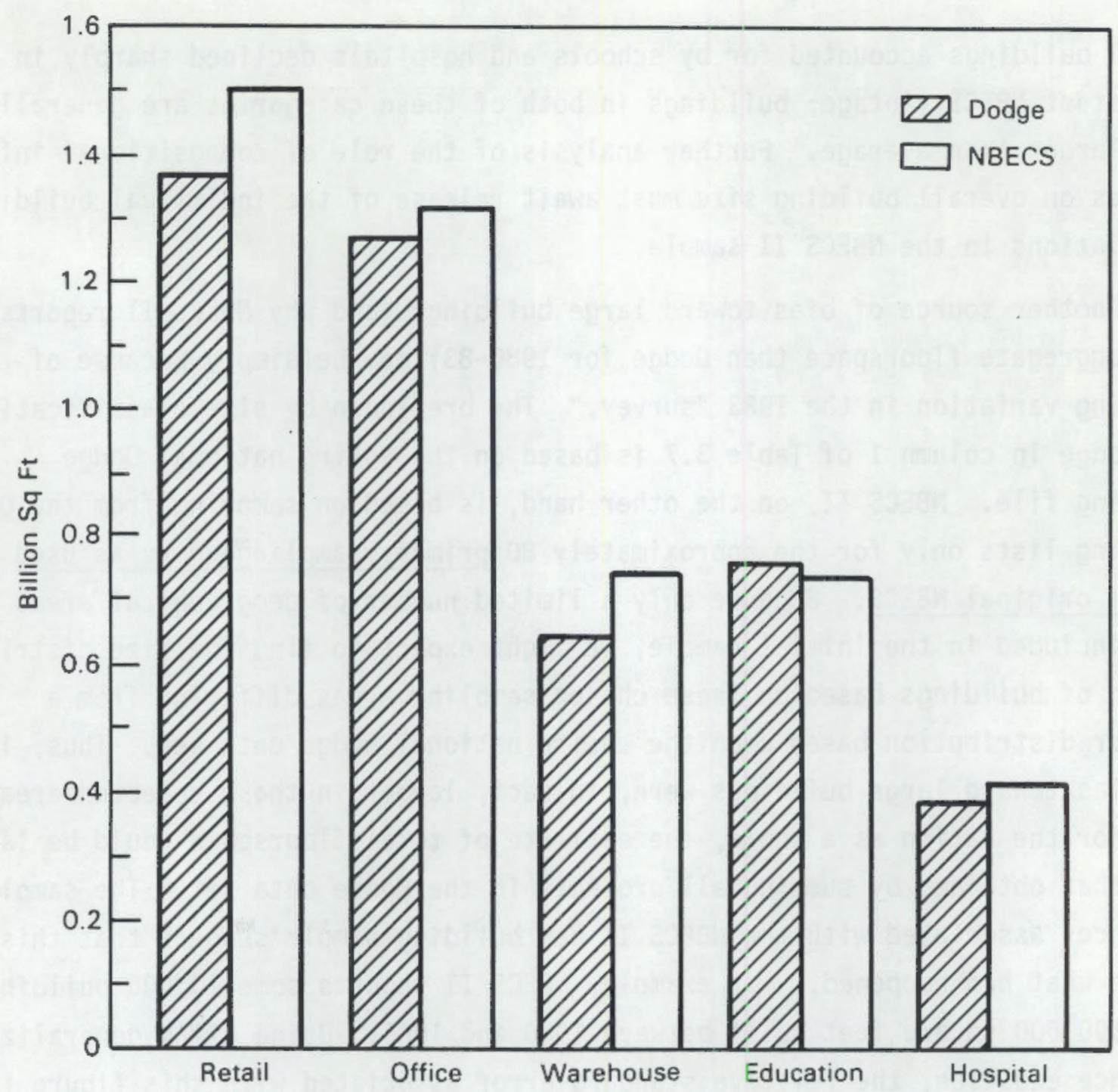

FIGURE 3.3. Dodge Versus NBECS Floorspace Stocks by Building Type, 1974-79

from 1974-79 (Table 3.6), the difference in floorspace is less than $3 \%$. For building categories not shown, the picture is mixed. The figures for auto repair, a relatively small category, were reasonably close during 1974-79: Dodge showing 190 million square feet and NBECS estimating 206 million square feet. However, the NBECS total for lodging (199.8) was less than two-thirds that of the Dodge category, hotels and motels. The remaining buildings are difficult to compare because of differences in the building classification scheme used. NBECS reports 1,018 million square feet for buildings in the assembiy and other categories. Dodge reports along more institutional lines; 
for public buildings, religious, and social and miscellaneous, a total of 1,025 million square feet was reported built from 1974 through 1979.

In conclusion, it appears that the Dodge information can be used to extrapolate NBECS floorspace stock estimates for about a half-dozen building categories. For the remainder, further work to reconcile these differences is needed.

\subsubsection{Comparison of NBECS and SEDS}

As mentioned in the beginning of Section 3.0, estimates of aggregate energy consumption for the Commercial Sector are regularly published by EIA in the State Energy Data System (SEDS). An obvious question is how well do the energy consumption figures in NBECS compare with those of the SEDS. In early 1986, EIA made such a comparison for 1979 data as part of a report focusing on the procedures of SEDS (EIA, 1986).

EIA's comparison table is reproduced below as Table 3.8. Differences in coverage between the two reporting systems may explain some of the differences. NBECS covers only buildings and thus excludes many nonbuilding energy uses for such items as bridges, street lights, and amusement parks. Many of these nonbuilding uses are probably electricity and would suggest that the NBECS figures would be lower than SEDS. With the exception of the west census region, however, the figures in Table 3.8 all show that the NBECS estimates are higher than SEDS for electricity.

A second source of the discrepancy between SEDS and NBECS may be attributable to buildings serving both residential and commercial functions. Such buildings are included in NBECS but may not be classified as commercial by the reporting system (primarily regulatory agencies) used for the SEDS. A related problem is the existence of master-metered apartments, particularly for natural gas and fuel oil, which may be reported as either residential or commercial.

EIA suggests that, in addition to classification and coverage, the differences may also be a result of large sampling errors in NBECS. NBECS, for example, reports relative standard errors for fuel oil and kerosene that range from 8.2 percent in the Northeast Census Region to 23 percent for the West 
TABLE 3.8. Regional Energy Consumption and Expenditures in the Commercial Sector for Calendar Year, By Fuel Type

\begin{tabular}{|c|c|c|c|c|c|}
\hline \multirow[b]{2}{*}{ Fuel Type } & \multirow[b]{2}{*}{ Region } & \multicolumn{2}{|c|}{ Tonsueption (trittion Btu) } & \multicolumn{2}{|c|}{ Expenditures (ailtion daltars) } \\
\hline & & KBECS & SEDS & NBECS & SEPEDS \\
\hline Electricity & $\begin{array}{l}\text { National } \\
\text { Northeast } \\
\text { North Central } \\
\text { South } \\
\text { Hest }\end{array}$ & $\begin{array}{r}2,055 \\
457 \\
643 \\
700 \\
255\end{array}$ & $\begin{array}{r}1,830 \\
355 \\
a / 436 \\
654 \\
0 / 385\end{array}$ & $\begin{array}{r}25,717 \\
7,042 \\
7,643 \\
8,278 \\
2,754\end{array}$ & $\begin{array}{r}25,415 \\
6,416 \\
6,016 \\
8,316 \\
a / 4,068\end{array}$ \\
\hline Natural Gas & $\begin{array}{l}\text { Mational } \\
\text { Northeast } \\
\text { North Central } \\
\text { South } \\
\text { Nest }\end{array}$ & $\begin{array}{r}2,354 \\
509 \\
1,086 \\
488 \\
270\end{array}$ & $\begin{array}{r}a / 2,777 \\
389 \\
1,092 \\
a / 844 \\
a / 452\end{array}$ & $\begin{array}{r}0,345 \\
1,529 \\
2,771 \\
1,313 \\
732\end{array}$ & $\begin{array}{r}a / 7,598 \\
1,321 \\
2,746 \\
a / 2,225 \\
1,306\end{array}$ \\
\hline Fuel oil & $\begin{array}{l}\text { National } \\
\text { Northeast } \\
\text { North Centrat } \\
\text { South } \\
\text { Uest }\end{array}$ & $\begin{array}{r}791 \\
364 \\
141 \\
257 \\
29\end{array}$ & $\begin{array}{r}a / 1,159 \\
\sigma / 533 \\
172 \\
a / 375 \\
a / 79\end{array}$ & $\begin{array}{r}3,239 \\
1,486 \\
601 \\
1,015 \\
138\end{array}$ & $\begin{array}{r}1 / 4,535 \\
a / 2,110 \\
685 \\
a / 1,450 \\
0 / 290\end{array}$ \\
\hline $\begin{array}{l}\text { Liquefied Petroleum } \\
\text { Gas }\end{array}$ & $\begin{array}{l}\text { National } \\
\text { Northeast } \\
\text { North Central } \\
\text { South } \\
\text { Yest }\end{array}$ & $\begin{array}{r}53 \\
4 \\
19 \\
19 \\
11\end{array}$ & $\begin{array}{r}a / 101 \\
8 \\
: / 44 \\
8 / 40 \\
9\end{array}$ & $\begin{array}{r}272 \\
23 \\
93 \\
103 \\
52\end{array}$ & $\begin{array}{r}1 / 408 \\
32 \\
a / 168 \\
4 / 167 \\
41\end{array}$ \\
\hline
\end{tabular}

a/An approximate 95-percent confidence intervat for an NBECS estimate can be created by adding and subtracting two standard errors from the estiate. For the noted comparisons, the SEDS/SEPEDS estimate lies outside the 95 -percent confidence interval.

Sources: OSEDS/SEPEDS, Energy Price and Expenditure Data Report, 1970-1980 (State and U.S. Total), Appendix C, P. 257. ONBECS, Nonresidential Buildings Energy Consumption Survey: 1979 Consumption and Expenditures, Part 2: Steam, Fuel 0il, LPG, and All Fuels, Table 7, pp. 57-58. 
Census Region. In Table 3.8, EIA has noted those fuel types and Census regions for which the SEDS estimates are within a 95-percent confidence interval for the corresponding NBECS estimate (those not marked with an "a"). This implies that for some census regions, large differences cannot be statistically rejected as different from zero. The principal examples are electricity and natural gas consumption in the Northeast.

EIA concluded that the differences in the NBECS and SEDS estimates could be attributed to either 1) differences in coverage between the two systems or 2) large sampling errors. Further insight into the first of these factors can only be obtained by in-depth analysis of utility reporting systems. More evidence on the role of sampling error in NBECS may be revealed with the publication of the 1983 NBECS consumption estimates.

\subsection{ASSESSMENT AND CONCLUSIONS}

\subsubsection{Assessment}

The only comprehensive data base that covers energy consumption in the commercial sector is NBECS. As a result, any assessment of commercial energy data bases primarily involves assessment of NBECS. NBECS is the first data base to provide the potential for relating measured energy use to specific building characteristics on a representative sample of commercial buildings across the U.S. This potential will be enhanced with the release of energy consumption data for the 1983 survey. Taken together, the two NBECS surveys will provide the opportunity to examine consumption changes over time while holding building structural characteristics constant. A key question to be addressed here, of course, is the relationship between consumption changes between 1979 and 1983 and changes in fuel prices. Of course, NBECS has value far beyond its ability to explain energy consumption at the building level. The building characteristics information has been used by many organizations for market assessments and for basing R\&D efforts related to commercial buildings.

Although NBECS filled in major gaps in our previous understanding of the commercial building stock, there are a number of areas that could be improved to make the data base more valuable for energy policy analysis. In preparation for NBECS III, which will be conducted in 19B7, EIA conducted a workshop for 
a group of NBECS users in April 1985 to discuss areas in which NBECS could be improved. A few of the suggestions by PNL are outlined below and, by implication, pertain to the present assessment of the current NBECS data.

First, the present sample size precludes any regional analysis. It is recommended that the sample size be increased to permit disaggregation to at least the 10 census regions and, ideally, to the state level. State level data would enable users to correlate the NBECS data with state energy prices and other economic data over time.

A second area for improvement involves the characterization of HVAC equipment. Matching equipment types in NBECS to those that exist in building energy models (e.g., DOE-2) would be extremely useful in running various building load simulations as well as for other types of analysis.

A third area involves bujlding retrofits. NBCS has focused primarily on changes made to the building shell. Additional questions that relate to the installation of energy management systems, or retriofits of HVAC systems, lighting, or window systems would be very valuable. The current NBECS also provides no information whatsoever regarding the behavioral and economic factors underlying retrofit activity. Knowing how building managers use payback or Iife-cycle costing criteria to rationalize energy conservation actions is of critical importance for many types of policy analysis.

The final area involves consumption by fuel type. Several questions are at issue here. First is the use of electricity for space heating. A very sizable number of buildings reported using electricity along with another fuel for space heating. The current survey makes no distinction between incidental electricty use for heating and, say, the use of electricity in an entire separate wing of a building. Thus, it is very difficult to use the data from these buildings, in conjunction with engineer"ng energy simulation models, to break out electricity consumption by end use.

The second question involves fuel switching. It is difficult to determine if a building uses two fuels for heating because of equipment design (e.g. normal operation requires the use of these fuels) or because of a boiler with dual fuel capablity. Gathering information on dual fuel capability would be very helpful in assessing the potential for short-run fuel substitution in 
the commercial sector, a question of critical importance as world oil prices continue to decline to real terms.

The cost or feasibility of adding questions to the present NBECS that address the above issues can only be assessed by EIA. However, more detailed information in these areas, particularly in regard to behavioral or motivational factors, would significantly improve the capability for policy analysis using NBECS.

Since the Dodge data contain no energy-related characteristics, this data base cannot be used on a stand-alone basis for energy policy analysis. However, the data are valuable for assessing current trends in new commercial building consumption, both by region and building type, that will influence aggregate energy consumption. As the charts in Section 3.3 showed, the correspondence between total recent floorspace additions reported by Dodge and NBECS is fairly good. This correspondence carries over to several of the key major building types. However, reconciliation of Dodge and NBECS for a more complete set of building categories would be a valuable study. Such a study would probably be most competently performed by EIA statisticians who are familiar with the building classification codes used in the NBECS. The results of this exercise would significantly aid studies and formal energy models that used the Dodge building classification to forecast additions of commercial floorspace.

The 1986 NBECS is based on an entirely new sampling frame. We would urge EIA to continue to analyze differences in the total building count data estimated in the new survey with that of Dodge. Given the apparent inconsistencies of the NBECS II with the original sample, we would also recommend revised procedures to update the 1986 survey from that employed in 1983.

Data presented in BOMA Experience Exchange Reports potentially represents a valuable source for studying how the office building industry uses energy and responds to changes in energy prices. Without a detailed study of the available data, assessing how the lack of physical quantity data (only costs are reported) and the sample turnover may affect the robustness of any statistical results. In addition, it is not clear how far the results associated with large office buildings could be extended to other building types. However, 
since office buildings represent nearly one-sixth of total floorspace, they warrant attention in and of themselves. The large number of office buildings now reporting in the EER and the relatively short turnaround for publication of results suggests that analysis of these data may be important in helping to give some early indication of how building managers are currently responding to stable or falling real energy prices.

\subsubsection{Conclusions}

The key source of information for policy analysis at the national level is and will continue to be the NBECS. With the publication of energy consumption data for the second (1983) survey, a wide variety of analytical studies may be undertaken that will help to measure the short-term response of building owners to changes in fuel prices. There are several areas in the present survey where more detail would significantiy aid in energy policy analysis. These include 1) more regional disaggregation 2) more detailed identification of HVAC types, 3 ) information on retrofits related to equipment and other non-shell components 4) behavioral and economic factors influencing retrofits, and 5) more information about buildings using several fuels for heating.

Although the construction data from Dodge contain no energy-related information, this data base is important in helping to project the size and composition of the future building stock. More work is needed to reconcile recent floorspace additions from Dodge, on a building type basis, with the sample data collected in the NBECS.

The BOMA Experience Exchange Report contains information on the largest single category of commercial buildings, offices, that heretofore has not be exploited for energy policy analysis. The large current sample and the short publication lag may provide an early indication of building owners' and managers' responses to the recent stability in energy prices. Although a number of technical problems are inherent with the use of this data base (e.g. deflation of energy costs), a major study using this data base may yield valuable insights that could not now be attained via any other data source. 


\subsection{CONCLUSIONS AND RECOMMENDATIONS}

This section is provided as service to those who are interested only in the "bottom line." The assessment of the two end-use sector data bases has led to a number of conclusions that are presented here first for the industrial sector and then for the commercial sector.

A number of deficiencies have appeared that limit effective policy analysis. These deficiencies could be overcome if some effort were devoted to constructing data to fill the gaps. In some cases there are obvious ways to fill those gaps; in other cases, the missing data could only be supplied by a survey or other major effort that, in the current environment, does not appear likely.

In the final section, some recommendations have been formulated that might serve to diminish some of the data gaps that have been uncovered. We advance no recommendation concerning the residential and transportation data bases. Argonne has undertaken the assessment of these end-use sector data bases, and so our recommendations are limited to the industrial and commercial sectors.

\subsection{CONCLUSIONS}

For the next several years policy analysis at the jndustrial sector level of aggregation will have to depend on the supply-side data sources provided by DOE. Time-series of historical consumption are available by industry for separate fuel types over the period 1958-1981. This information was constructed from the Purchased Fuel and Power Survey that was part of the Annual Survey of Manufactures in off-census years up until 1981. This part of the Annual Survey was terminated after 1981. The survey scheduled to collect Manufacturing Energy Consumption data (MECS) for the calendar year 1985 will not be available until publication in late 1987. This and the normal pubitication of the 1987 Census in 1989 will agajn allow benchmarks for the consumption data that currently end in 1981. Until then, however, the best source of data for policy analysis is the supply-side information available from the Energy Information Agency. In a few cases, trade associations collect data on industry energy use that can supplement the National Energy Accounts until those benchmarks are available. This loss of information will interject uncertainty into the 
policy arena that will be especially noticeable when industry-specific questions arise. For broad policy questions that can be handled at the level of the industrial sector, this certainly will not be a major drawback to effective policy analysis.

For policy analysis in the commercial sector, the only comprehensive data base that covers energy consumption is NBECS. As a result, any assessment of commercial energy data bases primarily involves assessment of NBECS. NBECS is the first data base to provide the potential for relating measured energy use to specific building characteristics on a representive sample of commercial buildings across the U.S. This potential will be enhanced with the release of energy consumption data for the 1983 survey. Taken together, the two NBECS surveys will provide the opportunity to examine consumption changes over time while holding building structural characteristics constant. A key question to be addressed here, of course, is the relationship between consumption changes between 1979 and 1983 and changes in fuel prices. Of course, NBECS has value far beyond its ability to explain energy consumption at the building level. The bujiding characteristics information has been used by many organizations for market assessments and for basing R\&D efforts related to commercial buildings.

Although NBECS filled in major gaps in our previous understanding of the commercial building stock, a number of areas could be improved to make the data base more valuable for energy policy analysis. First, the present sample size preciudes any substantive regional analysis. Regional analysis is critical for a number of poljcy questions including distributional and environmental impacts, and utility peak loads. A second area for improvement involves the characterization of HVAC equipment. More detailed information in this area would enhance the potential for calibration of energy simulation models to the NBECS data. A third area involves building retrofits. NBECS has focused primarily on changes made to the building shell. Additional questions that relate to the installation of energy management systems, or retrofits of HVAC systems, lighting, or window systems would be very valuable. Also, the current NBECS does not provide any information about the behavioral and economic factors underlying retrofit activity. Knowing how building managers use payback or 
life-cycle costing criteria to rationalize energy conservation actions is critical to many types of policy analysis.

Because data compiled by F.W. Dodge contain no energy-related characteristics, this data base cannot be used on a stand-alone basis for energy policy analysis. However, the data are valuable for assessing current trends in new commercial building consumption, both by region and building type, that will influence future aggregate energy consumption.

Data presented in BOMA Experience Exchange Reports potentially represents a valuable source for studying how the office building industry uses energy and responds to changes in energy prices. Without a detailed study of the available data, it is difficult to assess how the lack of physical quantity data (only costs are reported) and the sample turnover may affect the robustness of any statistical results. However, the large number of office buildings now reported in the EER and the relatively short turnaround for publication of results suggest that analysis of these data may be important in helping to give some early indication of how building managers are currently responding to stable or falling real energy prices.

\subsection{RECDMMENDATIONS}

Any number of recommendations have been made regarding the collection and publication of data. As analysts, frequently in need of more and better data, we are not in the position of having to make the hard policy choices that limited budgets require. Rather than admonish policy makers to collect more and better data, our recomnendations are limited to constructive proposals that might be considered as data collection continues.

The major recommendation for the industrial sector is simply that another three-year period not be allowed to elapse in which no data are collected. The Purchased Fuels and Power portion of the Annual Survey of Manufactures was terminated after 1981 without an adequate replacement. No amount of optimism about how quickly a replacement would be put into place could justify such an action, nor could the financial savings. The second recommendation is that the budget be allocated to update the National Energy Accounts after 
1981 when the MECS and Census data are available. This data set is an invaluable source of historical and behavioral information that should be perpetuated.

The major recommendations with regard to the commercial sector apply to the most useful of the surveys--NBECS. There are several areas in the present survey where additional detail would significantly aid in energy policy analysis. These include 1) more regional disaggregation 2) more detailed identification of HVAC types, 3) information on retrofits related to equipment and other non-shell components 4) behavioral and economic factors influencing retrofits, and 5) more information for buildings using several fuels for heating.

Although the construction data from Dodge contain no energy-related information, this data base is important in helping to project the size and composition of the future building stock. More work is needed to reconcile recent floorspace additions from Dodge, on a building type basis, with the sample data collected in the NBECS.

The BOMA Experience Exchange Report contains information on the largest single category of commercial buildings, offices, that heretofore has not been exploited for energy policy analysis. Although a number of technical problems are inherent with the use of this data base (e.g. deflation of energy costs), a mafor statistical or economic study using this data base may yield valuable insights that could not now be attained via any other data source. 


\section{REFERENCES}

Adams, R. C, , et al. 1985. A Retrospective Analysis of Energy Use and Conservation Trends, 1972-1982. PNL-5026, Pacific Northwest Laboratory, Richland, Washington.

American Gas Association. 1984. Gas Facts 1983: A Statistical Record of the Gas Utility Industry. Arlington, Virginia.

American Iron and Steel Institute. 1984. Annual Statistical Report. Washington, D.C.

Energy Information Administration. 1979. End Use Energy Consumption Data Base. Version 110. User's Manual. D0E/EIA-0175, U.S. Department of Energy, Washington, D.C.

Energy Information Administration. 1984. Model Documentation: Commercial Sector Energy Model. DOE/EIA-0453, Department of Energy, Washington, D.C.

Energy Information Administration. 1981. Nonresidential Buildings Energy Consumption Survey: Building Characteristics, D0E/EIA-0246, U.S. Department of Energy, Washington, D.C. March.

Energy Information Administration. 1983a. Nonresidential Bujldings Energy Consumption Survey: 1979 Consumption and Expenditures. Part 1: Natural Gas and Electricity. DOE/EIA-0318/1, U.S. Department of Energy, Washington, D.C. March.

Energy Information Administration. 1983b. Nonresidential 8uildings Energy Consumption Survey: 1979 Consumption and Expenditures. Part 2: Steam, Fuel $0 i 1, L P G$, and All Fuels. D0E/EIA-0318(79)/1, U.S. Department of Energy, Washington, D.C. December.

Energy Information Administration. 1986. An Assessment of the Quality of Selected EIA Data Series. DOE/EIA-0292, U.S. Department of Energy, Washington, D.C.

Frank, Owight K. 1982. "Just How Many Nonresidential Buildings Are There," Paper presented at the American Statistical Association Convention, Cincinnati, Ohio. August 1982.

Faucett, Jack, Associates, 1984. National Energy Accounts. JACKFAU-84-316. Chevy Chase, Maryland.

Gas Research Institute. 1986. United States Commercial Building Population and Energy Consumption: An Overview. Prepared by Applied Management Sciences, Inc. under Contract No. 5082-512-0723. Chicago, Illinois.

General Electric. 1981. Industrial Heat Pump Service Study. DOE/CS/40449-1, prepared for the U.S. Department of Energy, Washington, D.C. by General Electric Company. 
Horvath, R. Skip. 1984. "Industrial Gas Switching in 1983." In Weyant and Sheffield (listed below). International Association of Energy Economists, Washington, D.C.

Isser, S. and D. R. Limaye. 1982. Review of Industrial Energy Data Bases. EM-2647, prepared by Synergic Resources Corporation for the Electric Power Reasearch Institute, Palo Alto, California.

Kresge, David T. 1984. "The Major Industrial Plant Database of Dun \& Bradstreet Technical Economic Service." In Weyant and Sheffield (cited below). International Association of Energy Economists, Washington, D.C.

Penz, Alton J. 1984. "Analyzing Energy Use in Office Building with the Experience Exchange Report." Butlding Owners and Managers Association. Washington, D.C.

Roop, J. M. and M. Clement. 1984. "Use of Industrial Energy Data: A Consultant's Perspective." In Weyant and Sheffield (cited below). International Association of Energy Economists, Washington, D.C.

U.S. Department of Commerce, Bureau of the Census. 1980. 1977 Census of Manufacturers: Fuels and Electric Energy Consumed. MC77-SR-4, Washington, D.C.

U.S. Department of Commerce, Bureau of the Census. 1981. 1979 Annual Survey of Manufactures: Fuels and Electric Energy Consumed. M79(AS)-4.1, Washington, D.C.

U.S. Department of Energy. 1980. The Industrial Energy Efficiency Improvement Program. DOE/CE-0015, Washington, D.C.

U.S. Department of Energy. 1984. Residential and Commercial Buildings Data Book. DOE/RL/01830-16, prepared by Pacific Northwest Laboratory for U.S. Department of Energy, Office of Buildings and Community Systems, Washington, D.C.

Wilfert, G. L., et al, 1984. Characterization of Industrial Process Waste Heat and Input Heat Streams. PNL-4912, Pacific Northwest Laboratory, Richland, Washington.

Weyant, J. P., and D. B. Sheffield, eds. 1984. The Energy Industries in Transition 1985-2000: Proceedings, Sixth Annual North American Meeting, San Francisco, November 5-7, 1984. International Association of Energy Economists, Washington, D.C. 
PNL -5621

UC-98

\section{DISTRIBUTION}

No. of

Copies

DFFSITE

30 U.S. Department of Energy

Technical Information Center

P. 0. Box 62

Oak Ridge, TN 37830

Bruce Cranford

Office of Industrial Programs

Mail Stop CE-12

Forrestal Building

U.S. Department of Energy

1000 Independence Avenue, S. W. Washington, DC 20585

Barry McNutt

Office of Policy Integration

Mail Stop PE-40

Forrestal Building

U.S. Department of Energy

1000 Independence Avenue, S. W. Washington, DC 20585

Harvey Major

Office of Conservation

U.S. Department of Energy

Mail Stop CE-12

1000 Independence Avenue, S.W.

Washington, DC 20585

Ken Friedman

Office of Conservation

U.S. Department of Energy

Mail Stop CE-12

1000 Independence Avenue, S.W. Washington, DC 20585
No. of

Copies

OFFSITE

Robert Wendling

Office of Business Analysis

Room 4527

Main Commerce Building

Department of Commerce

Washington, DC 20543

Paul Werbos, Lead Analyst

Industrial Energy Demand

Energy Information Admin.

Mail Stop EI-621

Forrestal Building

1000 Independence Avenue S.W.

Washington, DC 20585

William B. Williams, Director Office of Industrial Programs

U.S. Department of Energy

Mail Stop CE-12

Forrestal Building

1000 Independence Avenue S.W. Washington, DC 20585

Peggy Podolak

Office of Policy Integration

U.S. Department of Energy

Forrestal Building, MAIL STOP PE-40

1000 Independence Avenue, S.W.

Washington, DC 20585

Vito Stagliano

Office of Policy Integration

U.S. Department of Energy

Forrestal Building, MAIL STOP PE-40

1000 Independence Avenue, S.W.

Washington, DC 20585 


\section{Distribution}

No. of

Copies

OFFSITE

Georgia R. Johnson

Office of Minority Impacts

U. S. Department of Energy

Mail Stop MI-3.3

1000 Independence Avenue, S. W. washington, D. C. 20585
No. of

Copies

ONSITE

DOE Richland Operations office

J. J. Sutey

40 Pacific Northwest Laboratory

R. C. Adams

'N. B. Ashton

D. B. Belzer

J. W. Currie

R. J. Moe

J. M. Roop (25)

Economics Library (3)

Publishing Coordination (2)

Technical Report Files (5) 